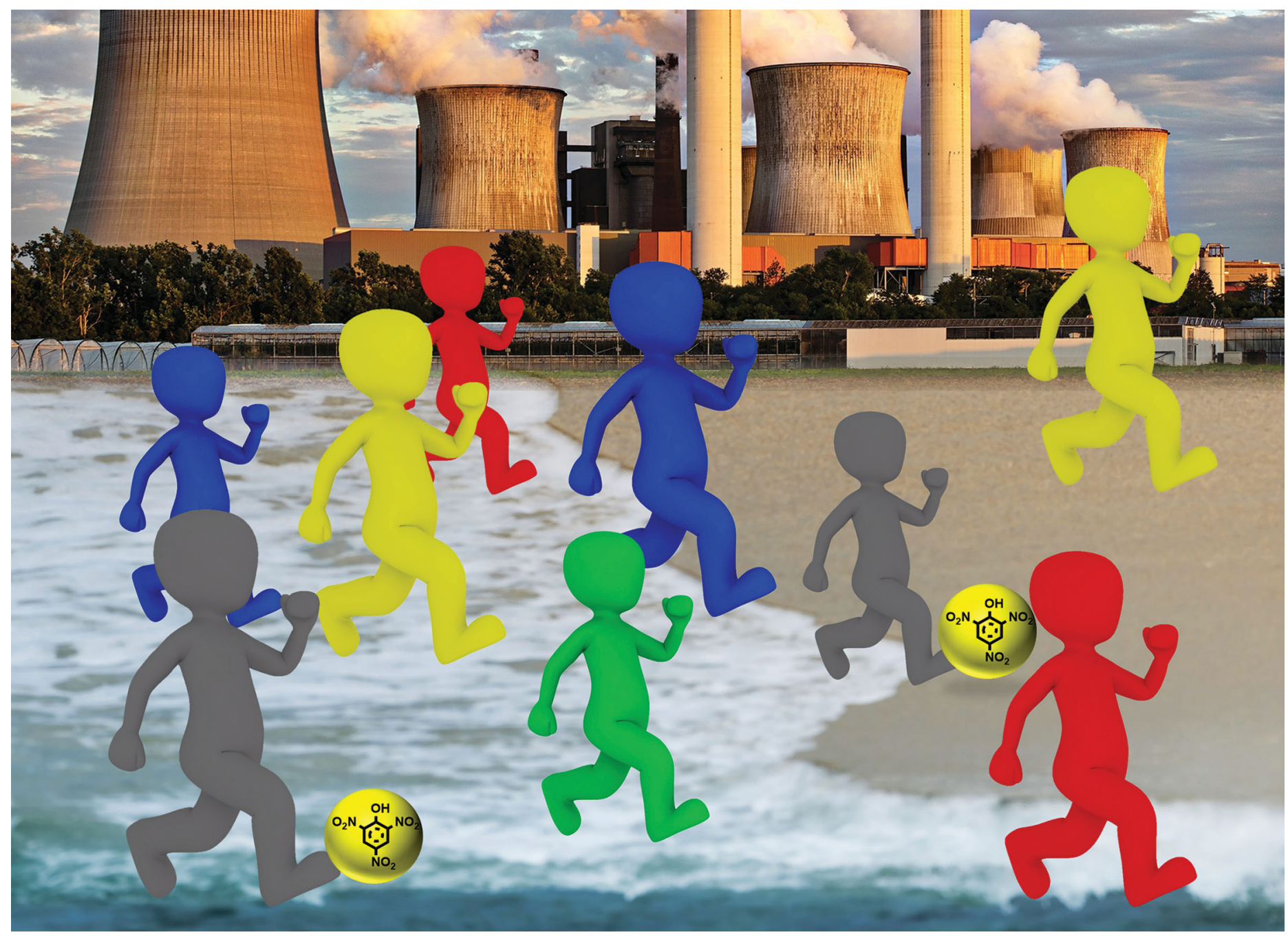

Showcasing research from Professor Subodh Kumar's laboratory, Department of Chemistry, Guru Nanak Dev University, Amritsar, Punjab, India.

Protonation- and electrostatic-interaction-based fluorescence probes for the selective detection of picric acid (2,4,6-trinitrophenol) - an explosive material

The nitroaromatic explosive materials are putative fluorescence quenchers and generate the non-distinctive spectral signatures. The manuscript highlights that increased proximity between picrate anion and positively charged fluorescent probe due to electrostatic interactions enhances electron or energy transfer processes and thus the quenching efficiency. These features enable selective recognition of picric acid in solid, solution, and vapor phases. This account provides a benchmark for the future design of fluorescent probes for picric acid.

\section{As featured in:}

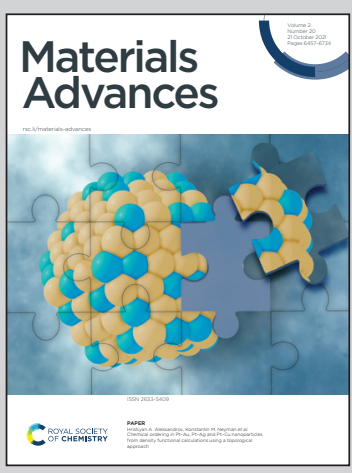

See Subodh Kumar et al., Mater. Adv., 2021, 2, 6466. 


\section{Check for updates}

Cite this: Mater. Adv., 2021, 2, 6466

Received 30th May 2021, Accepted 18th August 2021

DOI: $10.1039 / \mathrm{d} 1 \mathrm{ma} 00478 f$

rsc.li/materials-advances

\title{
Protonation- and electrostatic-interaction-based fluorescence probes for the selective detection of picric acid (2,4,6-trinitrophenol) - an explosive material
}

\author{
Sukhvinder Dhiman, (D) Nancy Singla, (D) Manzoor Ahmad, (D) Prabhpreet Singh (D) \\ and Subodh Kumar (D) *
}

Picric acid, due to its low $\mathrm{p} K_{\mathrm{a}}$ value, possesses distinct physicochemical features from all other nitroaromatic derivatives, enabling the design of fluorescent probes for its sensitive and selective detection. The electrostatic interactions between the positive charge on the fluorescent probe, which arises due to protonation or the presence of a quaternary nitrogen, and the picrate anion increase the proximity between the fluorescent probe and the analyte, thus increasing the efficiency of the electron or energy transfer processes. This provides a salient feature for the design of fluorescent probes for the selective detection of picric acid over other nitroaromatic compounds. Here, the literature on the use of fluorescent small organic molecules for the selective detection of picric acid based on electrostatic interactions between positively charged/protonated fluorophores and their ability to selectively detect picric acid has been discussed. The fluorescent probes have been classified into three broad categories - neutral fluorophores, which are selectively protonated by picric acid; positively charged probes, which exhibit electrostatic interactions with the picrate anion; and metal complexes with protonatable sites. This comprehensive review will prove a benchmark for the future design of fluorescent probes for picric acid.

\section{Introduction}

Anti-terrorism and security concerns at places of people movement and other locations have necessitated the development of methods for the trace detection of hazardous explosive materials. The nitroaromatic compounds (NACs) constitute a broad class of widely used explosive materials. In recent years, fluorescencebased detection of NACs has received remarkable attention due to its ease of execution, high sensitivity and the compatibility of technique with the solution, solid and vapor state. These nitroaromatic compounds can be classified into two major categories: (i) phenolic nitroaromatic compounds and (ii) non-phenolic nitroaromatic compounds (Chart 1). Structurally, these nitroaromatic compounds are electron-deficient $\pi$-systems, and in general, electron deficiency increases with the increase in the number of nitro groups on the benzene ring.

The phenolic nitroaromatic compound 2,4,6-trinitrophenol (TNP), which is also known as picric acid (PA), is superior to even TNT in energy content and was widely used as an explosive

Department of Chemistry, Center of Advanced Studies, Guru Nanak Dev University, Amritsar-143 005, India. E-mail: subodh_gndu@yahoo.co.in,

subodh.chem@gndu.ac.in material during the World Wars. ${ }^{1,2}$ PA finds applications in the manufacture of colored glass and the synthesis of dyes. ${ }^{3,4}$ It is also a key component in the rocket fuel, matchbox, electric battery and fireworks industries. ${ }^{5}$ Due to these industries, PA is released into the environment via anthropogenic activities, resulting in its presence in wastewater, aquatic systems ${ }^{6}$ and soil $^{7}$ and as a contaminant in the air. Its high solubility in basic solutions and water $\left(12.7 \mathrm{~g} \mathrm{l}^{-1}\right)^{8}$ and estimated soil absorption coefficient of 180 can lead to its easy transfer into the environment via groundwater, soil etc. ${ }^{9}$ PA causes skin sensitization, immunotoxicity and methemoglobinemia, headaches, liver damage, and anemia in humans and can also have a negative effect on the respiratory organs due to the effects of bio-amplification and bioaccumulation. It is a dermal sensitizer and strong eye irritant for animals such as rats. ${ }^{10,11}$ Additionally, PA can be metabolised to picramic acid, which has a higher mutagenic activity than PA itself. $^{12}$ PA can also be degraded by the Rhodococcus sp. strain in PA-contaminated soil. ${ }^{13}$

In the literature, fluorescence-based molecular probes for the detection of NACs have been reviewed, but in not even a single case has the focus been on the selective recognition of picric acid. ${ }^{14,15}$

Conventional analytical methods, including chromatographic methods such as gas chromatography ${ }^{16}$ and liquid 
<smiles>O=[N+]([O-])c1cc([N+](=O)[O-])c(O)c([N+](=O)[O-])c1</smiles>

2,4,6-Trinitrophenol (TNP) (Picric acid) V.P. $9.71 \times 10^{-10}$

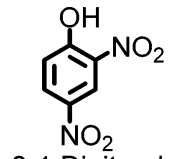

2,4-Dinitrophenol (2,4-DNP) V.P. $9.2 \times 10^{-4}$
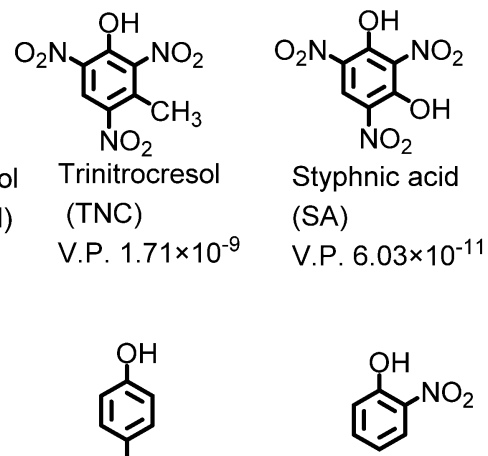

2-nitrophenol (2-NP)

4-nitropheno

(4-NP)

V.P. $3.15 \times 10^{-8}$<smiles>Cc1c([N+](=O)[O-])cc([N+](=O)[O-])cc1[N+](=O)[O-]</smiles>

2,4,6-Trinitrotoulen (TNT)

V.P. $9.15 \times 10^{-9}$<smiles>Cc1c([N+](=O)[O-])cccc1[N+](=O)[O-]</smiles>

2,6-Dinitrotoulene

(2,6-DNT)

V.P. $8.93 \times 10^{-7}$<smiles>O=[N+]([O-])c1cc([N+](=O)[O-])cc([N+](=O)[O-])c1</smiles><smiles>O=[N+]([O-])c1cccc([N+](=O)[O-])c1</smiles>

1,3,5-Trinitrobenzene (TNB)

V.P. $2.00 \times 10^{-8}$<smiles>Cc1ccc([N+](=O)[O-])cc1[N+](=O)[O-]</smiles>

2.4-Dinitrotoulene $(2,4-\mathrm{DNT})$ V.P. $4.11 \times 10^{-7}$<smiles>O=[N+]([O-])c1ccccc1</smiles>

Nitrobenzene (NB) V.P. $3.9 \times 10^{-4}$

V.P. = vapour pressure of the explosive in atm at RT;

Chart 1 Structures of phenolic and non-phenolic nitroaromatic compounds.

chromatography, ${ }^{17}$ mass spectrometry, ${ }^{18}$ electrochemical techniques $^{19}$ and Raman spectroscopy ${ }^{20}$ have been applied for the recognition of picric acid, but have found find limited use due to their low sensitivity, interference from other compounds sample pre-treatment requirements, use of expensive and sophisticated equipment, lack of portability, and difficult on-site operation. Numerous fluorescence-based platforms involving small organic molecules, supramolecules ${ }^{21}$ metal complexes ${ }^{22}$ metal organic frameworks (MOFs), ${ }^{23}$ and quantum dots/nanoclusters, ${ }^{24,25}$ coordination polymers, ${ }^{26}$ among others, have been synthesized for the real-time detection of picric acid.

In order to improve the sensitivity of fluorescent sensors towards PA, the primary focus must be either increasing the quenching efficiency by increasing the binding affinity for picric acid, or increasing the energy/electron transfer rate between the fluorophore and PA through appropriate design. The ability of picric acid $\left(\mathrm{p} K_{\mathrm{a}} 0.42\right)^{27}$ to protonate basic sites such as amines or heterocyclic nitrogens present in the fluorophore can induce electrostatic interactions between the protonated fluorophore and the picrate anion. Further, due to its low $\mathrm{p} K_{\mathrm{a}}$ value, PA remains in dissociated form in water or buffer solutions and electrostatic interactions can form between positively charged fluorescent probes and the picrate anion. Such electrostatic interactions lead to proximity between the electron-rich fluorophore and the picrate anion and positively affect the electron/ energy transfer process and sensitivity of the probe toward picric acid. The general mechanistic approach involved in the selective detection of picric acid by such fluorophores is presented in Scheme 1. Other nitrophenol derivatives have poor electron/energy transfer processes in comparison to picric acid, which is due to the difficulty in the protonation of the basic site(s) in the fluorophore in the case of 2,4-DNP ( $\left.\mathrm{p}_{\mathrm{a}} 4.04\right)$ and 4-NP $\left(\mathrm{p} K_{\mathrm{a}} 7.07\right)$ and the absence of electrostatic interactions in the case of neutral NACs; thus, they may not interfere in the detection of picric acid.
Generally, fluorophores without any protonation sites undergo fluorescence quenching with TNT and PA with equal ease $\mathrm{e}^{28-30}$ and display strong TNT-interference in the detection of picric acid. Furthermore, there are number of references in which the quenching of a fluorophore by PA has been evaluated, but the effect of other NACs has not been studied. ${ }^{31,32}$ Such literature has been omitted in the present discussion.

The discussion of the fluorescent probes (listed in Table 1-4) for picric acid has been classified into following sections:

2. Neutral fluorescent probes for the detection of picric acid

2.1 Protonation of amine-based fluorescent probes for picric acid

2.2 Protonation of pyridine-based fluorescent probes for picric acid

2.3 Protonation of imidazole-based fluorescent probes for picric acid

2.4 Protonation of imine-based fluorescent probes for picric acid

2.5 Protonation of amide-based fluorescent probes for picric acid 3. Positively charged probes for the detection of picric acid 3.1 Monopodal cationic fluorescent probes for picric acid 3.2 Dipodal dicationic fluorescent probes for picric acid 4.3 Tripodal tricationic fluorescent probes for picric acid 4. Metal complexes for the detection of picric acid

44. Miscellaneous

\section{Neutral fluorescent probes for the detection of picric acid}

In this section, the fluorescent probes $\mathbf{1 - 2 8}^{33-54}$ (Charts 2-4) undergo protonation by picric acid at the amine nitrogen to form quaternary anilinium picrate salts, and electron or energy transfer from the photo-excited probe to PA results in the formation of a non-emitting complex. However, the strong 


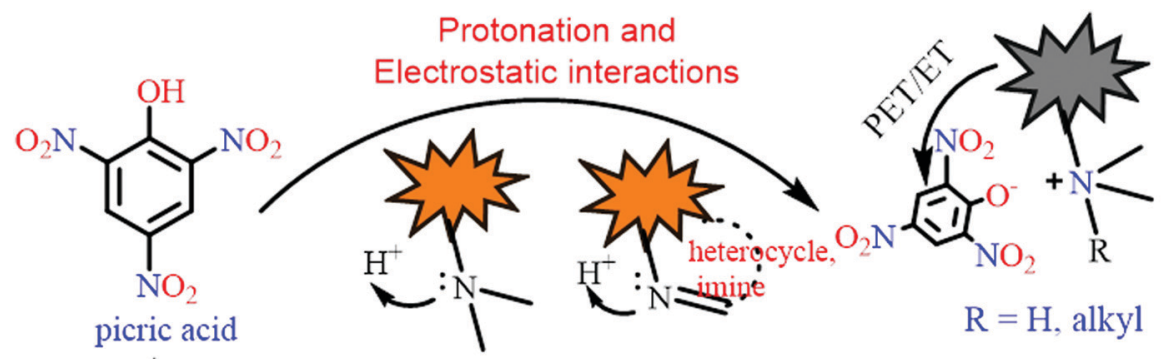<smiles>C=C[IH+]</smiles>

Or

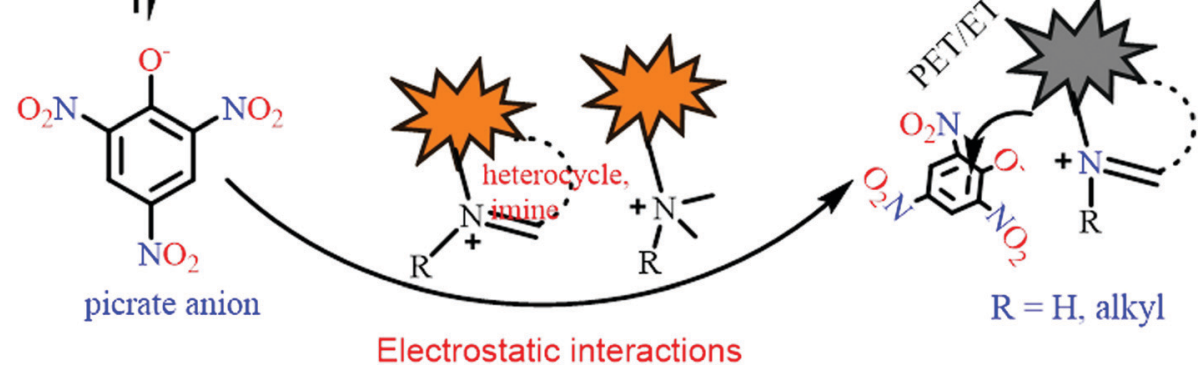

Scheme 1 A schematic presentation of the mechanisms involved in the selective fluorescence quenching of different probes by picric acid.

inhibition of PET in BODIPY-based probe $25^{52}$ and the aggregation of curcumin-based probes 27 and $28^{54}$ upon protonation with picric acid result in fluorescence enhancement. A comparison of the solvents, LODs, $K_{\mathrm{SV}}$ values, emission maxima and applications of probes 1-28 has been presented in Table 1.

\subsection{Protonation of amine-based fluorescent probes for picric acid}

Hexa-peri-hexabenzocoronene (HBC) probes 1 and $2^{33}$ (Chart 2) formed spherical nano-aggregates with respective diameters of 200 and $150 \mathrm{~nm}$ and exhibited $67 \%$ and $85 \%$ enhancements in fluorescence intensity between $460-600 \mathrm{~nm}$ in water-THF $(4: 6)$ owing to the restriction in rotation. Further increasing the amount of water caused lowered emission intensity due to $\pi-\pi$ interactions between the coronene cores. Probe 1 exhibited $98 \%$ fluorescence quenching in water-THF $(4: 6)$ at $\mathrm{pH} 7.0$, turning from a yellow fluorescent solution to a non-fluorescent one with 5 equivalents of PA. The formation of an electrostatic complex by proton transfer from PA to the basic amino group and electron transfer from photo-excited 1 to PA were responsible for the formation of the non-emitting complex. As the $\mathrm{pH}$ of the solution was lowered, the quenching efficiency of 1 by PA gradually decreased owing to the weaker interaction of PA with protonated $\mathrm{NH}_{2}$ and reduced electron transfer from the excited-state HBC core to PA. Probe 2 with no protonation site showed lower quenching efficiency by PA, and its ability to interact with PA remained unaffected by lowering of the $\mathrm{pH}$ of the solution. Probe 2 underwent fluorescence quenching by PA through an intermolecular charge transfer mechanism. Test paper strips coated with solutions of $\mathbf{1}$ and $\mathbf{2}$ detected PA by contact modes. A solution of $\mathbf{1}$ could detect PA vapor through fluorescence quenching.

Naphthyridine-based fluorescent probes 3 and $\mathbf{4}^{34}$ (Chart 2) were used for the detection of PA in both pure methanol and aqueous methanol solutions. Probes 3 and $\mathbf{4}$ showed complete fluorescence quenching with 4.5 and 4.0 equivalents of PA, respectively, due to the protonation of the amine and H-bonding between the nitrogen atom of the naphthyridine ring and PA. Similar fluorescence quenching of $\mathbf{3}$ and $\mathbf{4}$ was observed for 22 equivalents of 4-NP and significantly higher amounts of other NACs. Probes $\mathbf{3}$ and $\mathbf{4}$ formed ground-state complexes with PA and followed static quenching processes. TLC plates coated with probes $\mathbf{3}$ and $\mathbf{4}$ with PA exhibited a change in fluorescence colour from blue to non-fluorescent (Fig. 1).

Anthracenecarboxamide-based probe $\mathbf{5 a ^ { 3 5 }}$ (Chart 2) exhibited fluorescence quenching with 5 equivalents of nitrophenols; the fluorescence quenching followed the order PA $(>96 \%)>2,4$ $\operatorname{DNP}(35 \%)>3,4$-DNP $(17 \%)>4$-DNP $(10 \%)$ in ethanol. A Job's plot analysis showed 1:1 complexation between probe 5a and PA with an association constant of $4.14 \times 10^{5} \mathrm{M}^{-1}$. Probes $5 \mathrm{~b}$ and 5c also showed formation of a $1: 1$ complex with lower binding constant values of $3.34 \times 10^{4} \mathrm{M}^{-1}$ and $5.95 \times 10^{3} \mathrm{M}^{-1}$, respectively. The ${ }^{1} \mathrm{H}$ NMR downfield shift of the amide proton from $\delta 8.91$ to $9.55 \mathrm{ppm}$ and of the imidazole $\mathrm{C} 2-\mathrm{H}$ from $\delta 7.68$ to $9.05 \mathrm{ppm}$ for probe $\mathbf{5 a}$ upon the addition of PA revealed its multiple hydrogen bonding with PA. The fluorescence quenching of probes $5 \mathbf{a}-\mathbf{5 c}$ by PA could be assigned to multiple factors, including FRET, H-bonding and $\pi-\pi$ interactions.

Calix[4]arene-based probe $6^{36}$ (Chart 2) with aminonaphthalimide moieties conjugated at the 1 and 3 aryl rings displayed $97 \%$ fluorescence quenching at $520 \mathrm{~nm}\left(\lambda_{\mathrm{ex}}=\right.$ $410 \mathrm{~nm}$ ) by PA and resulted in a fluorescence colour change from green to non-florescent and a decrease in the quantum yield from 0.33 to 0.02 . 4-Nitrophenol and neutral NACs did not cause any considerable fluorescence quenching of 6 . The protonation of the amine by PA inhibited ICT and resulted in non-fluorescent complex formation. AFM studies revealed that 
Table 1 A comparison of solvent, LOD, $K_{\mathrm{SV}}$, emission maxima, and application data for amine-based probes 1-28

\begin{tabular}{|c|c|c|c|c|c|c|c|c|}
\hline S. no. & Probe & Solvent & $\mathrm{LOD}(\mu \mathrm{M})$ & $K_{\mathrm{SV}}\left(\mathrm{M}^{-1}\right)$ & $\lambda_{\mathrm{ex}}(\mathrm{nm})$ & $\lambda_{\mathrm{em}}(\mathrm{nm})$ & Applications & Ref. \\
\hline \multicolumn{9}{|c|}{ Protonation of amine-based fluorescent probes for picric acid } \\
\hline \multirow[t]{2}{*}{1} & 1 & $\mathrm{THF}-\mathrm{H}_{2} \mathrm{O}(6: 4)$ & 0.004 & $3.2 \times 10^{6}$ & 368 & 485 & Paper strips & 33 \\
\hline & & & & & 398 & 510 & & \\
\hline 2 & 2 & $\mathrm{THF}-\mathrm{H}_{2} \mathrm{O}(6: 4)$ & 0.009 & $2.0 \times 10^{6}$ & 370 & - & Paper strips & 33 \\
\hline \multirow[t]{2}{*}{3} & 3 & $\mathrm{CH}_{3} \mathrm{OH}$ & 4.89 & $7.203 \times 10^{4}$ & 340 & 385 & TLC plate & 34 \\
\hline & & $\mathrm{H}_{2} \mathrm{O}-\mathrm{CH}_{3} \mathrm{OH}(8: 2)$ & & & & & & \\
\hline \multirow[t]{2}{*}{4} & 4 & $\mathrm{CH}_{3} \mathrm{OH}$ & 4.16 & $3.903 \times 10^{4}$ & 345 & 397 & TLC plate & 34 \\
\hline & & $\mathrm{H}_{2} \mathrm{O}-\mathrm{CH}_{3} \mathrm{OH}(8: 2)$ & & & & & & \\
\hline 5 & $5 \mathbf{a}$ & EtOH & 1 & $4.14 \times 10^{5}$ & 362 & 417 & - & 35 \\
\hline 6 & 5b & EtOH & - & $3.34 \times 10^{4}$ & 362 & 417 & - & 35 \\
\hline 7 & $5 \mathbf{c}$ & EtOH & - & $5.95 \times 10^{3}$ & 362 & 417 & - & 35 \\
\hline 8 & 6 & THF & 0.3 & $4.51 \times 10^{5}$ & 410 & 520 & Paper strips & 36 \\
\hline \multirow[t]{3}{*}{9} & 7 & THF & 0.08 & $1.0 \times 10^{5}$ & 354 & 435 & Test strips & 37 \\
\hline & & THF- $\mathrm{H}_{2} \mathrm{O}(1: 1)$ & & & - & 460 & TLC plate & \\
\hline & & $\mathrm{THF}-\mathrm{H}_{2} \mathrm{O}(1: 9)$ & & & 371 & 438 & & \\
\hline 10 & 8 & $\mathrm{H}_{2} \mathrm{O}:$ THF $(1: 1)$ & 0.04 & $1.11 \times 10^{5}$ & 306 & 393 & - & 38 \\
\hline 11 & 9 & $\mathrm{H}_{2} \mathrm{O}:$ THF $(7: 3)$ & 0.035 & $1.95 \times 10^{5}$ & 322 & 458 & Paper strips & 38 \\
\hline 12 & 10a & $\mathrm{CH}_{3} \mathrm{CN}$ & - & $1.2 \times 10^{5}$ & 290 & 405 to 480 & - & 39,40 \\
\hline 13 & $10 \mathrm{~b}$ & $\mathrm{CH}_{3} \mathrm{CN}$ & 9.82 & $2.8 \times 10^{5}$ & 302 & 415 & - & 42 \\
\hline 14 & $10 \mathrm{c}$ & $\mathrm{CH}_{3} \mathrm{CN}$ & 6.55 & $3.31 \times 10^{5}$ & 295 & 425 & - & 41 \\
\hline \multirow[t]{2}{*}{14} & 11 & $\mathrm{H}_{2} \mathrm{O}$ & 0.0042 & $4.82 \times 10^{5}$ & 460 & 550 & Paper strips & 43 \\
\hline & & & & & & & Real sample & \\
\hline \multirow[t]{2}{*}{15} & 12 & $\mathrm{H}_{2} \mathrm{O}$ & 0.0116 & $5.232 \times 10^{5}$ & 550 & 650 & Paper strips & 43 \\
\hline & & & & & & & Real sample & \\
\hline \multirow[t]{2}{*}{16} & 13 & THF & 16 & $0.4 \times 10^{4}$ & 398 & 512 & Paper strips & 44 \\
\hline & & THF- $\mathrm{H}_{2} \mathrm{O}(4: 6)$ & 2 & $2.6 \times 10^{4}$ & & 550 & & \\
\hline 17 & 14 & EtOH- ${ }_{2} \mathrm{O}(5 \%)$ & 1.3 & - & 387 & 540 & - & 45 \\
\hline \multirow[t]{2}{*}{18} & 15 & THF & 5.7 & - & - & 454 & Paper strips & 46 \\
\hline & & & & & & & TLC plate & \\
\hline 19 & 16 & THF & - & - & - & 454 & - & 46 \\
\hline 20 & 17 & EtOH & 0.079 & $6.1 \times 10^{3}$ & 354 & 410 & - & 47 \\
\hline \multirow[t]{2}{*}{21} & 18 & THF-HEPES $(4: 1)$ & 0.0578 & $1.05 \times 10^{5}$ & 366 & 408 & Paper strips & 48 \\
\hline & & & & & & & Real sample & \\
\hline \multirow[t]{2}{*}{22} & 19 & THF & 26 & - & 384 to 400 & 467 to 576 & - & 49 \\
\hline & & THF- $\mathrm{H}_{2} \mathrm{O}(3: 7)$ & 38 & & & & & \\
\hline \multirow[t]{2}{*}{23} & 20 & THF & - & - & 390 & 471 & - & 49 \\
\hline & & THF- $\mathrm{H}_{2} \mathrm{O}(3: 7)$ & & & $400 \rightarrow 490$ & 490 & & \\
\hline \multirow[t]{2}{*}{24} & 21 & THF & - & - & 392 & $490 \rightarrow 540$ & - & 49 \\
\hline & & THF- $\mathrm{H}_{2} \mathrm{O}(3: 7)$ & & & $400 \rightarrow 490$ & & & \\
\hline \multirow[t]{2}{*}{25} & 22 & THF & - & - & 402 & $490 \rightarrow 540$ & - & 49 \\
\hline & & THF- $\mathrm{H}_{2} \mathrm{O}(3: 7)$ & & & $400 \rightarrow 490$ & & & \\
\hline \multirow[t]{2}{*}{26} & 23 & $\mathrm{CH}_{3} \mathrm{CN}$ & 7.2 . & $1.4 \times 10^{4}$ & 260 & 350 & - & 50 \\
\hline & & & & & & 520 & & \\
\hline 27 & 24 & $\mathrm{CH}_{3} \mathrm{CN}-\mathrm{H}_{2} \mathrm{O}(8: 2)$ & 0.44 & - & 365 & 540 & & 51 \\
\hline 28 & 25 & EtOH & 0.0028 & $1.91 \times 10^{4}$ & 499 & 513 & - & 52 \\
\hline 29 & 26 & DMSO : $\mathrm{H}_{2} \mathrm{O}(1: 4)$ & 0.0032 & $4.37 \times 10^{4}$ & 367 & 496 to 454 & $\begin{array}{l}\text { Real water sample } \\
\text { Paper strips }\end{array}$ & 53 \\
\hline 30 & 27 & Aqueous media & 0.0135 & - & 430 & 540 & Real sample & 54 \\
\hline 31 & 28 & Aqueous media & 0.0135 & - & 430 & 535 & Real sample & 54 \\
\hline
\end{tabular}

the donut-like structures of $\mathbf{6}$ were transformed into extended ribbon-like structures (Fig. 2A) with a length of several microns, a width of 100-160 nm, and a height of 35-45 $\mathrm{nm}$ upon treatment with PA. A solution of 6 and cellulose filter paper strips coated with probe 6 (Fig. $2 \mathrm{~B}$ ) could detect $0.3 \mu \mathrm{M}$ and $0.1 \mu \mathrm{M}$ PA, respectively, as the lowest limits.

Hydrazono-sulfonamide adduct $7^{37}$ (Chart 2), which is weakly emissive in THF, became strongly emissive with a maximum between 434-460 $\mathrm{nm}$ upon the addition of 50-100\% water, owing to the inhibition of $\mathrm{C}=\mathrm{N}$ isomerization. Solutions of 7 in $\mathrm{THF}$, THF-water (1:1) and THF-water (1:9) exhibited complete fluorescence quenching by 50,30 and 30 equivalents of PA, respectively. However, the Stern-Volmer constant $(1.0 \times$ $\left.10^{5} \mathrm{M}^{-1}\right)$ was highest in the THF-water $(1: 1)$ mixture. In the
THF-water (1:1) mixture, the aggregates of 7 formed a greater number of voids to interact with PA, and this loose packing was responsible for the higher sensing performance compared to that observed in other solvents. The quenching efficiency of nitrophenols followed the order PA $>4$-NP $>2,4$-DNP. The protonation of the dimethylarylamine nitrogen associated with electron transfer from the excited state of fluorophore 7 to PA was responsible for the fluorescence quenching.

Triphenylene derivatives 8 and $9^{38}$ revealed a 1.5- to 1.6-fold fluorescence enhancement in an $\mathrm{H}_{2} \mathrm{O}-\mathrm{THF}(7: 3)$ mixture owing to the formation of aggregates (Fig. $3 \mathrm{~A}$ and $\mathrm{B}$ ) and the restriction of TICT. The fluorescent aggregates of $8^{38}$ (Chart 2) with 20 equivalents $\mathrm{PA}$ in an $\mathrm{H}_{2} \mathrm{O}$-THF $(1: 1)$ mixture displayed $98 \%$ fluorescence quenching following the energy transfer 
Table 2 A comparison of solvent, LOD, $K_{\mathrm{SV}}$, emission maxima, and application data for pyridine-based probes 29-60

Protonation of pyridine-based fluorescent probes for picric acid

\begin{tabular}{|c|c|c|c|c|c|c|c|c|}
\hline S. no. & Probe & Solvent & LOD $(\mu \mathrm{M})$ & $K_{\mathrm{SV}}\left(\mathrm{M}^{-1}\right)$ & $\lambda_{\mathrm{ex}}(\mathrm{nm})$ & $\lambda_{\mathrm{em}}(\mathrm{nm})$ & Applications & Ref. \\
\hline 1 & $29 a$ & $\mathrm{H}_{2} \mathrm{O}-\mathrm{DMSO}(1: 1)$ & 0.720 & $3.40 \times 10^{3}$ & 310 & 481 & Paper strips & 55 \\
\hline 2 & $29 b$ & $\mathrm{H}_{2} \mathrm{O}-\mathrm{DMSO}(1: 1)$ & 0.650 & $4.36 \times 10^{3}$ & 310 & 481 & Paper strips & 55 \\
\hline 3 & $29 c$ & $\mathrm{H}_{2} \mathrm{O}-\mathrm{DMSO}(1: 1)$ & 0.600 & $6.52 \times 10^{3}$ & 310 & 492 & Paper strips & 55 \\
\hline 4 & 30 & $\mathrm{H}_{2} \mathrm{O}-\mathrm{THF}(9: 1)$ & 0.250 & $8.44 \times 10^{3}$ & 300 & 475,555 & Paper strips & 55 \\
\hline 5 & 31 & $\mathrm{H}_{2} \mathrm{O}-\mathrm{THF}(9: 1)$ & 0.290 & $3.61 \times 10^{3}$ & 300 & 475,555 & Paper strips & 55 \\
\hline 6 & 32 & $\mathrm{H}_{2} \mathrm{O}-\mathrm{EtOH}(6: 4)$ & 0.026 & - & 273 & 339 to 460 & Paper strips & 56 \\
\hline 7 & 33 & $\mathrm{H}_{2} \mathrm{O}-\mathrm{EtOH}(3: 7)$ & - & - & 273 & 339 to 460 & - & 56 \\
\hline 8 & 34 & $\mathrm{H}_{2} \mathrm{O}-\mathrm{EtOH}(6: 4)$ & - & - & 290 & 345 & - & 56 \\
\hline 9 & 35 & $\mathrm{CHCl}_{3}$ & $0.131-0.294$ & $2.54 \times 10^{4}$ & 334 & 417 & Paper strips & 57 \\
\hline 10 & 36 & $\mathrm{CHCl}_{3}$ & $0.131-0.294$ & $2.63 \times 10^{4}$ & 339 & 435 & Paper strips & 57 \\
\hline 11 & 37 & $\mathrm{CHCl}_{3}$ & $0.131-0.294$ & $2.69 \times 10^{4}$ & 341 & 437 & Paper strips & 57 \\
\hline 12 & 38 & $\mathrm{CHCl}_{3}$ & $0.131-0.294$ & $8.08 \times 10^{4}$ & 390 & 498 & Paper strips & 57 \\
\hline 13 & 39 & Hydrosol & 0.43 & $7.8 \times 10^{4}$ & 315 & 359 & - & 58 \\
\hline 14 & 40 & $\mathrm{MeOH}$ & 0.056 & - & - & 405 to 522 & - & 59 \\
\hline 15 & 41 & $\mathrm{H}_{2} \mathrm{O}-\mathrm{DMSO}(1: 1)$ & 0.063 & - & - & 530 & Smartphone device & 60 \\
\hline 16 & 42 & DMSO- $\mathrm{H}_{2} \mathrm{O}(1: 99)$ & 0.0315 & $2.3 \times 10^{6}$ & 380 & 527 & Water sample, test strips & 61 \\
\hline 17 & 43 & DMSO- $\mathrm{H}_{2} \mathrm{O}(1: 1)$ & 0.013 & $7.69 \times 10^{4}$ & 375 & 522 & Real sample & 62 \\
\hline 18 & 44 & THF & 1.747 & $4.106 \times 10^{5}$ & 350 to 424 & 440 to 550 & - & 63 \\
\hline 19 & 45 & $\mathrm{CH}_{3} \mathrm{CN}-\mathrm{H}_{2} \mathrm{O}(4: 1)$ & 0.5 & $4.4 \times 10^{5}$ & 330 & 410 & Water sample & 64 \\
\hline 20 & 46 & $\mathrm{THF}$ & 2.184 & $4.3 \times 10^{4}$ & 360 to 500 & 500 & $\begin{array}{l}\text { Paper strips } \\
\text { TLC plates }\end{array}$ & 65 \\
\hline 21 & 47 & $\mathrm{MeOH}: \mathrm{H}_{2} \mathrm{O}(8: 2)$ & 100.4 & - & 400 & 500 & - & 66 \\
\hline 22 & 48 & $\mathrm{DMF}$ & 0.108 & $3.86 \times 10^{5}$ & 419 & 483 & - & 67 \\
\hline 23 & 49 & $\mathrm{DMF}$ & 0.138 & $3.21 \times 10^{5}$ & 369 & 420 & - & 68 \\
\hline 24 & 50 & DMF & 0.102 & $4.65 \times 10^{5}$ & 353 & 448 & - & 68 \\
\hline 25 & 51 & DMF & 0.196 & $1.57 \times 10^{5}$ & 335 & 416,559 & - & 68 \\
\hline \multirow[t]{2}{*}{26} & 52 & EtOH & 0.075 & $4.15 \times 10^{5}$ & 500 & 545 & Paper strips & 69 \\
\hline & & $\mathrm{H}_{2} \mathrm{O}$ & 0.570 & $3.94 \times 10^{4}$ & 400 & 542 & & \\
\hline \multirow[t]{2}{*}{27} & 53 & $\mathrm{EtOH}$ & 0.110 & $2.5 \times 10^{5}$ & 517 & 558 & Paper strips & 69 \\
\hline & & $\mathrm{H}_{2} \mathrm{O}$ & 0.93 & $2.1 \times 10^{4}$ & 400 & 555 & & \\
\hline 28 & 54 & $\mathrm{H}_{2} \mathrm{O}$ & 2.62 & $5.78 \times 10^{4}$ & - & 420 & Paper strips & 70 \\
\hline 29 & 55 & $\mathrm{H}_{2} \mathrm{O}$ & 6.98 & $3.26 \times 10^{4}$ & & 450 & Paper strips & 70 \\
\hline 30 & 56 & $\mathrm{MeOH}$ & 0.0056 & $6.87 \times 10^{4}$ & 490 & $537,576,627$ & - & 71 \\
\hline \multirow[t]{2}{*}{31} & 57 & $\mathrm{CH}_{3} \mathrm{CN}$ & 0.644 & $3.45 \times 10^{5}$ & 365 & 493 & Test strips & 72 \\
\hline & & $\mathrm{H}_{2} \mathrm{O}$ & 0.586 & $2.18 \times 10^{5}$ & 365 & 460 & & \\
\hline 32 & 58 & $\mathrm{CH}_{3} \mathrm{CN}$ & - & - & 365 & 438 & - & 72 \\
\hline 33 & $59 a$ & EtOH & - & $67.6 \times 10^{3}$ & 370 & 474 & - & 73 \\
\hline 34 & $59 b$ & EtOH & - & $60.3 \times 10^{3}$ & 370 & 474 & - & 73 \\
\hline 35 & $59 c$ & EtOH & - & $74.2 \times 10^{3}$ & 370 & 474 & - & 73 \\
\hline 36 & 59d & EtOH & - & $62.2 \times 10^{3}$ & 370 & 474 & - & 73 \\
\hline 37 & 60 & $\mathrm{CH}_{3} \mathrm{CN}-\mathrm{H}_{2} \mathrm{O}(1: 9)$ & 0.0373 & $6.4 \times 10^{7}$ & 540 & 581 & Paper strips, water samples & 74 \\
\hline
\end{tabular}

process at $393 \mathrm{~nm}$, as observed from the overlap of the fluorescence spectrum of $\mathbf{8}$ with the absorbance spectrum of PA. The aggregates of 9 with 26 equivalents of $\mathrm{PA}$ in an $\mathrm{H}_{2} \mathrm{O}-\mathrm{THF}(7: 3)$ mixture exhibited fluorescence quenching at $458 \mathrm{~nm}$ due to the protonation of the basic $\mathrm{NH}_{2}$ groups and electrostatic interactions between the protonated aggregates of $\mathbf{9}$ and the picrate anion. Probe 9 displayed higher selectivity towards PA than derivative 8. Paper strips coated with 9 (Fig. 3C) could detect $10^{-11} \mathrm{M}$ PA. Other NACs such as TNT, 2,4-DNT, 1,4-DNB, NB, 4-NT, BQ, NM and DMNB caused fluorescence quenching, but at significantly higher concentrations.

The C3-symmetric 1,3,5-tris( $4^{\prime}$-aminophenyl)benzene $\mathbf{1 0 a}^{39,40}$ (Chart 2) exhibited a red shift in its emission maximum from $405 \mathrm{~nm}$ to $480 \mathrm{~nm}$ due to PA. A solution of 10a with 32 equivalents of PA and 450-640 equivalents of TNT, DNT and 1,4-DNB exhibited $>80 \%$ quenching of fluorescence intensity, pointing to the selective fluorescence quenching by PA (Fig. 4A). The X-ray crystal structures of 10a with PA (Fig. 4B) and TNT revealed the formation of $1: 1$ stoichiometric complexes through strong intermolecular $\pi-\pi$ interactions between 10a and the NACs. The layers of the probe could intercalate three molecules of 1,3-DNB. The crystal lattices are further stabilized through inter-stack hydrogen bonds $(\mathrm{N}-\mathrm{H} \cdots \mathrm{N}$ and $\mathrm{N}-\mathrm{H} \cdots \mathrm{O})$ between the amino groups of the probe and nitro groups of the NACs (Fig. 4B). Thin films prepared from 10a could detect TNT and DNT vapor, but not PA vapor.

Probe 10c, ${ }^{41}$ which exhibited reduced H-bond donor characteristics in comparison to probe 10a, but increased basicity of the amine nitrogen, revealed $90 \%$ fluorescence quenching with only 10 equivalents of PA in comparison to the 32 equivalents of $\mathrm{PA}$ required by probe 10a. Furthermore, 10c formed a $1: 3$ $\left(10 \mathrm{c} \cap(\mathrm{PA})_{3}\right)$ stoichiometric complex through proton transfer from three molecules of PA to the three amine nitrogens of 10c, as was clearly evident from the X-ray crystal structure (Fig. 4C). However, 10a formed only a 1:1 stoichiometric complex through H-bonding (Fig. 4B). The association constants of 10c with NACs followed the order PA $\gg 1,4-\mathrm{DNB}>\mathrm{TNT} \approx$ 2,4 -DNT $\approx 1,3$-DNB, with PA being almost 25 times more effective 
Table 3 A comparison of solvent, LOD, $K_{\mathrm{SV}}$, emission maxima, and application data for imidazole, amide, and imide probes $\mathbf{6 1 - 8 4}$

\begin{tabular}{|c|c|c|c|c|c|c|c|c|}
\hline S. no. & Probe & Solvent & LOD $(\mu \mathrm{M})$ & $K_{\mathrm{SV}}\left(\mathrm{M}^{-1}\right)$ & $\lambda_{\mathrm{ex}}(\mathrm{nm})$ & $\lambda_{\mathrm{em}}(\mathrm{nm})$ & Applications & Ref. \\
\hline 1 & 61 & DMSO- $\mathrm{H}_{2} \mathrm{O}(7: 3)$ & 0.17 & $3.75 \times 10^{4}$ & 270 & 392 & Water samples & 75 \\
\hline 2 & 62 & $\mathrm{EtOH}-\mathrm{H}_{2} \mathrm{O}(7: 3)$ & 0.49 & $2.4 \times 10^{4}$ & 280 & 345 & Water samples & 75 \\
\hline 3 & 63 & $\mathrm{DMSO}-\mathrm{H}_{2} \mathrm{O}(1: 9)$ & 3.223 & $1.168 \times 10^{4}$ & 312 & 413 & Paper strips & 76 \\
\hline 4 & 64 & $\mathrm{DMSO}-\mathrm{H}_{2} \mathrm{O}(1: 9)$ & 2.987 & $2.65 \times 10^{4}$ & 309 & 409 & Paper strips & 76 \\
\hline 5 & 65 & $\mathrm{DMSO}-\mathrm{H}_{2} \mathrm{O}(1: 9)$ & 2.996 & $2.05 \times 10^{4}$ & 309 & 401 & Paper strips & 76 \\
\hline 6 & $66 a$ & EtOH & 2.8 & $8.62 \times 10^{4}$ & 340 & 386 & - & 77 \\
\hline 7 & $66 b$ & $\mathrm{EtOH}$ & 2.3 & $1.45 \times 10^{5}$ & 340 & 486 & - & 77 \\
\hline 8 & $66 c$ & EtOH & 4.6 & $8.53 \times 10^{4}$ & 340 & 456 & - & 77 \\
\hline 9 & 67 & $\mathrm{H}_{2} \mathrm{O}-\mathrm{THF}(9: 1)$ & 0.0025 & $2.54 \times 10^{5}$ & 335 & 422 & Paper strips, water samples & 78 \\
\hline 10 & 68 & THF & 0.218 & $1.115 \times 10^{5}$ & 300 & 376 & $\begin{array}{l}\text { TLC plate } \\
\text { Paper strip }\end{array}$ & 79 \\
\hline 11 & 69 & $\mathrm{CHCl}_{3}$ & 21.6 & $5.1 \times 10^{4}$ & 307 & 367 to 381 & -1 & 80 \\
\hline 12 & $70 b$ & $\begin{array}{l}\mathrm{CHCl}_{3} \\
\text { Acetone- } \mathrm{H}_{2} \mathrm{O}(1: 1)\end{array}$ & 19.0 & $9.9 \times 10^{6}$ & 307 & 367 to 383 & Paper strips & 80 \\
\hline 13 & 71 & $\begin{array}{l}\text { Toluene } \\
\mathrm{CH}_{3} \mathrm{CN}\end{array}$ & $\begin{array}{l}2.515 \\
1.065\end{array}$ & $\begin{array}{l}6.58 \times 10^{4} \\
1.85 \times 10^{6}\end{array}$ & 345 & 378,397 & - & 81 \\
\hline 14 & 72 & $\mathrm{H}_{2} \mathrm{O}-\mathrm{DMF}(9: 1)$ & 3.55 & $1.3 \times 10^{4}$ & 400 & 574 & Mechanochromic behaviour & 82 \\
\hline \multicolumn{9}{|c|}{ Protonation of imine-based fluorescent probes for picric acid } \\
\hline 15 & 73 & $\mathrm{CH}_{3} \mathrm{CN}$ & 0.01 & $6.814 \times 10^{6}$ & 368 to 344 & 425 to 462 & Paper strips & 83 \\
\hline 16 & 74 & $\mathrm{CH}_{3} \mathrm{CN}-\mathrm{H}_{2} \mathrm{O}(2: 8)$ & - & - & 390 & 467 & Paper strips & 84 \\
\hline 17 & 75 & $\mathrm{THF}-\mathrm{H}_{2} \mathrm{O}(1: 9)$ & 0.010 & $2.03 \times 10^{4}$ & 375 & 469 & Test strips & 85 \\
\hline 18 & 76 & $\mathrm{THF}-\mathrm{H}_{2} \mathrm{O}(1: 9)$ & 0.0726 & $70 \times 10^{-6}$ & 430 & 585,620 & TLC plate, test strip & 86 \\
\hline \multicolumn{9}{|c|}{ Protonation of amide-based fluorescent probes for picric acid } \\
\hline 19 & 77 & $\mathrm{H}_{2} \mathrm{O}-\mathrm{THF}(9: 1)$ & 0.47 & $7.0 \times 10^{4}$ & 371 & 558 & Filter paper & 87 \\
\hline 20 & 78 & DMSO & 0.011 & $7.40 \times 10^{4}$ & 370 & 435 & Paper strips & 88 \\
\hline 21 & 79 & PBS buffer & 0.0000256 & $2.20 \times 10^{7}$ & 338 & 484 & Paper strips, TLC plate & 89 \\
\hline 22 & 80 & $\mathrm{THF}-\mathrm{H}_{2} \mathrm{O}(1: 9)$ & 3.93 & $9.6 \times 10^{4}$ & 350 & 590 & TLC plate & 90 \\
\hline 23 & 81 & THF & 2.98 & $6.02 \times 10^{3}$ & 455 & 529 & -1 & 91 \\
\hline 24 & 82 & EtOH & 0.820 & - & 314 & 420 to 460,586 & Paper strips & 92 \\
\hline 25 & $83 a$ & $\mathrm{MeOH}-\mathrm{H}_{2} \mathrm{O}(1: 4)$ & 0.00002 & $7.05 \times 10^{7}$ & 480 & 539 to 581 & Water sample & 93 \\
\hline 26 & $\mathbf{8 3 b}$ & $\mathrm{MeOH}-\mathrm{H}_{2} \mathrm{O}(1: 4)$ & - & - & - & - & - & 93 \\
\hline 27 & 84 & $\mathrm{MeOH}$ & 0.035 & - & 314 & 430 to 578 & TLC strip-solid PA & 94 \\
\hline
\end{tabular}

as a quencher in comparison to the other NACs. Additionally, instead of the PET mechanism operative in the case of probe 10a, here, proton transfer is the actual quenching mechanism. The quenching efficiency of $\mathbf{1 0 b}^{\mathbf{4 2}}$ was intermediate between those of probes 10a and 10c, and their quenching efficiency followed the same order as the basicity of the amine nitrogens. The emission spectrum of 10b showed 85\% quenching of the emission maximum with 20 equivalents of PA with a detection limit of $9.82 \mu \mathrm{M}$.

The curcumin-based fluorophores 11 and $12^{43}$ (Chart 3) with PA exhibited 92 and 93\% quenching of the intense emission at $550 \mathrm{~nm}$ for 11 and $650 \mathrm{~nm}$ for 12, respectively, with a visible colour change from yellow to red for $\mathbf{1 1}$ and pink to bluish green for 12 in the aqueous solution. No change in the FI was observed with the addition of other NACs. The protonation of 11/12 by PA and electron transfer from the fluorophore to PA are responsible for fluorescence quenching via the static process. The probes were also used to detect PA in water samples.

Probe $13^{44}$ showed a red shift in its emission maximum from $485 \mathrm{~nm}$ to $543 \mathrm{~nm}$ when moving from the non-polar solvent toluene to the highly polar solvent methanol, indicating that due to increased ICT, the molecular geometry in the first excited state is more polarized than that in the ground state. A THF- $\mathrm{H}_{2} \mathrm{O}(4: 6)$ solution of $\mathbf{1 3}$ displayed the highest emission intensity among the binary solutions owing to the formation of aggregates with restriction in the $\pi-\pi$ stacking interactions and intramolecular rotations. The high emission of $\mathbf{1 3}$ in $\mathrm{THF}-\mathrm{H}_{2} \mathrm{O}$
( $4: 6$ ) decreased by $97.32 \%$ upon the addition of 30 equivalents of PA, whereas in pure THF, 95.43\% fluorescence quenching was observed with 40 equivalents of PA. The emission quenching mechanism is explained by the electron transfer and/or energy transfer processes. Among PA, 2,4-DNP, 4-NP, TNT, 1,4DNB and NB, PA had the greatest quenching efficiency (Fig. 5). Paper strips coated with 13 showed a dark spot for $10^{-3} \mathrm{M}$ PA.

$\alpha$-Cyanostilbene derivative $\mathbf{1 4}^{\mathbf{4 5}}$ (Chart 3) with 4 equivalents of PA in an ethanol-water ( $95: 5$ ) mixture revealed $60 \%$ fluorescence quenching (at $540 \mathrm{~nm}$ ), but the quenching did not exceed $20 \%$ with other NACs. Remarkable acidochromic behaviour was observed with TFA, hydrochloric acid, TEA and/or their vapors due to the basicity of the nitrogen atom. Using mechanical grinding, solvent writing and vapor erasing, a reversible fluorescence switching cycle was observed.

Thiophene-based probes 15 and $16^{46}$ (Chart 3) were used for the detection of PA and intracellular pH. 15 was more selective for PA as compared to $\mathbf{1 6}$. Probe 15 showed a $30 \%$ reduction in emission intensity in THF with 0.1 equivalents of PA and could detect concentrations as low as 5.7 $\mu \mathrm{M}$ PA. Paper strips and TLC plates coated with probe 15 solution detected PA in visible light (colourless to yellow) and under $365 \mathrm{~nm}$ (blue fluorescent to non-fluorescent). The compound was also used for the fluorescence-based determination of $\mathrm{pH}$ in live cells.

Fluorophore $17^{47}$ (Chart 3) displayed quenching of its fluorescence intensity with no shift in the emission maximum 
Table 4 A comparison of solvent, LOD, $K_{\mathrm{SV}}$, emission maxima, and application data for positively charged probes $\mathbf{8 5 - 1 2 8}$

Monopodal positively charged probes for picric acid

\begin{tabular}{|c|c|c|c|c|c|c|c|c|}
\hline S. no. & Probe & Solvent & LOD $(\mu \mathrm{M})$ & $K_{\mathrm{SV}}\left(\mathrm{M}^{-1}\right)$ & $\lambda_{\mathrm{ex}}(\mathrm{nm})$ & $\lambda_{\mathrm{em}}(\mathrm{nm})$ & Applications & Ref. \\
\hline 1 & 85 & $\mathrm{MeOH}-\mathrm{H}_{2} \mathrm{O}(9: 1)$ & 4.7 & $2.38 \times 10^{4}$ & 430 to 350 & 580 & - & 95 \\
\hline 2 & 86 & $\left.\mathrm{MeOH}-\mathrm{H}_{2} \mathrm{O}(9: 1)\right)$ & 3.6 & $1.08 \times 10^{4}$ & 430 to 350 & 593 & - & 95 \\
\hline 3 & 87 & $\mathrm{MeOH}-\mathrm{H}_{2} \mathrm{O}(9: 1)$ & - & - & 430 & 599 & - & 95 \\
\hline 4 & 88 & $\mathrm{H}_{2} \mathrm{O}$ & 1.98 & - & 365 & 390 to 455 & Water sample & 96 \\
\hline 5 & 89 & $\mathrm{H}_{2} \mathrm{O}-\mathrm{THF}(1: 1)$ & 0.0082 & $1.67 \times 10^{9}$ & $\begin{array}{l}550 \\
610\end{array}$ & $\begin{array}{l}620 \\
730\end{array}$ & Paper strips & 97 \\
\hline 6 & 90 & $\mathrm{H}_{2} \mathrm{O}-\mathrm{THF}(1: 1)$ & 0.0088 & - & 460 & $\sim 710$ & Paper strips & 97 \\
\hline 7 & 91 & $\mathrm{H}_{2} \mathrm{O}$ & 0.107 & $2.2 \times 10^{4}$ & 325 to 340 & 480 & TLC plate & 98 \\
\hline 8 & 92 & $\mathrm{H}_{2} \mathrm{O}$ & 0.087 & $5 \times 10^{4}$ & 325 to 340 & 410 & TLC plate & 98 \\
\hline 9 & 93 & $\mathrm{H}_{2} \mathrm{O}$ & 1.878 & - & 292 & 402 & - & 99 \\
\hline 10 & 94 & PBS-DMSO (0.5\%) & - & $5.52 \times 10^{3}$ & 336 & 378 & - & 100 \\
\hline 11 & 95 & PBS-DMSO (0.5\%) & - & $6.55 \times 10^{4}$ & 336 & 383 & - & 100 \\
\hline 12 & 96 & PBS-DMSO (0.5\%) & 0.00029 & $8.34 \times 10^{6}$ & 336 & 494 & Paper strips, water sample & 100 \\
\hline 13 & 97 & $\mathrm{CH}_{3} \mathrm{CN}$ & 0.070 & - & 620 & 684 to 644 & Paper strips & 101 \\
\hline \multicolumn{9}{|c|}{ Dipodal positively charged probes for picric acid } \\
\hline 14 & 98 & $\mathrm{SDS}-\mathrm{H}_{2} \mathrm{O}$ & 1 & - & 345 & 480 & - & 102 \\
\hline 15 & 99 & Aqueous media, 95\% & 0.00056 & $0.1 \times 10^{8}$ & 325 & 406 & Paper strips & 103 \\
\hline 16 & 100 & $\mathrm{H}_{2} \mathrm{O}$ & - & $1.75 \times 10^{4}$ & 365 & 513 & - 1 & 104 \\
\hline 17 & 101 & $\mathrm{H}_{2} \mathrm{O}$ & - & $6.04 \times 10^{4}$ & 365 & 485 & - & 104 \\
\hline 18 & 102 & NMP & 1.0 & $16.8 \times 10^{6}$ & 337 & $\sim 470$ & - & 105 \\
\hline 19 & 103 & DMF and $\mathrm{H}_{2} \mathrm{O}$ & 1.0 & - & 370 & 545,580 & - & 106 \\
\hline 20 & 104 & DMF & 1.0 & - & 370 & 543 & - & 106 \\
\hline 21 & 105 & DMF & 1.0 & - & 370 & 543 & - & 106 \\
\hline \multicolumn{9}{|c|}{ Tripodal positively charged probes for picric acid } \\
\hline 22 & 106 & DMSO & 2.039 & $3.8 \times 10^{4}$ & 371 & $399,422,446$ & Water samples & 107 \\
\hline 23 & 107 & DMSO & 1.545 & $3.3 \times 10^{4}$ & 371 & $399,422,446$ & Water samples & 107 \\
\hline 24 & 108 & HEPES-DMSO (2\%) & - & $2.67 \times 10^{5}$ & 290 & 402 & - & 108 \\
\hline 25 & 109 & HEPES-DMSO (2\%) & 0.001 & $3.57 \times 10^{5}$ & 290 & 470 & Paper strips & 108 \\
\hline 26 & 110 & HEPES-DMSO (2\%) & - & - & 290 & 450 to 485 & - & 108 \\
\hline 27 & 111 & $\mathrm{H}_{2} \mathrm{O}-\mathrm{DMSO}(2 \%)$ & 0.000005 & $\begin{array}{l}1.20 \times 10^{11} \\
1.10 \times 10^{8} \\
4.78 \times 10^{5}\end{array}$ & 290 & 402 & Paper strips & 109 \\
\hline 28 & 112 & HEPES-DMSO (2\%) & 0.00001 & $1.57 \times 10^{9}$ & 335 & 520 & Paper strips & 110 \\
\hline 29 & 113 & $\mathrm{H}_{2} \mathrm{O}-\mathrm{DMSO}(2 \%)$ & 0.025 & $6.25 \times 10^{5}$ & 290 & 454 & Paper strips & 111 \\
\hline 30 & 114 & $\mathrm{H}_{2} \mathrm{O}-\mathrm{DMSO}(2 \%)$ & 0.0000001 & $2.56 \times 10^{11}$ & 290 & 448 & Paper strips & 111 \\
\hline 31 & 115 & $\mathrm{H}_{2} \mathrm{O}-\mathrm{DMSO}(2 \%)$ & 0.0000001 & $5.04 \times 10^{11}$ & 290 & 412 & Paper strips & 111 \\
\hline 32 & 116 & $\mathrm{H}_{2} \mathrm{O}-\mathrm{DMSO}(2 \%)$ & 0.0000001 & $6.73 \times 10^{8}$ & 335 & 480 & Paper strips & 112 \\
\hline 33 & 117 & $\mathrm{H}_{2} \mathrm{O}$ & 15.2 & $3.43 \times 10^{3}$ & 340 & $\sim 480$ & Paper strips & 113 \\
\hline 34 & 118 & HEPES buffer & $\begin{array}{l}0.0001(\mathrm{UV}) \\
0.003(\mathrm{FL})\end{array}$ & - & 490 & 615 & Soil sample & 114 \\
\hline 35 & 119 & HEPES buffer & $\begin{array}{l}0.020(\mathrm{UV}) \\
0.002(\mathrm{FL})\end{array}$ & - & 490 & 615 & $\begin{array}{l}\text { Turn-ON } \\
\text { Paper strips }\end{array}$ & 115 \\
\hline \multicolumn{9}{|c|}{ Metal-complex-based probes for picric acid } \\
\hline 36 & 120 & DMSO- $\mathrm{H}_{2} \mathrm{O}(5: 95)$ & 0.0121 & $1.165 \times 10^{6}$ & 383 & 485 & Paper strips & 116 \\
\hline 37 & 121 & $\mathrm{H}_{2} \mathrm{O}$ & 0.99 & $5.29 \times 10^{4}$ & 400 & 470 & Thin film & 117 \\
\hline 38 & 122 & $\mathrm{H}_{2} \mathrm{O}-\mathrm{THF}(4: 6)$ & 0.03 & $1.92 \times 10^{5}$ & 380 & 460 & Paper strips & 118 \\
\hline 39 & 123 & $\mathrm{THF}-\mathrm{H}_{2} \mathrm{O}(9: 1)$ & 0.170 & $9 \times 10^{4}$ & 380 & 458 & - & 119 \\
\hline 40 & 124 & DMSO & 3.056 & $1.6 \times 10^{5}$ & 630 & 684,752 & Thin film & 120 \\
\hline 41 & 125 & DMSO & 4.803 & $2.02 \times 10^{5}$ & 630 & 696,761 & Thin film & 120 \\
\hline \multicolumn{9}{|c|}{ Miscellaneous } \\
\hline 42 & 126 & Toluene & 0.131 & $2.1 \times 10^{6}$ & 500 & 600 & Paper strips & 121 \\
\hline 43 & 127 & $\mathrm{CH}_{3} \mathrm{CN}-\mathrm{H}_{2} \mathrm{O}(9: 1)$ & $0.707 \pm(0.06)$ & $9.2 \times 10^{6}$ & 504 to 516 & 518 to 535 & Thin film & 122 \\
\hline 44 & 128 & $\mathrm{H}_{2} \mathrm{O}$ & 0.0172 & $1.65 \times 10^{6}$ & 279 & 348 & - & 123 \\
\hline
\end{tabular}

with PA in ethanol. The quenching was due to the H-bonding interactions of the $\mathrm{NH}_{2}$ group of 17 with the phenolic $-\mathrm{OH}$ group of PA, as the singlet at $\delta 5.33 \mathrm{ppm}$ for the free $\mathrm{NH}_{2}$ group shifted downfield to $\delta 6.48 \mathrm{ppm}$ after interaction with PA in the ${ }^{1} \mathrm{H}$ NMR experiment. Probe 17 formed a 1:1 stoichiometric complex with PA with a Stern-Volmer constant of $6.1 \times 10^{3} \mathrm{M}^{-1}$.

Inner filter effect and protonation assisted PET-based detection of PA using conjugated polymer 18 (Chart 4) was developed by Iyer et $a l .{ }^{48}$ Upon excitation of a THF solution of 18 at $366 \mathrm{~nm}$, emission was observed at $408 \mathrm{~nm}$. The fluorescence of
18 in THF-HEPES (4:1) buffer solution was quenched by $25 \%$ with only 3.3 equivalents of $\mathrm{PA}$, and was decreased by $95 \%$ with 50 equivalents of PA. The LOD was found to be $0.0578 \mu \mathrm{M}$. Metal ions, anions, and other nitroaromatics did not produce the same quenching phenomena as PA. The significant spectral overlap and insignificant lifetime change revealed the quenching mechanism to be the inner filter effect (IFE). Along with the IFE, the PET from polymer 18 to PA induced by acid-base interaction was also responsible for the quenching. The probe was able to detect PA in natural water samples, as well as on probe-18-coated test strips. 
View Article Online

Review

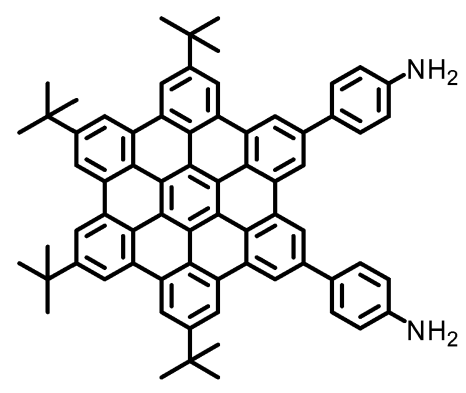

1<smiles>[R]CCCN([R1])C(=O)c1c2ccccc2cc2ccccc12</smiles>

Sa $R=$ Imide $R_{1}=H$

Sb $\mathrm{R}=\mathrm{CH}_{3}, \mathrm{R}_{\mathbf{1}}=\mathrm{H}$

Sc $\mathbf{R}=\mathrm{CH}_{3}, \mathrm{R}_{1}=\mathrm{CH}_{3}$<smiles>Cc1ccc(-c2cc3c(cc2-c2ccc(C#N)cc2)c2cc(-c4ccc(C#N)cc4)c(-c4ccc(C#N)cc4)cc2c2cc(-c4ccc(C#N)cc4)c(-c4ccc(C#N)cc4)cc32)cc1</smiles>

8

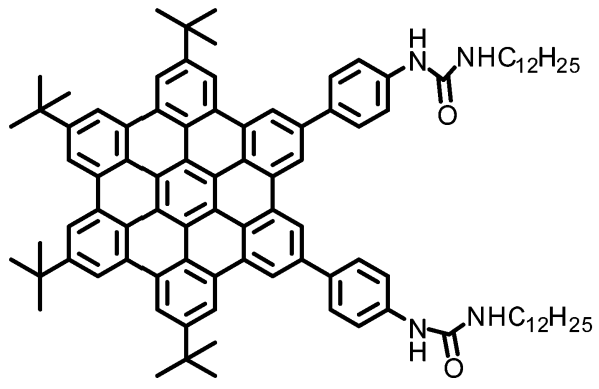

2

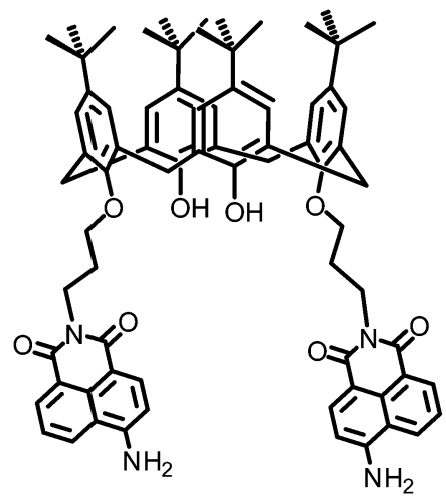

6

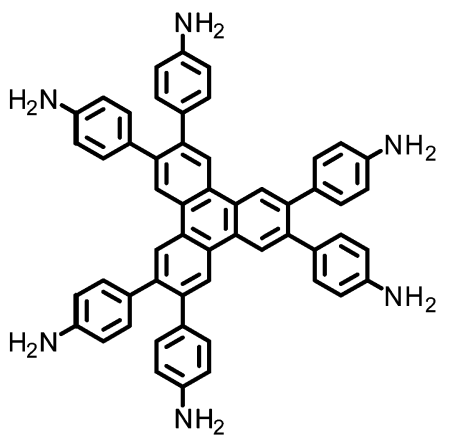

9<smiles>Nc1ccc2ccc(O)nc2n1</smiles>

3<smiles>Nc1ccc2ccc(Cl)nc2n1</smiles>

4

Materials Advances 
<smiles>CC(C)(C)c1ccc(-c2ccc3c(c2)C(CCCCCCCOc2ccc(N)cc2)(CCCCCCOc2ccc(N)cc2)c2cc(C(C)(C)C)ccc2-3)cc1</smiles>

18

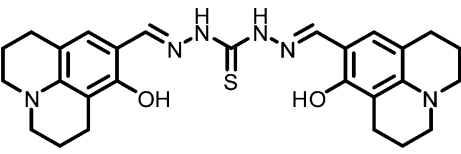

26<smiles>[R]N([R])c1ccc(/C=N/N=C/c2ccc(N([R])[R])cc2)cc1</smiles>

$19 \mathrm{R}=-\mathrm{CH}_{3}$

$20 \mathrm{R}=-\mathrm{CH}_{2} \mathrm{CH}_{3}$

$21 \mathrm{R}=-\mathrm{CH}_{2} \mathrm{CH}_{2} \mathrm{CH}_{3}$

$22 \mathrm{R}=-\mathrm{C}_{6} \mathrm{H}_{5}$<smiles>COc1cc(/C=C/C(=O)CC(=O)/C=C/c2ccc(OC(=O)[C@@H](N)CS)c(OC)c2)ccc1OC(=O)[C@@H](N)CS</smiles>

27<smiles>CN(C)c1ccc(/N=N/c2ccc(SNCc3cccs3)cc2)cc1</smiles>

23<smiles></smiles>

24<smiles></smiles>

25

Chart 4 Structures of probes $\mathbf{1 8 - 2 8}$
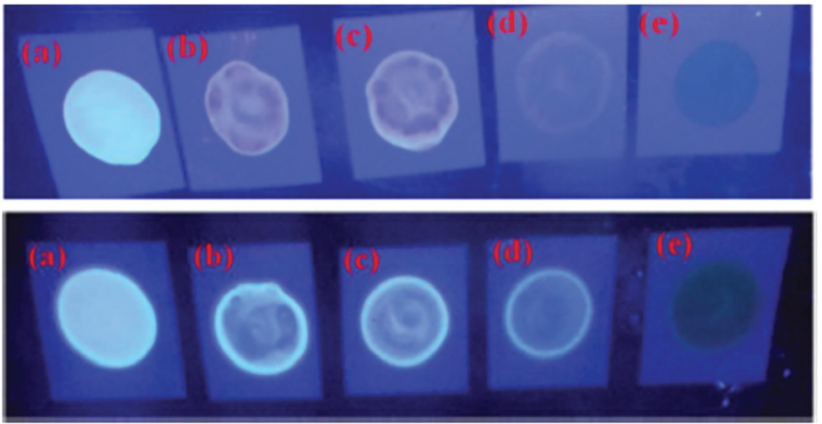

Fig. 1 Fluorescence images of TLC plates coated with probe 3 (upper) and probe 4 (lower) with various amounts of PA: (a) $0 \mathrm{M}$; (b) $10^{-5} \mathrm{M}$; (c) $10^{-4} \mathrm{M}$; (d) $10^{-3} \mathrm{M}$; and (e) $10^{-2} \mathrm{M}$. Reprinted from ref. 34, Copyright 2015 Royal Society of Chemistry.

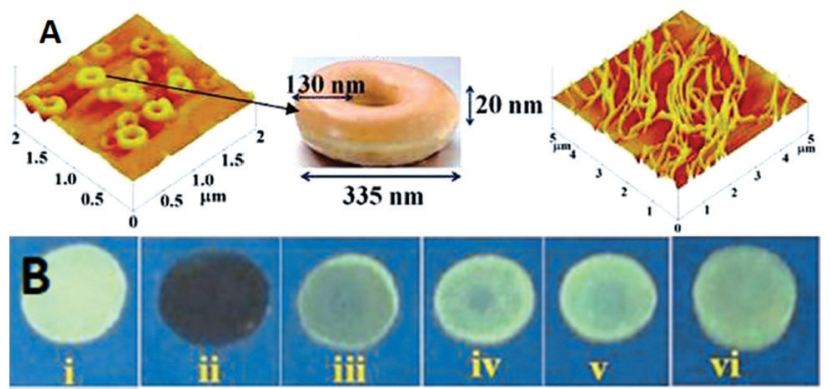

Fig. 2 (A) The donut-like structure of 6 transformed into ribbon-like fibrils upon treatment with PA. (B) Fluorescence quenching of $\mathbf{6}$ at different concentrations of PA: (i) only 6; (ii-vi) $\{6+P A\}$ : (ii) $100 \mathrm{~mm}$, (iii) $10 \mathrm{~mm}$, (iv) $1 \mathrm{~mm}$, (v) $100 \mathrm{~nm}$, and (vi) $10 \mathrm{~nm}$. Reprinted from ref. 36, Copyright 2015 Wiley Online.

AIE-based azine derivatives 19-22 ${ }^{49}$ (Chart 4) exhibited the appearance of a new absorption band with PA in THF. In the

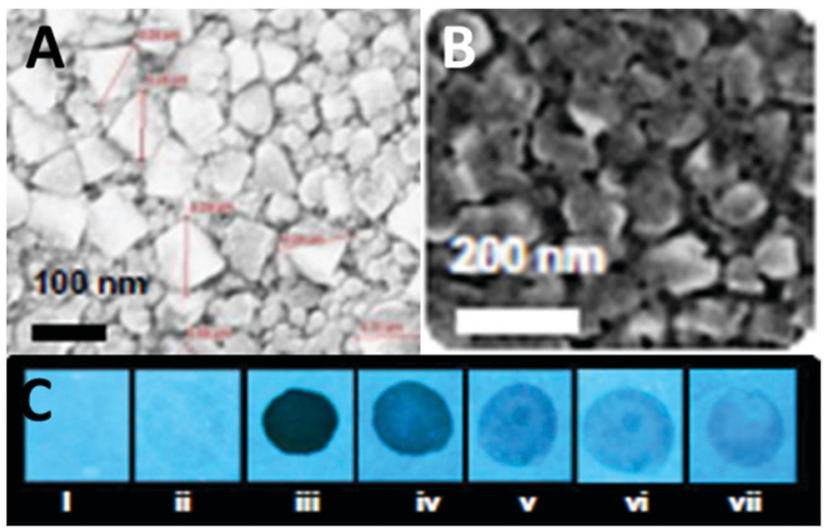

Fig. 3 Scanning electron microscopy (SEM) images of (A) 9 in a $\mathrm{H}_{2} \mathrm{O}-\mathrm{THF}$ (1:1) mixture and (B) 9 in a $\mathrm{H}_{2} \mathrm{O}: \mathrm{THF}(7: 3)$ mixture. (C) Photographs of paper strips coated with 9 showing fluorescence quenching (under $365 \mathrm{~nm}$ light): (i) blank paper strip and (ii) paper strip with a drop of water; paper strips upon the addition of $10 \mu \mathrm{l}$ of solutions of PA with different concentrations: (iii) $10^{-3} \mathrm{M}$, (iv) $10^{-5} \mathrm{M}$, (v) $10^{-7} \mathrm{M}$, (vi) $10^{-9} \mathrm{M}$, and (vii) $10^{-11}$ M. Reprinted from ref. 38, Copyright 2015 Royal Society of Chemistry.

presence of PA, probe 19 displayed decreased absorption at $380 \mathrm{~nm}$ and the appearance of a new maximum at $480 \mathrm{~nm}$ with an isosbestic point at $415 \mathrm{~nm}$ and a colour change from colourless to yellow. Upon excitation at $415 \mathrm{~nm}, 19$ displayed a gradual increase in fluorescence intensity at its emission maximum (576 nm) with increasing concentration of PA. Other NACs, such as 2-NP, 3-NP, 4-NP, 2,4-dinitrobenzoic acid and $\mathrm{NB}$, did not induce any such change in the absorption and emission of the azine derivative in THF. This highly selective increase in fluorescence intensity by PA could be assigned to the formation of $\mathrm{H}$-bonding between PA and the nitrogen of the 

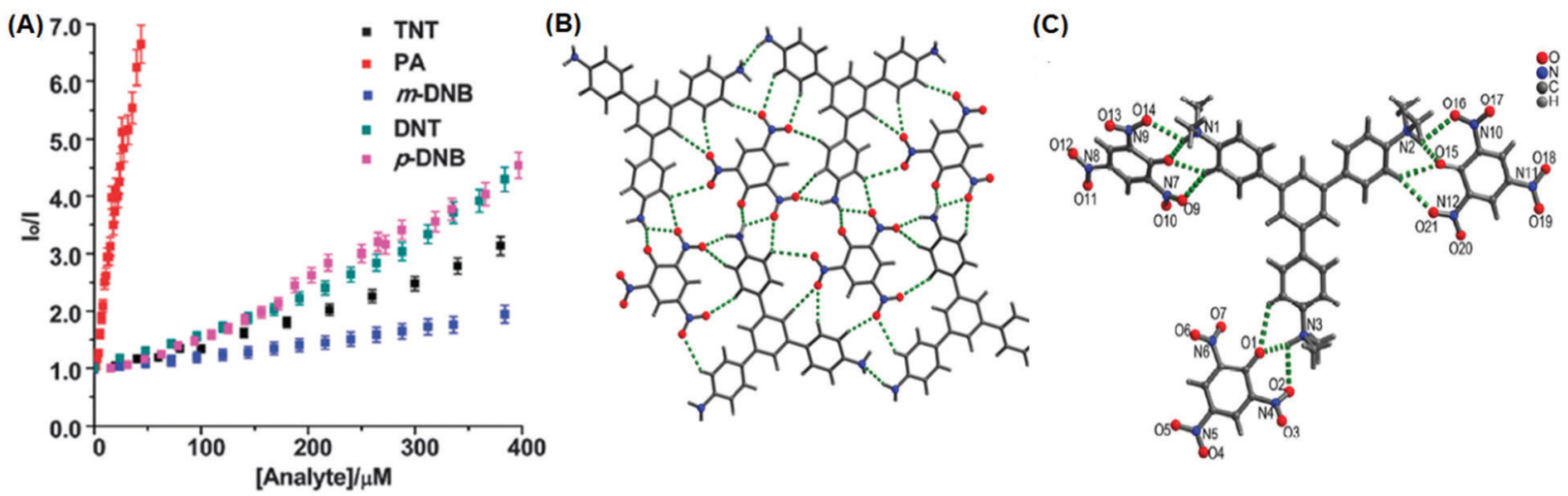

Fig. 4 (A) Stern-Volmer plots of the fluorescence quenching of 10a (1.0 mM in acetonitrile) with TNT, PA, $m$-DNB, DNT, and $p$-DNB. (B) The crystal structure of the $10 a(P A)$ complex showing hydrogen bonds. (C) The crystal structure of the $10 c(P A)_{3}$ complex showing hydrogen bonds $(H$-bonds are shown as dashed bonds). Reprinted from ref. 39, Copyright 2014 Royal Society of Chemistry. Reprinted from ref. 40, Copyright 2014 American Chemical Society. Reprinted from ref. 41, Copyright 2015 Royal Society of Chemistry.

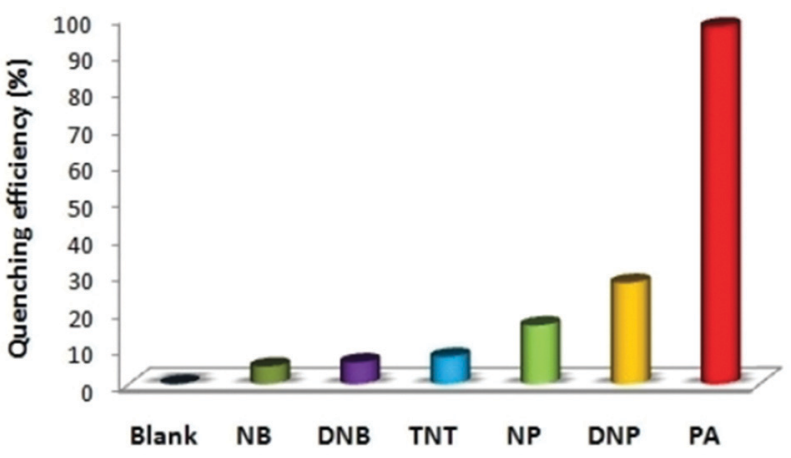

Fig. 5 Relative fluorescence quenching of $13\left(10^{-5} \mathrm{M}\right)$ in THF- $\mathrm{H}_{2} \mathrm{O}(4: 6)$ upon the addition of various NACs (30 equivalents). Reprinted from ref. 44, Copyright 2018 Wiley Online.

$N, N$-dimethylamino moiety, resulting in increased internal charge transfer and the stabilization of the more-polarised excited state. In THF- $\mathrm{H}_{2} \mathrm{O}(3: 7)$, probe 19 exhibited a similar red-shift in the absorption band to $490 \mathrm{~nm}$ with PA due to ground-state complex formation, but displayed fluorescence quenching at $567 \mathrm{~nm}$ in fluorescence studies.

The addition of picric acid to probe $23^{50}$ (Chart 4) caused a shift in the absorption maximum from $440 \mathrm{~nm}$ to $500 \mathrm{~nm}$ and fluorescence quenching at $350 \mathrm{~nm}$ and $520 \mathrm{~nm}$. The ${ }^{1} \mathrm{H}$ NMR spectrum of probe 23 with picric acid revealed the downfield shift of the $-\mathrm{N}\left(\mathrm{CH}_{3}\right)_{2}$ protons from $\delta 3.13 \mathrm{ppm}$ to $3.25 \mathrm{ppm}$, as well as a shift in the aromatic protons of picric acid from $\delta 9.00 \mathrm{ppm}$ to $\delta$ $9.10 \mathrm{ppm}$ due to electrostatic and hydrogen-bond interactions.

Hydrazine-substituted BODIPY probe $\mathbf{2 4}^{51}$ (Chart 4) displayed emission with a maximum at $540 \mathrm{~nm}$ in $\mathrm{CH}_{3} \mathrm{CN}$-water $(8: 2)$ and distinctly differentiated RDX and PA from each other and from other explosives through different absorption and fluorescence signals. $40 \mu \mathrm{M}$ of 2,4-DNT, PA, TNT and RDX were tested, and only RDX caused the fluorescence enhancement of probe $\mathbf{2 4}$, together with an obvious color change to bright yellow, while PA prominently decreased the fluorescence intensity (Fig. 6a). The fluorescence intensity of probe $\mathbf{2 4}$ declined linearly as the

\section{(A)}
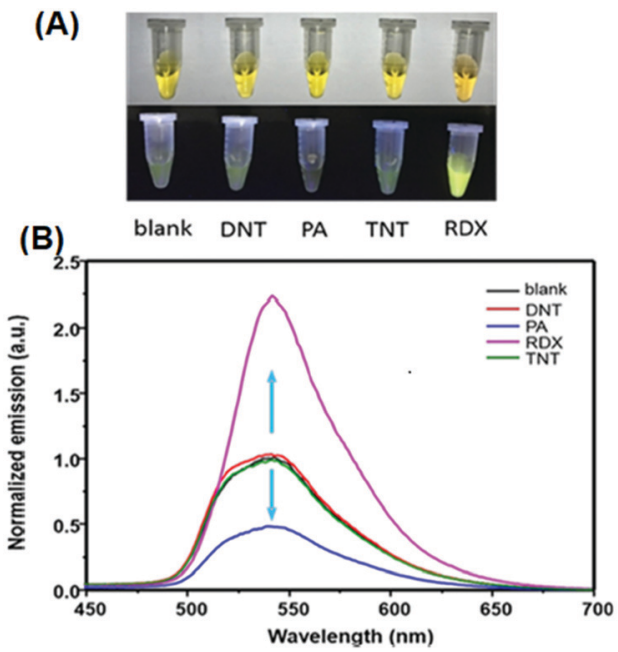

Fig. 6 (A) Images of the products after the reaction of different explosives with probe $\mathbf{2 4}$ in daylight (top) and under a $365 \mathrm{~nm}$ UV lamp (bottom). (B) Normalized emission spectra in the presence of different explosives. The concentration of the explosives is $40 \mu \mathrm{M}, \lambda_{\mathrm{ex}}=365 \mathrm{~nm}$, and $\lambda_{\mathrm{em}}=540 \mathrm{~nm}$. Reprinted from ref. 51, Copyright 2019 American Chemical Society.

concentration of PA was increased from 0 to $40 \mu \mathrm{M}$, and a quenching efficiency of $65.14 \%$ was obtained. In the case of RDX, the HCHO released from RDX formed a Schiff base with the hydrazine derivative to inhibit the PET process and resulted in a fluorescence enhancement (Fig. 6b). In case of PA, the inner-filter effect caused fluorescence quenching of fluorophore 24.

The "turn-on" fluorescent BODIPY probe $25^{52}$ (Chart 4) revealed a 300-fold enhancement in emission intensity at $513 \mathrm{~nm}$ with 10 equivalents of PA in ethanol upon excitation at $499 \mathrm{~nm}$. The Job's plot showed the formation of a 1:1 stoichiometric complex between probe 25 and PA. Therefore, only one of the two amino groups could be protonated by PA. The Benesi-Hildebrand plot gave a binding constant of $1.91 \times 10^{4} \mathrm{M}^{-1}$. Probe 25 could detect PA concentrations as low as $0.65 \mathrm{ppb}$.

Hydrazone-based probe $\mathbf{2 6}^{53}$ (Chart 4) in DMSO- $\mathrm{H}_{2} \mathrm{O}(1: 4)$ exhibited intense green fluorescence centred at $496 \mathrm{~nm}$ due to 


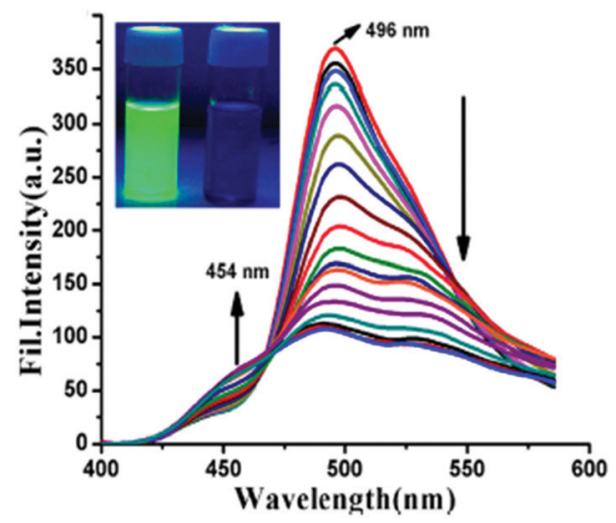

Fig. 7 Emission spectra of probe $26\left(\lambda_{\mathrm{ex}}=367 \mathrm{~nm}\right.$ ) with PA ( $0-2$ equiv.). The inset shows the fluorescence color change before (intense green) and after (low-intensity blue) the addition of PA to $\mathbf{2 6}$. Reprinted from ref. 53, Copyright 2017 American Chemical Society.

an ESIPT process. With 2 equivalents of PA, the intensity of the probe at the $496 \mathrm{~nm}$ emission maximum decreased with the appearance of a new maximum at $454 \mathrm{~nm}$ (Fig. 7). This quenching behaviour was due to the hydrogen bonding interactions between PA and the basic amine $\mathrm{NH}$ of probe 26, which resulted in inhibition of the ESIPT. The model compound $O$-methylated derivative of $\mathbf{2 6}$ was non-fluorescent and showed no interaction with PA. This proved the importance of the phenolic -OH group and the ESIPT mode for quenching. The quenching effect was found to be rapid (response time $<1 \mathrm{~min}$ ), selective, and $\mathrm{pH}$ independent. Furthermore, probe $\mathbf{2 6}$ was used to detect PA in the solid and vapor state, and in real water samples.
The two curcumin-based probes $\mathbf{2 7}$ and $28^{54}$ (Chart 4) were synthesized by linking curcumin with L-cysteine in probe 27 and L-tryptophan in probe 28 . These probes bind with PA due to the presence of basic amine groups. The weak emission bands at $540 \mathrm{~nm}$ and $535 \mathrm{~nm}$ for 27 and 28, respectively, were enhanced 26.5-fold after the addition of $70 \mathrm{nM}$ PA. The electrostatic interactions of the protonated fluorophore with the picrate anion caused strong association and aggregation, which were responsible for the fluorescence enhancement. The probes had high selectivity, low interference, and a quick response. Practical applications for sensing PA in the solid state and in real water samples were also studied.

\subsection{Protonation of pyridine-based fluorescent probes for picric acid}

In general, picric acid can form a hydrogen bond with a pyridine nitrogen to stabilize the hydrogen-bonded complex or can completely transfer the proton to the pyridine nitrogen to form an ionic complex. These situations differ only in the extent of internal charge transfer. The fluorescent probes 29-60 (Charts 5-7) protonate the pyridine nitrogen, and a comparison of the solvents, LODs, $K_{\mathrm{SV}}$ values, emission maxima and applications of probes 29-60 has been presented in Table 2.

The AIEE-active mono-, di- and tetra-pyridine-substituted pentacenequinone-based probes 29a-29 $\mathbf{c}^{55}$ (Chart 5) exhibited increased fluorescence intensity upon increasing the water fraction or viscosity and decreasing the temperature due to restriction in rotation (RIR). In DMSO- $\mathrm{H}_{2} \mathrm{O}(1: 1)$ mixtures, probes 29a, 29b and 29c showed $>95 \%$ fluorescence quenching

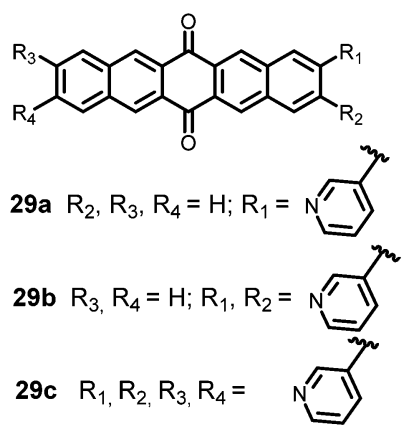

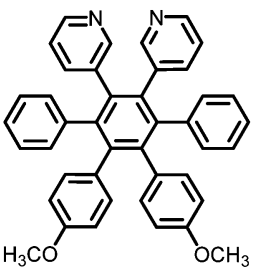

34

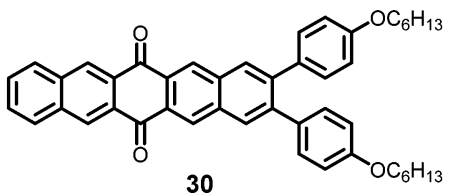

30<smiles>O=C1c2cc3ccccc3cc2C(=O)c2cc3cc(-c4ccccc4)c(-c4ccccc4)cc3cc21</smiles>

31

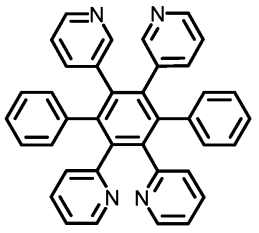

32

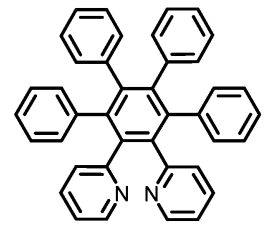

33

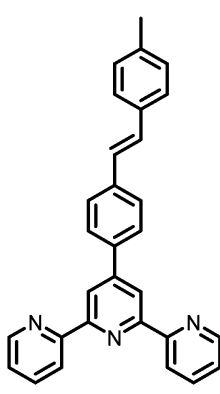

35<smiles>Fc1ccc(/C=C/c2ccc(-c3cc(-c4ccccn4)nc(-c4ccccn4)c3)cc2)cc1</smiles>

36<smiles>C(=C/c1cccc2ccccc12)\c1ccc(-c2cc(-c3ccccn3)nc(-c3ccccn3)c2)cc1</smiles>

37<smiles>C(=C/c1c2ccccc2cc2ccccc12)\c1ccc(-c2cc(-c3ccccn3)nc(-c3ccccn3)c2)cc1</smiles>

38

Chart 5 Structures of probes $29-38$ 
<smiles>c1ccc(-c2ccc3ccccc3n2)cc1</smiles>

39<smiles></smiles>

43<smiles>c1ccc(-c2ccc3ccc4cccc5ccc2c3c45)nc1</smiles>

40<smiles>c1ccc(-c2nc(-c3ccc4ccc5cccc6ccc3c4c56)n3ccccc23)nc1</smiles>

41

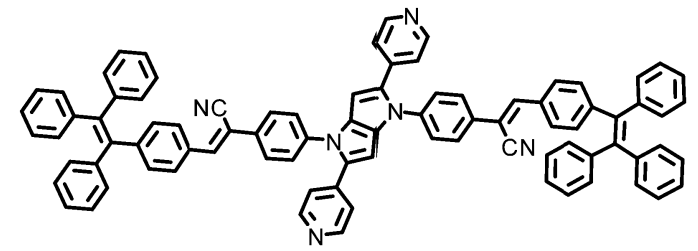

42

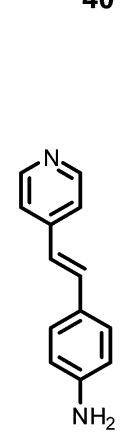

44<smiles>C(=N/c1ccncc1)\c1ccncc1</smiles>

45

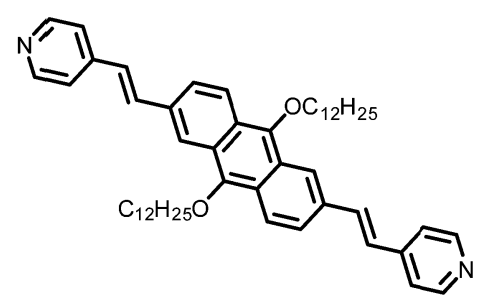

46<smiles>C(=C/c1ccc(N(c2ccc(-c3nc4ccccc4s3)cc2)c2ccc(-c3nc4ccccc4s3)cc2)cc1)\c1ccncc1</smiles>

Chart 6 Structures of probes $39-47$<smiles>O=C(N/N=C/c1c2ccccc2cc2ccccc12)c1ccncc1</smiles>

48<smiles>O=C(N/N=C/c1cccc2ccccc12)c1ccncc1</smiles>

49<smiles>O=C(N/N=C/c1ccc2ccc3cccc4ccc1c2c34)c1ccncc1</smiles>

50<smiles>O=C(N/N=C/c1cc2ccccc2c(-c2c(O)ccc3ccccc23)c1O)c1ccncc1</smiles>

51<smiles>O=C(N/N=C/c1c(O)ccc2c1Oc1cc(O)ccc1C21OC(=O)c2ccccc21)c1ccncc1</smiles>

52<smiles>O=C(N/N=C/c1c(O)ccc2c1Oc1c(ccc(O)c1/C=N/NC(=O)c1ccncc1)C21OC(=O)c2ccccc21)c1ccncc1</smiles>

53<smiles>c1ccc(CN(CCCCN(Cc2cccc3ccccc23)Cc2cccc3ccccc23)Cc2ccccn2)nc1</smiles>

54<smiles></smiles>

55<smiles>O=C(CC(C(=O)NCc1ccncc1)N1C(=O)c2ccc3c4ccc5c6c(ccc(c7ccc(c2c37)C1=O)c64)C(=O)N(C(CC(=O)NCc1ccncc1)C(=O)NCc1ccncc1)C5=O)NCc1ccncc1</smiles>

56<smiles>CCCCCCCCN1C(=O)c2cccc3c(Oc4cccnc4)ccc(c23)C1=O</smiles>

57<smiles>CCCCCCCCCCN1C(=O)c2cccc3c(Oc4ccccc4)ccc(c23)C1=O</smiles>

58

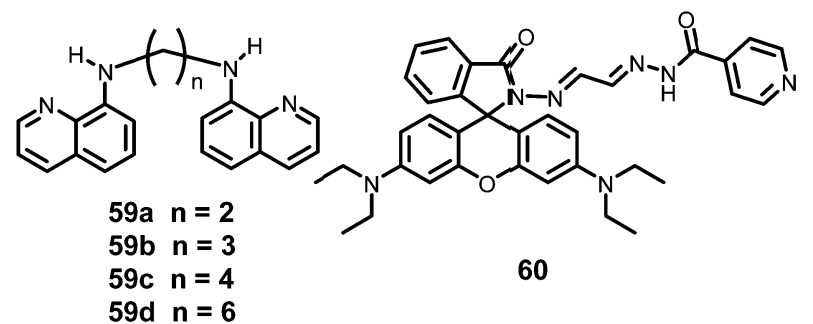

Chart 7 Structures of probes $48-60$

with 62, 60 and 58 equivalents of PA, respectively. The fluorescence quenching by PA was attributed to electron and/or energy transfer mechanisms.
The minimum detection limit for PA was $600 \mathrm{nM}$ with probe 29c. Probes 29a-29c were non-selective towards PA, and other NACs such as TNT, 2,4-DNT, 1,3-DNB, and DNBA also caused 
competitive fluorescence quenching in these probes. Probes 30-31 showed similar results with PA and other NACs. TLC strips coated with 29c could detect $10^{-8}$ M PA via fluorescence quenching.

Among the hetero-oligophenylene derivatives $32-34,{ }^{56}$ (Chart 5), derivative 32 bearing four 3-pyridyl moieties exhibited quenching of its fluorescence intensity at an emission maximum of $339 \mathrm{~nm}$ with 2.5 equivalents of $\mathrm{PA}$, but with $>2.5$ equivalents of PA, a new emission band appeared at $446 \mathrm{~nm}$. Its intensity increased gradually with increasing amounts of PA and was finally red-shifted to $460 \mathrm{~nm}$ (Fig. 8A and B). The $\pi-\pi$ interactions of derivative 32 with PA probably caused the fluorescence quenching at $339 \mathrm{~nm}$, and at higher amounts of PA, the excited-state intermolecular proton transfer from PA to the pyridyl nitrogen resulted in the new emission band at $460 \mathrm{~nm}$. Derivative 33 with 2-pyridyl groups exhibited similar results with PA, but derivative 34 exhibited only fluorescence quenching. Paper strips (Fig. 8C) coated with 32 could detect $10^{-12} \mathrm{M}$ PA.

The extended $\pi$-conjugated arylene-vinylene probes $35-\mathbf{3 8} \mathbf{5}^{57}$ (Chart 5) displayed a gradual red-shift of their emission maximum from 417 (in the case of 35) to $498 \mathrm{~nm}$ (in the case of 38). The maximum quantum yield and red-shift of the emission for probe 38 were found to be due to anthracene having the maximum $\pi$-conjugation and minimum HOMO-LUMO energy gap. The intensity of the emission for all four probes in chloroform solution decreased after the addition of PA, but there was no interference
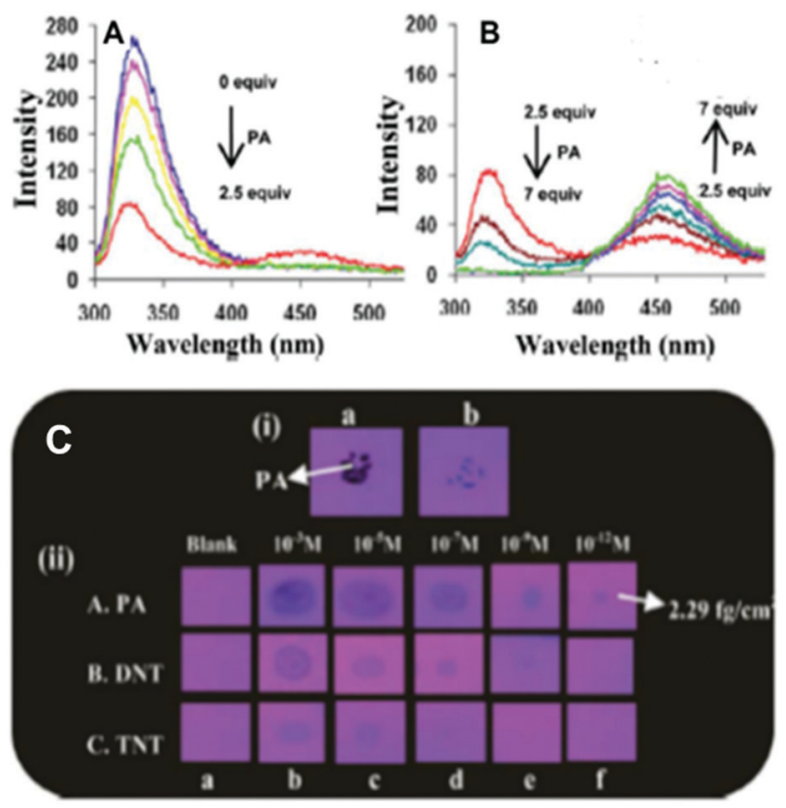

Fig. 8 (A) Fluorescence spectra of $32(50 \mu \mathrm{M})$ with picric acid $(125 \mu \mathrm{M})$ in $\mathrm{H}_{2} \mathrm{O}-\mathrm{EtOH}(6: 4)$ in HEPES, $\mathrm{pH}=7.0 ; \lambda_{\text {ex }}=273 \mathrm{~nm}$. (B) Fluorescence spectra of $32(50 \mu \mathrm{M})$ with $350 \mu \mathrm{M}$ of PA in $\mathrm{H}_{2} \mathrm{O}-\mathrm{EtOH}(6: 4) ; \lambda_{\mathrm{ex}}=273 \mathrm{~nm}$. (C) Photographs of 32-coated TLC strips under different experimental conditions: (i) (a) PA crystals on top of TLC strips coated with derivative 32 and (b) the removal of the PA crystal after $5 \mathrm{~s}$; (ii) photographs of the fluorescence quenching of 32-coated TLC strips by PA, DNT, and TNT in contact mode $\left(10 \mu \mathrm{L}\right.$ of analyte with a contact area of $\left.0.05 \mathrm{~cm}^{2}\right)$. Reprinted from ref. 56, Copyright 2014 Royal Society of Chemistry.

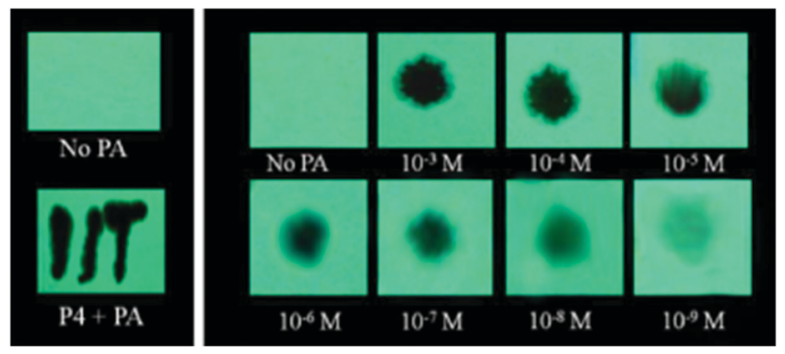

Fig. 9 The visual detection of different concentrations of PA using paper test strips coated with probe $\mathbf{3 8}$, demonstrating its remarkable sensitivity towards trace PA down to the nanomolar level. Reprinted from ref. 57, Copyright 2017 Royal Society of Chemistry.

from any other nitroaromatics, such as NB, NT, 4-NP, 4-NB acid, or 2,4-DNT. With PA, the colour of the probe 38 solution turned an intense yellow owing to the formation of a charge-transfer complex with PA. Moreover, the spectral overlap of the absorption with the emission bands of the probes permitted energy transfer from the excited state of the arylene-vinylene unit of probes 35-38 to the ground state of PA and increased the fluorescence quenching efficiency. Paper strips (Fig. 9) coated with probe 38 could detect $10^{-9} \mathrm{M}$ PA from $5 \mu \mathrm{l}$ of solution.

The small molecule phenyl quinoline $(39)^{58}$ (Chart 6) emits weakly at $359 \mathrm{~nm}$ in THF, but the addition of 90\% water (SDS $4 \mathrm{mM}$ ) resulted in an increase in the fluorescence intensity and quantum yield due to the formation of rod-like microstructures (Fig. 10). The addition of PA resulted in $80 \%$ quenching of the fluorescence intensity via a static quenching mechanism with no change in the emission maximum, whereas the other NACs exhibited lower fluorescence quenching, viz. 4-NP (34\%), 2,4-DNP (15\%), NA (12\%), DNT (5\%) and DNB (3\%). Probe 39 was also used as an acid-base sensor due to its ratiometric fluorescence emission in presence of acids and bases.

Probe $\mathbf{4 0}^{59}$ (Chart 6) in methanol with PA displayed a linear relationship between the ratio of the emission intensities $\left(I_{522} / I_{405}\right)$ and the concentration of PA in the range of 5-100 $\mu \mathrm{M}$. In the ${ }^{1} \mathrm{H}$ NMR spectrum of the probe-PA in $\mathrm{CDCl}_{3}$, the up-field shift of the $\mathrm{OH}$ signal of picric acid from $\delta 9.23 \mathrm{ppm}$ to $8.56 \mathrm{ppm}$ and the down-field shift of the pyridine protons supported the formation of a ground state charge transfer complex, and the overlap of the emission of probe with the absorption spectrum of PA supported a FRET process.
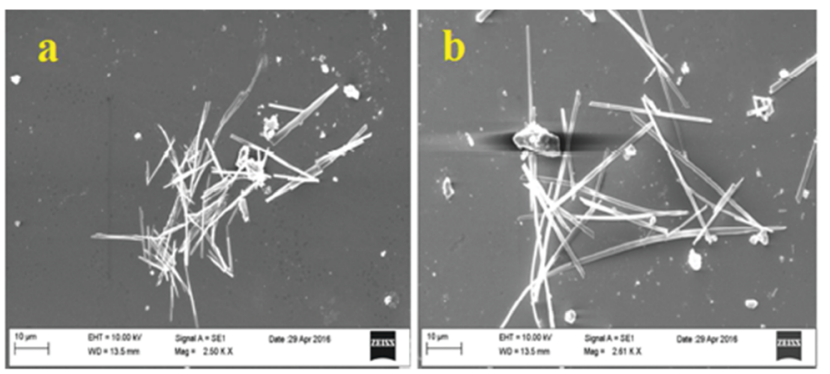

Fig. 10 SEM images of probe 39 with 4 mM SDS. Reprinted from ref. 58, Copyright 2018 Royal Society of Chemistry. 


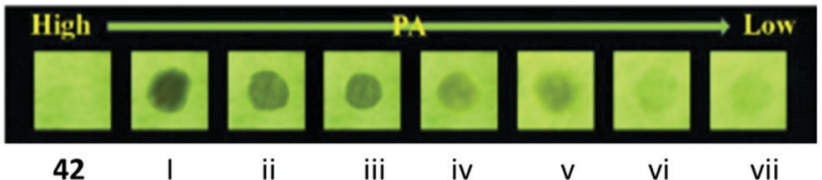

42

Fig. 11 Photographs of the fluorescence quenching of probe $\mathbf{4 2}$ for detecting different concentrations of PA. From left to right: blank, (i) $5.0 \times$ $10^{-3} \mathrm{M}$, (ii) $1.0 \times 10^{-3} \mathrm{M}$, (iii) $5.0 \times 10^{-4} \mathrm{M}$, (iv) $1.0 \times 10^{-4} \mathrm{M}$, (v) $5.0 \times 10^{-5} \mathrm{M}$, (vi) $1.0 \times 10^{-5} \mathrm{M}$. Reprinted from ref. 61, Copyright 2019 Elsevier.

Pyrene-tethered probe $\mathbf{4 1}^{60}$ (Chart 6) exhibited an emission maximum at $495 \mathrm{~nm}$ in THF, which gradually shifted to $515 \mathrm{~nm}$ with increasing amounts of DMF in THF-DMF binary mixtures and demonstrated the occurrence of an ICT transition in probe 41. A solution of probe $\mathbf{4 1}$ in DMSO displayed efficient fluorescence quenching at an emission maximum of $530 \mathrm{~nm}$ by PA. Among other nitroaromatics, only 2,4-DNP showed some interference. Theoretical studies clearly indicated that the pyridine nitrogen preferably formed a hydrogen bond with the $\mathrm{OH}$ group of PA and was primarily responsible for the fluorescence quenching. Probe 41 could also detect PA in a 50\% DMSOwater medium. A portable fluorimeter module interfaced wirelessly with a smartphone could detect $99 \mathrm{nM}$ PA.

TPE- and pyridine-unit-based probe $42^{61}$ (Chart 6) revealed strong AIE behaviour with a strong green emission maximum at $527 \mathrm{~nm}$ in a DMF-water (1:99) mixture. These aggregates of probe $42^{61}$ with PA exhibited fluorescence quenching at $527 \mathrm{~nm}$ with a color change from yellow to dark with an LOD of 31.5 nM. ${ }^{1} \mathrm{H}$ NMR and DFT studies clearly indicated that the protonation of the pyridine nitrogen by the $\mathrm{OH}$ group of $\mathrm{PA}$ followed by PET from the fluorophore to PA was primarily responsible for the fluorescence quenching. Paper strips coated with probe 42 detected $10^{-5} \mathrm{M}$ of PA (Fig. 11).

Upon excitation at $375 \mathrm{~nm}, p$-pyridine BODIPY probe $\mathbf{4 3}{ }^{62}$ (Chart 6) showed a 95.8\% decrease in the emission intensity at

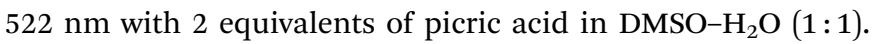
The bright green fluorescence color of probe $\mathbf{4 3}$ changed to dark in $30 \mathrm{~s}$ due to the protonation of the pyridine nitrogen followed by PET from the excited-state probe to the groundstate PA. The Stern-Volmer constant $\left(K_{\mathrm{SV}}\right)$ of the probe was calculated to be $7.69 \times 10^{4} \mathrm{~mol} \mathrm{~L}^{-1}$, and it could detect PA concentrations as low as $0.013 \mu \mathrm{M}$.

Pyridine-based probe $\mathbf{4 4}^{63}$ (Chart 6) in THF displayed the formation of a new absorption maximum at $424 \mathrm{~nm}$ with PA with a color change from colorless to yellow. Probe $\mathbf{4 4}$ showed an $87 \%$ reduction in fluorescence intensity at $440 \mathrm{~nm}$ with 1 equivalent of picric acid, and with higher amounts of PA, a new emission band with weak emission appeared at $550 \mathrm{~nm}$. The appearance of the new emission band could be assigned to the increased ICT upon protonation at the pyridine nitrogen, which is supported by the X-ray crystal structure in the solid state. The $K_{\mathrm{SV}}$ and LOD were calculated to be $4.106 \times 10^{5} \mathrm{M}^{-1}$ and $400 \mathrm{ppb}$, respectively.

Probe $\mathbf{4 5}^{64}$ (Chart 6) in $\mathrm{CH}_{3} \mathrm{CN}-$ HEPES buffer $(4: 1)$ exhibited fluorescence quenching with a gradual shift in the emission maximum from $410 \mathrm{~nm}$ to $460 \mathrm{~nm}$ as the amount of PA was increased to 2.0 equivalents. These results, along with Job's plot and DFT-DT studies, suggest that two molecules of PA bind with one molecule of probe $\mathbf{4 5}$ and cause fluorescence quenching through a combination of ICT and FRET mechanisms. A lightweight, convenient and portable prototype for PA detection was also fabricated.

Probe $46^{65}$ (Chart 6) revealed intense emission at $500 \mathrm{~nm}$ in THF, which vanished (94\%) with 100 equivalents of PA. In the fluorescence spectrum of probe 46 , the presence of the shoulder at $625 \mathrm{~nm}$ with higher equivalents of PA indicated the presence of charge-transfer character. Other nitro-phenols also induced significant fluorescence quenching of probe $\mathbf{4 6}$ at higher concentrations (Fig. 12A). Based on studies of the dynamic quenching mechanism of 46 by PA, the X-ray crystal structure of the $46 \cap$ PA complex and titrations, the combined effect of the proton-induced ICT in 46 and electron transfer from the electron-rich anthracene to the electrondeficient PA moiety was assigned as the cause of the fluorescence quenching. Moreover, a human thumb impression (Fig. 12B) was clearly visible on a test strip coated with probe 46 .

Triphenylamine-based probe $\mathbf{4 7 ^ { 6 6 }}$ (Chart 6) having two benzothiazole moieties and one vinyl pyridine moiety at its 1 ,
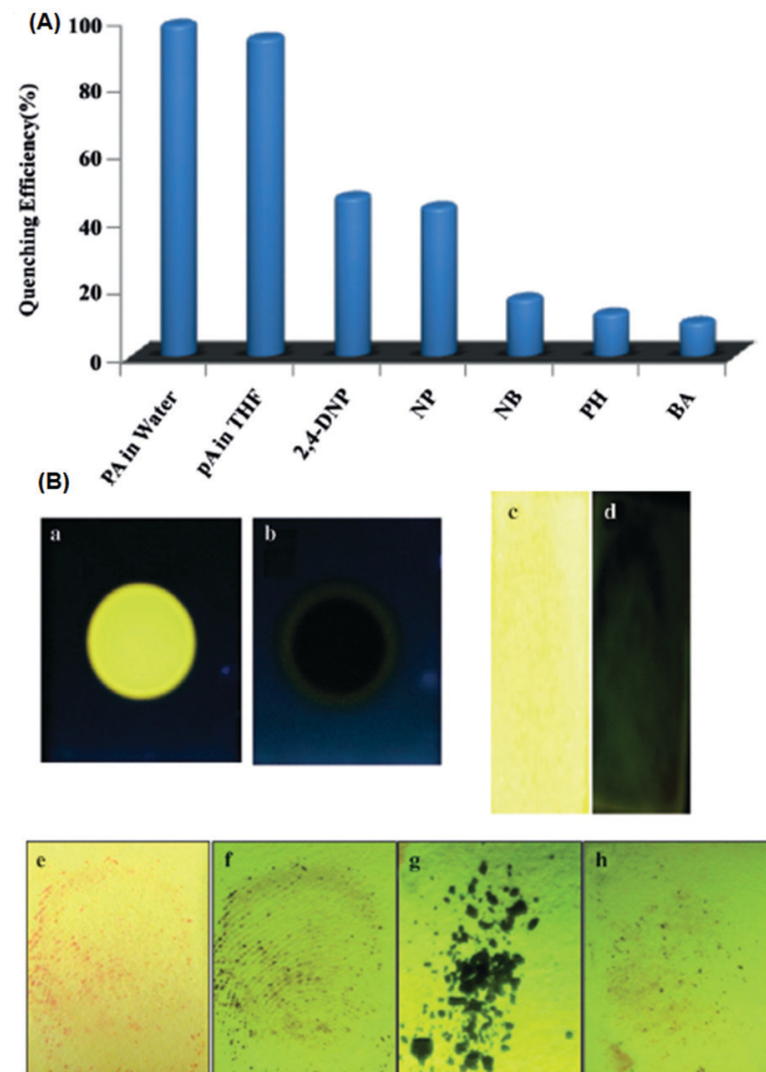

Fig. 12 (A) Fluorescence quenching efficiency of $\mathbf{4 6}$ towards different analytes. (B) Images of a 46-coated TLC plate under UV light (a) before and (b) after the addition of PA. Images of test strips consisting of 46-coated Whatman Filter (c) before and (d) after being dipped into aqueous solutions of PA. Thumb impressions with PA on a test strip under (e) normal light and (f) UV light. (g) PA crystals on top of a test strip for $5 \mathrm{~min}$, and the strip after the removal of the PA crystals. Reprinted from ref. 65, Copyright 2016 Wiley Online. 
3 and 5 positions underwent fluorescence quenching at $500 \mathrm{~nm}$ with a decrease in quantum yield from 0.31 to 0.08 with one equivalent of PA in a methanol-water $(8: 2)$ mixture. The protonation of the pyridine nitrogen associated with ICT was mainly responsible for the formation of a $1: 1$ stoichiometric non-fluorescent complex. The LOD was found to be $100.4 \mu \mathrm{M}$. Probe $\mathbf{4 7}$ was also used for the detection of $\mathrm{Fe}^{3+}$ ions.

$N$-Acylhydrazone $\mathbf{4 8}^{67}$ (Chart 7 ) displayed an excimer emission band at $483 \mathrm{~nm}\left(\lambda_{\mathrm{ex}}=419 \mathrm{~nm}\right)$, which underwent a 97\% decrease in fluorescence intensity with 3 equivalents of PA in DMF. An ethanolic solution of 48 with 1 equivalent of PA gave vermilion precipitates (Fig. 13). None of the other tested NACs, viz. TNT, 2,6-DNT, NB, 4-NP, 1,3-DNB and NBA, caused fluorescence quenching or resulted in the formation of precipitates. The down-field shift of the protons of pyridine in the ${ }^{1} \mathrm{H}$ NMR titration of 48 with PA pointed to proton transfer from PA to the pyridine nitrogen. The X-ray crystal structure of the $48 \cap$ PA complex confirmed the proton transfer to pyridine nitrogen and the formation of a supramolecular complex through multiple hydrogen-bond and $\pi-\pi$ interactions.

Extending this work, these authors synthesized three additional $N$-acylhydrazone ${ }^{68}$-based probes, 49-51, for PA detection. Among probes 49-51, probe $\mathbf{5 0}$ with a pyrene moiety as the fluorophore exhibited the greatest fluorescence quenching with PA and had the highest Stern-Volmer constant $\left(5.12 \times 10^{6} \mathrm{M}^{-1}\right)$ and lowest detection limit $(0.102 \mu \mathrm{M})$. Their host-guest interactions were studied using ${ }^{1} \mathrm{H}$ NMR titration and X-ray structural studies and revealed the formation of $1: 1$ host-guest complexes through multiple hydrogen-bond interactions in solution and in the solid state.

Fluorescein-based chemosensors 52 and $53^{69}$ (Chart 7) (20 equivalents) in ethanol or water (buffer) solution with PA revealed fluorescence quenching at $545 \mathrm{~nm}$ and $558 \mathrm{~nm}$ upon excitation at $500 \mathrm{~nm}$. The $K_{\mathrm{sv}}$ values and detection limits of probes 52 and 53 in ethanol were better than those observed in buffer. Probes 52 and 53 displayed fluorescence quenching with PA due to H-bonding and electron transfer. Paper strips coated with $\mathbf{5 2}$ and $\mathbf{5 3}$ could detect PA concentrations down to $10^{-6} \mathrm{M}$ from a droplet (Fig. 14).

Pyridine-based fluorescent sensors $\mathbf{5 4}$ and $\mathbf{5 5}^{\mathbf{7 0}}$ (Chart 7) displayed fluorescence quenching at $420 \mathrm{~nm}$ and $450 \mathrm{~nm}$ with PA, respectively. Both probes 54 and 55 displayed similar fluorescence quenching efficiency (Fig. 15A) by PA (98\% for $\mathbf{5 4}$ and $\mathbf{9 0 \%}$ for $\mathbf{5 5}$ ), but probe $\mathbf{5 4}$ exhibited higher selectivity towards PA over other NACs than that observed for probe $\mathbf{5 5}$.

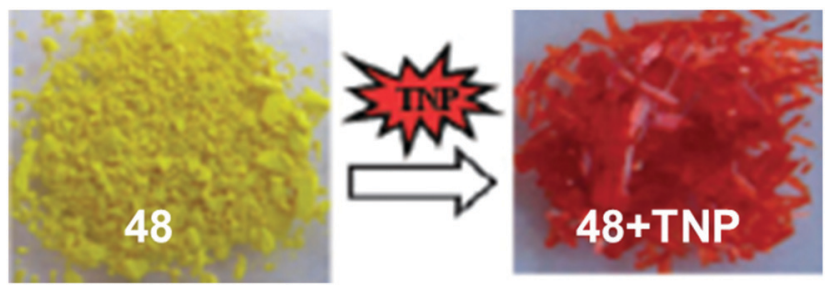

Fig. 13 Photographs of solid 48 and its complex $48 \cap$ PA. Reprinted from ref. 67, Copyright 2011, Royal Society of Chemistry.

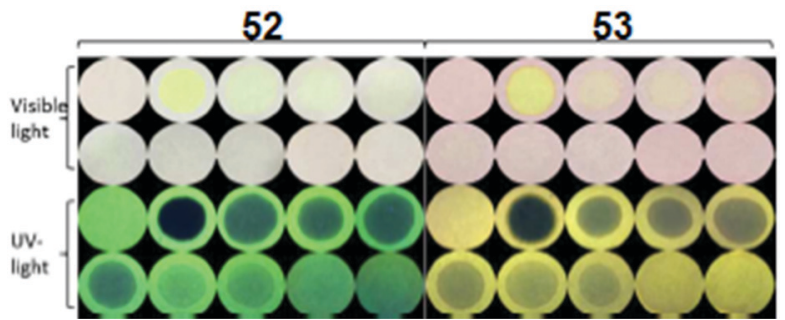

Fig. 14 Paper strips for the visual detection of different concentrations of PA under visible and UV light. $[P A]=0 \mathrm{mM}, 10.0 \mathrm{mM}, 1.0 \mathrm{mM}, 8.0 \times$ $10^{-1} \mathrm{mM}, 6.0 \times 10^{-1} \mathrm{mM}, 4.0 \times 10^{-1} \mathrm{mM}, 2.0 \times 10^{-1} \mathrm{mM}, 1.0 \times 10^{-1} \mathrm{mM}$, $1.0 \times 10^{-2} \mathrm{mM}$, and $1.0 \times 10^{-3} \mathrm{mM}$. Reprinted from ref. 69 , Copyright 2017 Royal Society of Chemistry.

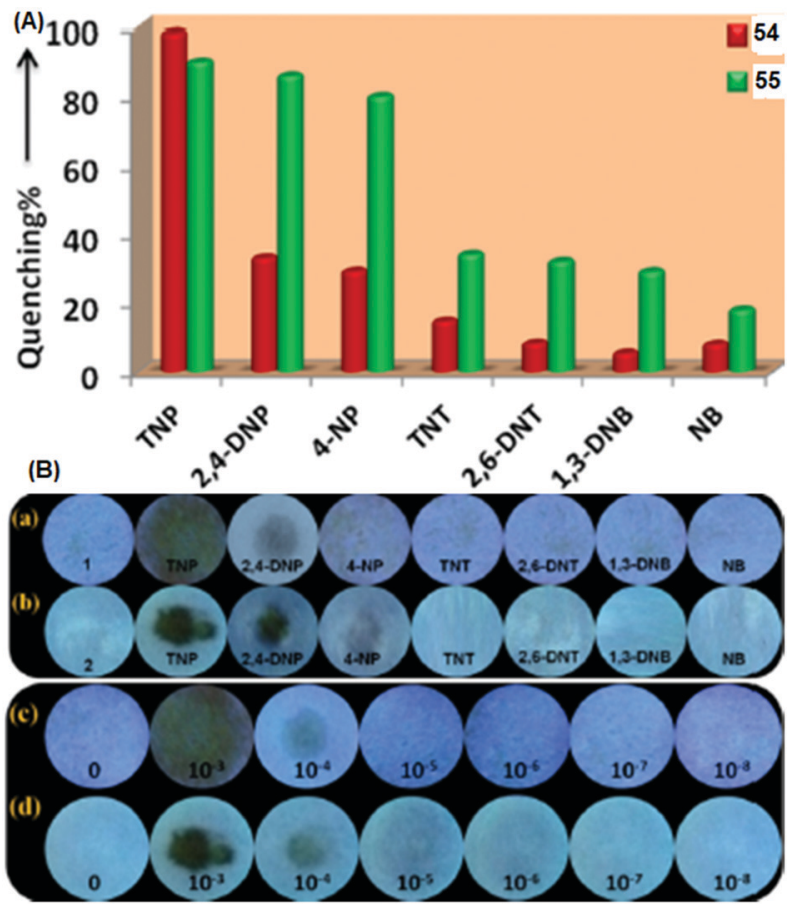

Fig. 15 (A) A comparison of the percent quenching of 54 and $\mathbf{5 5}$ with different NACs. (B) Photographs of test paper strips coated with (a) $\mathbf{5 4}$ and (b) $\mathbf{5 5}$ and their responses towards NACs. Photographs of paper strips coated with (c) $\mathbf{5 4}$ and (d) $\mathbf{5 5}$ for the visual detection of increasing amounts of PA $\left(10^{-8}\right.$ to $\left.10^{-3} \mathrm{M}\right)$. Reprinted from ref. 70, Copyright 2018 American Chemical Society.

The smaller size of the naphthalene moiety in probe $\mathbf{5 5}$ resulted in less steric bulk than the anthracene moiety of $\mathbf{5 4}$ and provided space to allow for $\pi-\pi$ interactions with PA, 2,4-DNP and 4-NP with equal ease. Based on ${ }^{1} \mathrm{H}$ NMR and DFT studies, hydrogen bonding between the pyridine nitrogen and $\mathrm{OH}$ group of PA and energy transfer via $\pi-\pi$ interactions were proposed as mechanisms. The $K_{\mathrm{SV}}$ values for PA were $5.78 \times$ $10^{4}$ for probe 54 and $3.26 \times 10^{4}$ for probe 55. Filter paper strips coated with aqueous suspensions of $\mathbf{5 4}$ and $\mathbf{5 5}$ detected PA concentrations as low as $10^{-8} \mathrm{M}$ (Fig. 15B).

Perylenediimide-pyridine conjugate $\mathbf{5 6}^{\mathbf{7 1}}$ (Chart 7) displayed red-shifts in its absorption maxima from 488/523 $\mathrm{nm}$ to 493 / $529 \mathrm{~nm}$ and decreased fluorescence intensity due to proton 
transfer from picric acid to probe 56. The $K_{\mathrm{SV}}$ and LOD were found to be $6.87 \times 10^{4} \mathrm{M}^{-1}$ and $0.0056 \mu \mathrm{M}$, respectively. Job's plot and ${ }^{1} \mathrm{H}$ NMR titration analyses revealed the protonation of all four pyridine nitrogen atoms with four molecules of picric acid and the formation of a $1: 4$ complex between probe 56 and picric acid.

Probe $57^{72}$ (Chart 7) in $\mathrm{CH}_{3} \mathrm{CN}-\mathrm{H}_{2} \mathrm{O}(1: 1)$ and probe $58^{72}$ in $\mathrm{CH}_{3} \mathrm{CN}$ formed an organo-gel with an intertwined fiber network at critical gelation concentrations of $0.69 \mathrm{w} / \mathrm{v} \%$ and $0.45 \mathrm{w} / \mathrm{v} \%$, respectively. The organo-gel prepared from probe $\mathbf{5 7}$ was more sensitive than that prepared from probe $\mathbf{5 8}$ towards PA and could also extract PA from the aqueous solution into the organogel system. The $16 \mathrm{~nm}$ blue-shift of the fluorescence emission band of the gel of $\mathbf{5 7}$ at $501 \mathrm{~nm}$ with PA pointed to the suppression of the TICT excited state of 57. Probe 57 displayed greater fluorescence quenching than probe $\mathbf{5 8}$ with PA ( 1 equiv.) due to the $\mathrm{H}$-bonding between the pyridine nitrogen and $\mathrm{OH}$ of $\mathrm{PA}$. The protons of the pyridine group in probe 57 shifted downfield in the ${ }^{1} \mathrm{H}$ NMR titration with PA. Paper strips (Fig. 16) coated with probe 57 showed a change in fluorescence from blue to non-fluorescent.

Quinoline-based probes $\mathbf{5 9 a - 5 9 d ^ { 7 3 }}$ (Chart 7) showed fluorescence quenching of $86-88 \%$ upon excitation at $335 \mathrm{~nm}$ due to ground-state complexation between the probe and PA. The downfield shift of the quinoline protons in the ${ }^{1} \mathrm{H}$ NMR spectra of these probes upon the addition of picric acid and Job's plot analysis confirmed the protonation of the quinoline nitrogen and the formation of $1: 2$ stoichiometric complexes with the picrate anion.

The rhodamine-isonicotinic hydrazide-based "turn-on" fluorescent probe $\mathbf{6 0}^{74}$ (Chart 7) showed selective detection of $\mathrm{PA}$ in $\mathrm{CH}_{3} \mathrm{CN}-\mathrm{H}_{2} \mathrm{O}$ (1:9) through a spirolactam ring-opening process. Probe 60 underwent protonation by PA at the pyridine nitrogen and displayed a new absorption maximum at $559 \mathrm{~nm}$ with a color change from colourless to pink and enhancement of the emission intensity at $581 \mathrm{~nm}$. A Job's plot analysis revealed a $1: 1$ stoichiometry between probe 60 and $\mathrm{PA}$ with a binding constant of $6.4 \times 10^{7} \mathrm{M}^{-1}$. Probe 60 could detect PA concentrations as low as $0.0373 \mu \mathrm{M}$. Colourless paper strips (Fig. 17) coated with probe $\mathbf{6 0}$ became pink when exposed to PA.

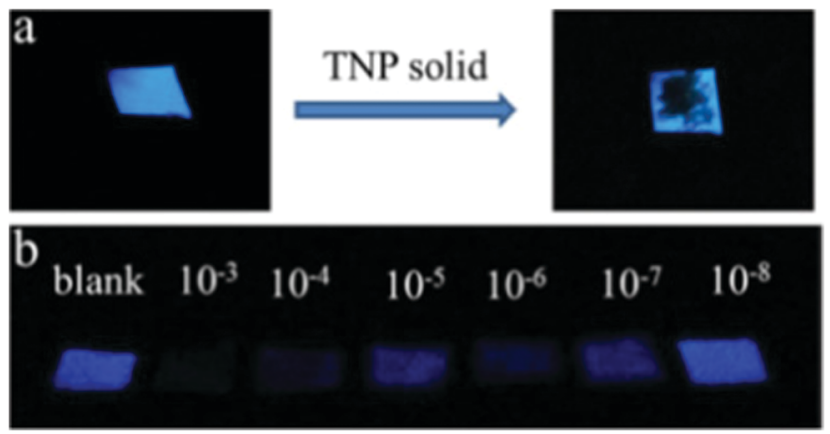

Fig. 16 Photographs of paper strips coated with probe $\mathbf{5 7}$ under a UV lamp $(365 \mathrm{~nm})$ for the visual detection of PA: (a) solid PA and (b) dropped PA solutions with different concentrations $\left(\mathrm{M} \mathrm{L}^{-1}\right)$. Reprinted from ref. 72 , Copyright 2017 American Chemical Society.

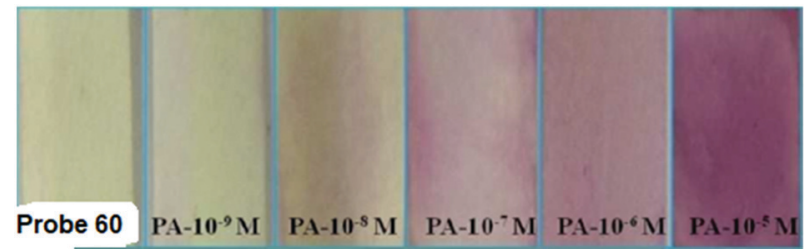

Fig. 17 Photographs of probe 60 on test strips, showing the colour changes for the visual detection of PA. Reprinted from ref. 74, Copyright Wiley Online.

\subsection{Protonation of imidazole-based fluorescent probes for picric acid}

Probes 61-72 undergo protonation by picric acid at the imidazole nitrogen to form imidazolium salts, and in each case, quenching of the fluorescence intensity is observed. A comparison of the solvents, LOD, $K_{\mathrm{SV}}$ values, emission maxima and applications of probes 61-72 has been given in Table 3 .

Imidazole-based probe $\mathbf{6 1}^{75}$ (Chart 8) displayed 95.3\% fluorescence quenching at $392 \mathrm{~nm}$ (Fig. 18) in DMSO- $\mathrm{H}_{2} \mathrm{O}$ ( $7: 3$ ), and probe 62 underwent $92.4 \%$ fluorescence quenching at $345 \mathrm{~nm}$ in $\mathrm{EtOH}-\mathrm{H}_{2} \mathrm{O}(7: 3)$ with 12 equivalents of PA, whereas the other NACs induced insignificant changes in the fluorescence intensity of probes 61 and 62. In their ${ }^{1} \mathrm{H}$ NMR spectra, the imidazole $\mathrm{NH}$ signals of $\mathbf{6 1}$ and 62 disappeared upon the interaction of PA with the probe. Probes $\mathbf{6 1}$ and $\mathbf{6 2}$ formed $1: 2$ and $1: 1$ stoichiometric complexes with PA, respectively. Probes 61 and 62 detected PA concentrations as low as $0.17 \mu \mathrm{M}$ and $0.49 \mu \mathrm{M}$.

Probes $63-\mathbf{6 5}^{76}$ (Chart 8) displayed blue emission maxima between $400-413 \mathrm{~nm}$, which were selectively quenched by PA in a DMSO- $\mathrm{H}_{2} \mathrm{O}$ (1:9) mixture. These derivatives formed GSCT complexes with PA owing to the protonation of the imidazole nitrogen, and the increased efficiency of PET and IFE caused faster fluorescence quenching. Probe 63, due to the additional hydrogen bonding interaction of the $\mathrm{OH}$ of the probe with picric acid, exhibited higher-efficiency fluorescence quenching by PA than that observed for probes 64 and 65. Cyclic voltammetry studies showed electron transfer from the high-energy LUMO of the photo-excited probe to the low-energy LUMO of PA. These probes were able to detect PA from real samples. Paper strips coated with these probes could detect PA via fluorescence quenching.

The phenanthroline based probes $66 \mathbf{a}-66 \mathbf{c}^{77}$ (Chart 8) exhibited emission maxima at $386 \mathrm{~nm}, 486 \mathrm{~nm}$ and $456 \mathrm{~nm}$, respectively. Solutions of these probes in ethanol showed fluorescence quenching with picric acid with respective limits of detection of $2.8 \mu \mathrm{M}, 2.3 \mu \mathrm{M}$ and $4.6 \mu \mathrm{M}$. The X-ray crystal structures of complexes of $66 \mathrm{a}$ and $66 \mathrm{c}$ with picric acid clearly show the transfer of the proton from picric acid to the phenanthroline nitrogen to form an ionic complex. The lack of change in the fluorescence lifetimes of these probes with picric acid further indicated that the existence of electrostatic interactions between the protonated probe and the picrate ion followed by PET was mainly responsible for the fluorescence quenching of probes 66 with picric acid. 
<smiles>COC(=O)c1ccc(-c2cccc(-c3nc4c5ccccc5c5ccccc5c4[nH]3)c2)cc1</smiles><smiles>COC(=O)c1ccc(-c2cccc(-c3nc(-c4ccccc4)c(-c4ccccc4)[nH]3)c2)cc1</smiles><smiles>Cc1ccc(-c2nc(-c3ccccc3)c(-c3ccccc3)[nH]2)o1</smiles><smiles>C=CCOc1ccc(-c2nc(-c3ccccc3)c(-c3ccccc3)[nH]2)cc1</smiles>

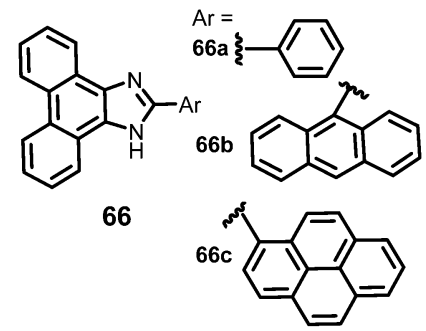

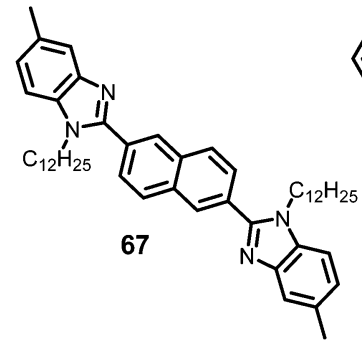

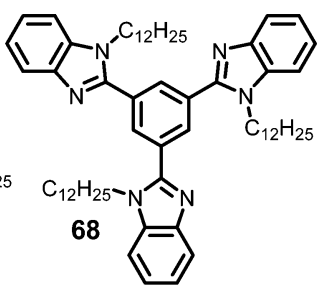<smiles>c1ccc2sc(-c3ccc(Cn4cnc5ccccc54)cc3)nc2c1</smiles>
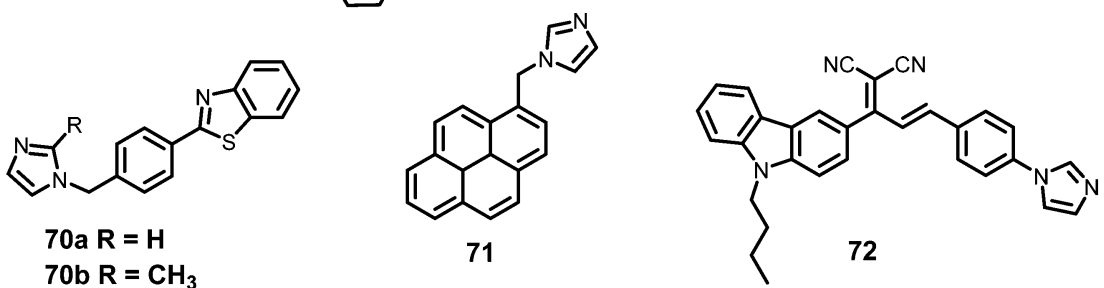

Chart 8 Structures of probes $\mathbf{6 1 - 7 2}$

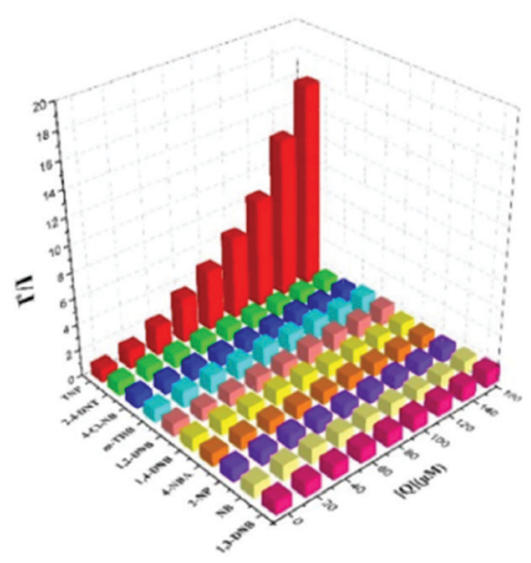

Fig. 18 Change in the fluorescence intensity of probe $\mathbf{6 1}$ with various NACs. Reprinted from ref. 75, Copyright 2019 Elsevier.

Probe $67^{78}$ (Chart 8) with two benzimidazole moieties linked at the 2- and 6-positions of the naphthalene and long hydrophobic alkyl chains at the benzimidazole nitrogen selfassembled in water to form rod-like structures (Fig. 19), which
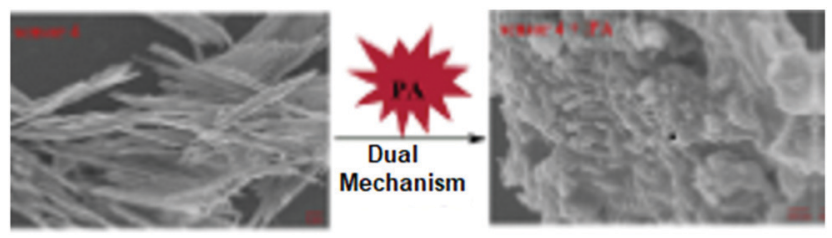

Fig. 19 The rod-like self-assemblies of probe $\mathbf{6 7}$ undergo a morphological change in the presence of two equivalents of PA (SEM images). Reprinted from ref. 78, Copyright 2017 Elsevier. were disrupted by PA. A solution of probe 67 displayed an emission band at $422 \mathrm{~nm}$, which was completely quenched by 5 equivalents of PA. GSCT complex formation via the picric-acidmediated protonation of the benzimidazole nitrogen followed by efficient electron transfer from the fluorophore to picric acid are responsible for the fluorescence quenching. Probe 67 can detect PA from both the solution phase (LOD $0.0025 \mu \mathrm{M}$ ) and the solid-state via a contact mode $\left(11.46 \mathrm{ag} \mathrm{cm}^{2}\right)$.

Among a series of benzimadazole-based tripodal derivatives, probe $\mathbf{6 8}^{79}$ (Chart 8) with a $\mathrm{C}_{12} \mathrm{H}_{25}$ alkyl chain exhibited detection of picric acid (Fig. 20) both in solution and the solid phase with a detection limit of $0.218 \mu \mathrm{M}$. Chain lengths longer or shorter than $\mathrm{C} 12$ reduced the sensitivity of the probe towards picric acid. The fluorescence intensity enhancement of probe $\mathbf{6 8}$ was due to the protonation of the benzimidazole nitrogen with benzoic acid. In the case of picric acid and 2,4-DNP, the electrostatic interactions between protonated 68 and the picrate/2,4-dinitrophenolate anions caused efficient

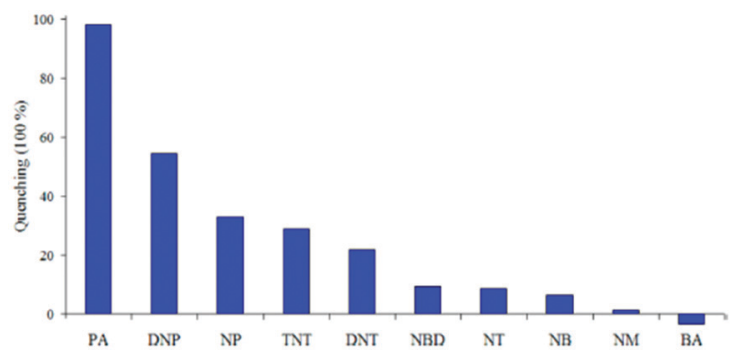

Fig. 20 The effects of different NACs on the fluorescence quenching of probe 68. Reprinted from ref. 79, Copyright 2014 American Chemical Society. 
energy transfer from the photoexcited $\pi$-electron-rich 68 to the ground state of electron-deficient PA, resulting in fluorescence quenching.

Probe $69^{80}\left(\mathrm{CHCl}_{3}\right)$ with one equivalent PA and probe $70^{80}$ (Chart 8) with two equivalents of PA displayed $>90 \%$ fluorescence quenching of the fluorescence at $\sim 367 \mathrm{~nm}$, along with a red-shift of the maxima to $381 \mathrm{~nm}$. Probe 69 formed a 1:1 (probe:picric acid) stoichiometric complex, while probe 70 formed a 1:2 stoichiometric complex. ${ }^{1} \mathrm{H}$ NMR, Job's plot and absorbance studies revealed that in the case of $\mathbf{7 0}$, both the imidazole and benzothiazole nitrogen atoms are protonated by two molecules of picric acid to form a GSCT complex. Other NACs, such as DNT and 2,4-DNP, also induced significant quenching of the fluorescence of probes 69 and 70 (Fig. 21).

Paper strips coated with 70 turned from fluorescent blue to non-fluorescent (under $365 \mathrm{~nm}$ light) with $1 \mathrm{mM}$ PA.

Probe $71^{81}$ (Chart 8) displayed both ON-OFF and OFF-ON fluorescence behaviour with picric acid, depending on the solvent. In $\mathrm{CH}_{3} \mathrm{CN}, 71$ displayed $\mathrm{OFF}-\mathrm{ON}$ behaviour, but exhibited $\mathrm{ON}-\mathrm{OFF}$ fluorescence quenching upon PA binding in toluene solution. In toluene, the fluorescence of probe 71 at 378 and $397 \mathrm{~nm}$ was quenched owing to GSCT complex formation and FRET from the fluorophore to picrate anion, and the detection limit for PA was $2.515 \mu \mathrm{M}$. However, in $\mathrm{CH}_{3} \mathrm{CN}$, the fluorescence intensity of 71 increased only 1.25-fold with a LOD of $1.065 \mu \mathrm{M}$ for PA. The down-field shift of the imidazole and pyrene protons in the ${ }^{1} \mathrm{H}$ NMR spectrum of 71 pointed to protonation of the imidazole nitrogen and face-to-face $\pi-\pi$ stacking interaction between the pyrene and picrate rings. Probe $\mathbf{7 1}$ formed two types (Fig. 22) of crystals with PA (space groups $P 2_{1} / n$ and $P 2_{1} / c$ ), and strong electrostatic interactions between the picrate anion and imidazolium moiety and $\pi-\pi$ interactions between the pyrene ring and picrate anion were observed in the X-ray structures of both crystals.

Probe $72^{82}$ (Chart 8) gave an emission maximum of $460 \mathrm{~nm}$ in DMF, which was red-shifted to $574 \mathrm{~nm}$ in $90 \%$ water due to the formation of spherical aggregates with a diameter of

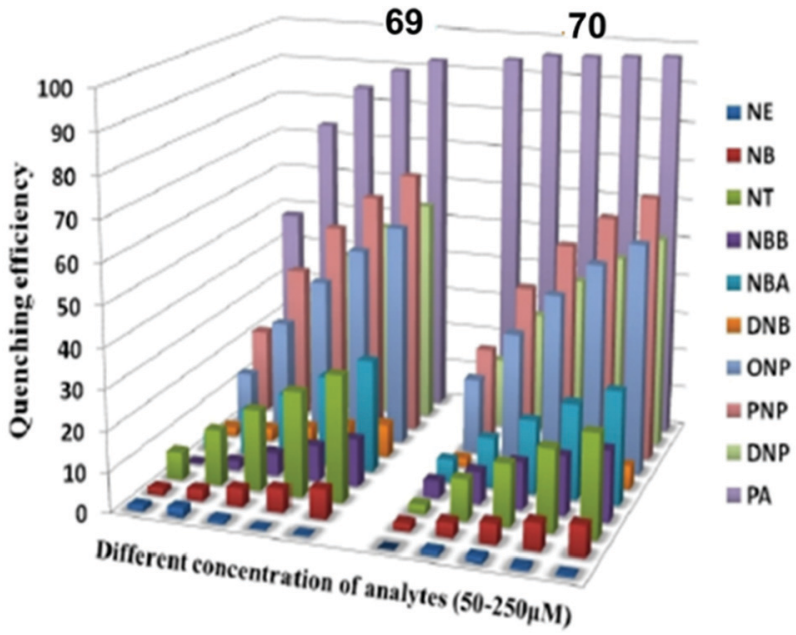

Fig. 21 The quenching efficiencies of different NACs toward probes 69 and 70. Reprinted from ref. 80, Copyright 2019 Wiley Online.

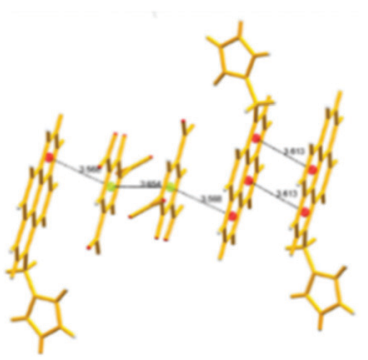

space group $\mathrm{P} 2_{1} / \mathrm{n}$

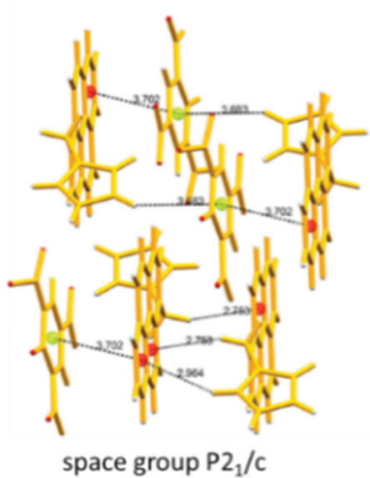

Fig. $22 \mathrm{X}$-ray crystal structures of complexes of probe 71 with PA showing $\pi-\pi$ interactions between pyrene and the picrate anion. Reprinted from ref. 81, Copyright 2017 Elsevier.

$233 \mathrm{~nm}$. These aggregates showed 96\% fluorescence quenching with 10 equivalents of picric acid and an LOD of $3.5 \mu \mathrm{M}$ for picric acid. In the ${ }^{1} \mathrm{H}$ NMR spectrum of 72 , the $\mathrm{C} 2-\mathrm{H}$ of the imidazole moiety was shifted downfield by $1.39 \mathrm{ppm}$, which pointed to the formation of an imidazolium moiety via proton transfer from picric acid, and the resulting electrostatic interactions caused efficient PET from the fluorophore to the picrate anion to form a non-fluorescent complex.

\subsection{Protonation of imine-based fluorescent probes for picric acid}

The nitrogen in Schiff bases is basic in nature and is well known to undergo protonation with general acids, and accordingly, forms a salt with the nitrophenolate ions upon protonation by phenolic nitroaromatic compounds and facilitates electron transfer/energy transfer processes for efficient fluorescence quenching. A comparison of solvents, LOD, $K_{\mathrm{SV}}$ values, emission maxima and applications of probes 73-76 has been presented in Table 3.

Fluorescent probe $73^{83}$ (Chart 9) in $\mathrm{CH}_{3} \mathrm{CN}$ with PA exhibited a blue-shift in its absorption band from $368 \mathrm{~nm}$ to $344 \mathrm{~nm}$, and fluorescence quenching with a red-shift of the emission band<smiles>O=C(N/N=C/c1ccc2ccc3cccc4ccc1c2c34)c1cccs1</smiles><smiles>O=[N+]([O-])c1ccc(NC/N=C/c2ccc3ccc4cccc5ccc2c3c45)cc1</smiles><smiles>COC(=O)c1cc(/N=C/c2ccc3ccc4cccc5ccc2c3c45)cc(C(C)=O)c1</smiles><smiles>COc1cccc(/C=N\c2ccc(/N=C\c3cccc(OC)c3O)cc2)c1O</smiles>

75

76

Chart 9 Structures of probes $73-76$ 


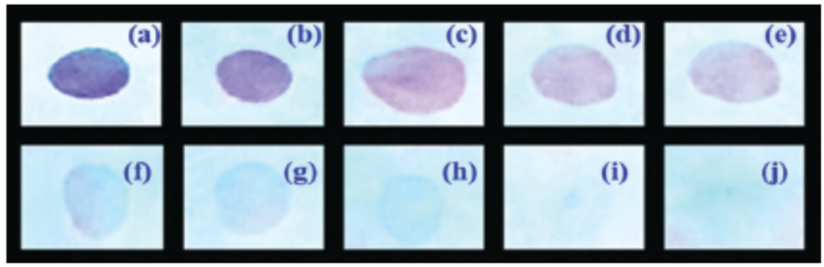

Fig. 23 Response of probe-73-coated paper strips to PA: (a) $10 \mu \mathrm{M}$, (b) $1.0 \mu \mathrm{M}$, (c) $0.1 \mu \mathrm{M}$, (d) $0.01 \mu \mathrm{M}$, (e) $8 \mathrm{nM}$, (f) $4 \mathrm{nM}$, (g) $1 \mathrm{nM}$, (h) $0.5 \mathrm{nM}$, (i) $0.1 \mathrm{nM}$, and (j) 0. Reprinted from ref. 83, Copyright 2019 Royal Society of Chemistry.

from $425 \mathrm{~nm}$ to $462 \mathrm{~nm}$ and a fluorescence color change from blue to dark. A Job's plot analysis showed a 1:1 stoichiometry with a binding constant of $6.814 \times 10^{6} \mathrm{M}^{-1}$. The protonation of the imine nitrogen followed by energy transfer from the probe to the picrate was responsible for the quenching of the emission intensity. The LOD and $K_{\mathrm{SV}}$ values are $0.01 \mu \mathrm{M}$ and $2.29 \times 10^{7} \mathrm{M}^{-1}$ respectively. Probe 73 detected $10^{-9} \mathrm{M}$ PA using paper strips (Fig. 23).

Probe $\mathbf{7 4}{ }^{84}$ (Chart 9) is AIEE-active, and upon the addition of $80 \%$ water to its solution in $\mathrm{CH}_{3} \mathrm{CN}$, displayed an 833-fold enchantment in fluorescence intensity and achieved a 0.79 quantum yield. Probe $\mathbf{7 4}$ with 24 equivalents of PA exhibited $>98 \%$ fluorescence quenching at $476 \mathrm{~nm}$ with a change from a cyan-blue colour to non-fluorescence. Other phenolic NACs, such as 2,4-DNP and 4-NP (Fig. 24), also caused significant fluorescence quenching of probe $\mathbf{7 4}$. Along with the probable protonation of amine nitrogen, the intercalation of the picric acid between two pyrene rings held together by $\pi-\pi$ stacking interactions in the aggregated state contributed to a CT process from pyrene to picric acid.

Another pyrene-Schiff-base AIE fluorescent probe, $75^{85}$ (Chart 9), exhibited fluorescence quenching at $469 \mathrm{~nm}$ in THF$\mathrm{H}_{2} \mathrm{O}$ (1:9) with the gradual addition of PA due to ground-state energy transfer via $\pi-\pi$ and coulombic interaction between the fluorescent probe and the picrate anion. The $K_{\mathrm{SV}}$ and detection

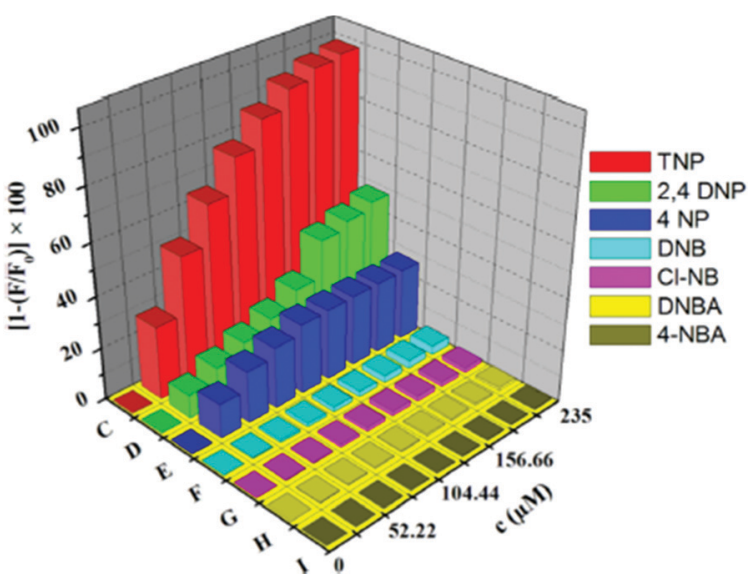

Fig. 24 Quenching efficiency (\%) of the excimer fluorescence (at $\lambda_{\mathrm{em}}=$ $467 \mathrm{~nm}$ with $\left.\lambda_{\mathrm{ex}}=390 \mathrm{~nm}\right)$ of probe $74(10 \mu \mathrm{M})$ in $8: 2 \mathrm{H}_{2} \mathrm{O} / \mathrm{CH}_{3} \mathrm{CN}$ upon the addition of different NACs. Reprinted from ref. 84, Copyright 2018 American Chemical Society.

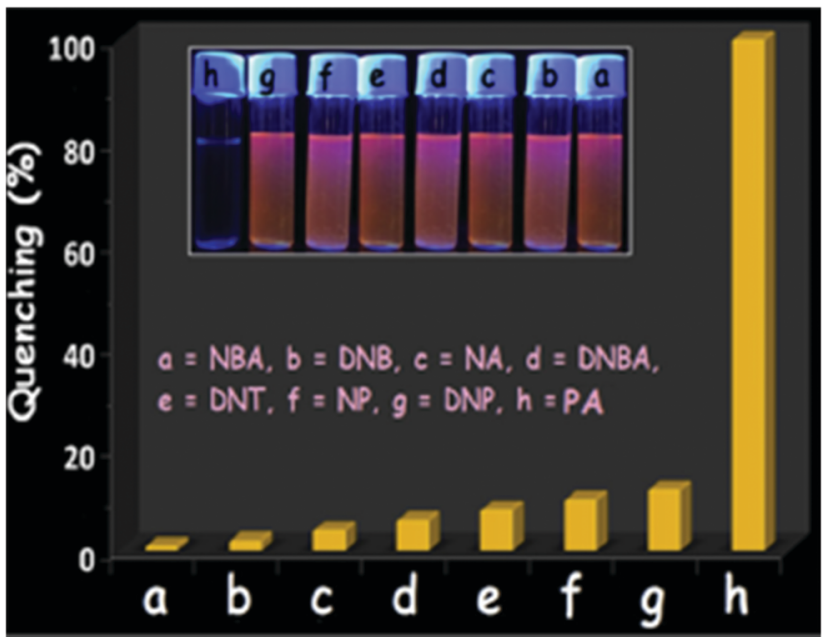

Fig. 25 Quenching efficiency (\%) $\left(\lambda_{\mathrm{em}}=585 \mathrm{~nm}\right)$ of aggregates of 76 with NACs (50 equivalents). Inset: Visual colour change observed with only PA under illumination at $365 \mathrm{~nm}$. Reprinted from ref. 86, Copyright 2019 Elsevier.

limit were calculated to be $2.03 \times 10^{4} \mathrm{M}^{-1}$ and $0.01 \mu \mathrm{M}$, respectively. Probe 75 showed fluorescence quenching by NACs, which followed the order PA $>2,4-\mathrm{DNP}>4$-NP $>$ TNB $>$ NM, DNT, NT.

AIE-based probe $76^{86}$ (Chart 9) showed the formation of $\mathrm{J}$ aggregates with an emission maximum at $585 \mathrm{~nm}$ in THF- $\mathrm{H}_{2} \mathrm{O}$ (1:9). These aggregates underwent $>98 \%$ fluorescence quenching with 4 equivalents of picric acid, with a change in fluorescence colour from orange to dark (Fig. 25), and could detect PA concentrations as low as $0.072 \mu \mathrm{M}$ in solution. The other NACs caused only a slight change in the fluorescence intensity of 76. TLC strips coated with aggregates of 76 could detect $\sim 0.3 \mathrm{pg}$ of PA.

\subsection{Protonation of amide-based fluorescent probes for picric acid}

Due to the resonance of the nitrogen lone pair with the amide oxygen, the amide oxygen is very electron-rich and easily undergoes protonation. The amide-based probes 77 to $\mathbf{8 4}$ exhibit fluorescence quenching upon protonation by picric acid. A comparison of the solvents, LODs, $K_{\mathrm{SV}}$ values, emission maxima and applications of probes 77-84 is given in Table 3.

The fluorescent probe $77^{87}$ (Chart 10) with anthracene and 1,8-naphthalimide units displayed fluorescence enhancement upon the addition of $>50 \%$ water to its THF solution, which pointed to the formation of aggregates. These aggregates showed $\sim 88 \%$ and $\sim 30 \%$ fluorescence quenching at $508 \mathrm{~nm}$ upon the addition of 50 equivalents of picric acid or TNT, respectively. The effect of DNP on the fluorescence of 77 was not evaluated. TD-DFT studies revealed that in the excited state, the intermolecular proton transfer from picric acid to the oxygen of 1,8-naphthalimide is strengthened, which facilitates the non-irradiative PET process to induce the fluorescence quenching.

When the concentration of the tripodal probe $78^{88}$ was increased to $>10 \mu \mathrm{M}$ in DMSO, a sudden increase in blue fluorescence $\left(\lambda_{\mathrm{em}}=435 \mathrm{~nm}\right)$ was observed due to the formation 
<smiles></smiles>

77

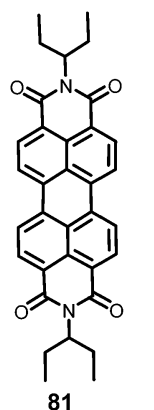

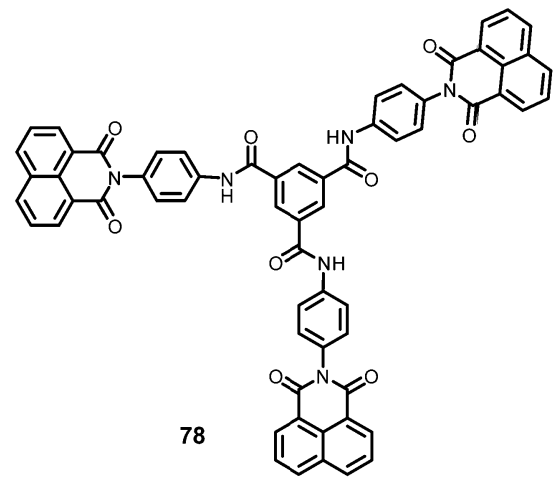

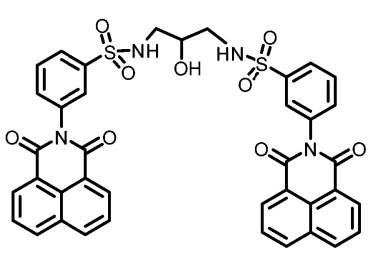

79
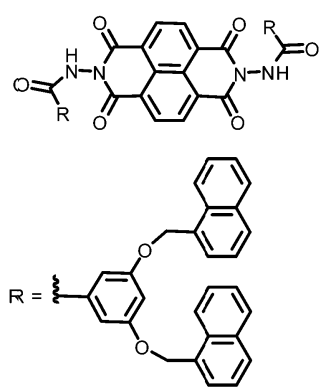

80
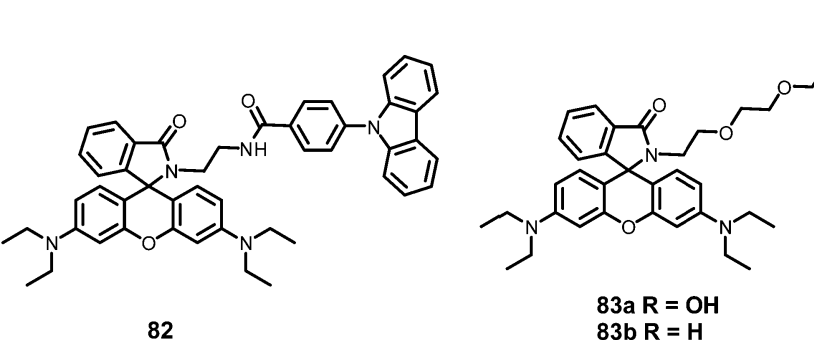

83b $R=H$

Chart 10 Structures of probes $77-84$

of self-assembled aggregates. In ${ }^{1} \mathrm{H}$ NMR studies, the downfield shift of the amide $\mathrm{NH}$ protons and up-field shift of the aromatic protons with increasing amounts of the probe were highly consistent with the formation of aggregates through $\pi-\pi$ and hydrogen bond interactions. These aggregates displayed $99.2 \%$ fluorescence quenching with 10 equivalents of picric acid owing to protonation at the amide oxygen, which resulted in the de-aggregation of the molecules of probe 78. The addition of cyanide ions removed the proton and caused re-aggregation of the molecules of probe $\mathbf{7 8}$ to restore the blue emission. Paper strips coated with 78 could detect $10^{-8} \mathrm{M}$ PA.

Probe $\mathbf{7 9}^{89}$ (Chart 10) showed an AIEE phenomenon at $484 \mathrm{~nm}$ in a mixture of DMSO- $\mathrm{H}_{2} \mathrm{O}$ with increasing amounts of water, and this emission was quenched by 2 equivalents of PA. Picric acid caused much more efficient fluorescence quenching than that observed for 2,4-DNP and 4-NP. Probe 79 formed 1:2 (probe 79:NAC) stoichiometric complexes with picric acid, 2,4-DNP and 4-NP, but the binding constant for picric acid $\left(35 \times 10^{7} \mathrm{M}^{-1}\right)$ was much higher than those for 2,4$\operatorname{DNP}\left(8.71 \times 10^{5} \mathrm{M}^{-1}\right)$ and 4 -NP $\left(3.83 \times 10^{5} \mathrm{M}^{-1}\right)$. The partial de-aggregation of the aggregates and $\pi-\pi$ interactions with energy transfer from the probe to PA were responsible for the fluorescence quenching. Paper strips coated with probe $\mathbf{7 9}$ solution allowed the detection of $10 \mathrm{nM}$ PA by the naked eye (Fig. 26). The paper strips coated with 79 exhibited fluorescence quenching in the presence of PA vapor.

Naphthalene-1,8-diimide derivative $\mathbf{8 0}^{90}$ (Chart 10) showed excimer emission centred at $600 \mathrm{~nm}$ in THF-water $(1: 9)$ due to the formation of aggregates. The formation of these aggregates was confirmed by SEM and DLS studies. Probe 80 displayed $99 \%$ fluorescence quenching at $600 \mathrm{~nm}$ with 30 equivalents of
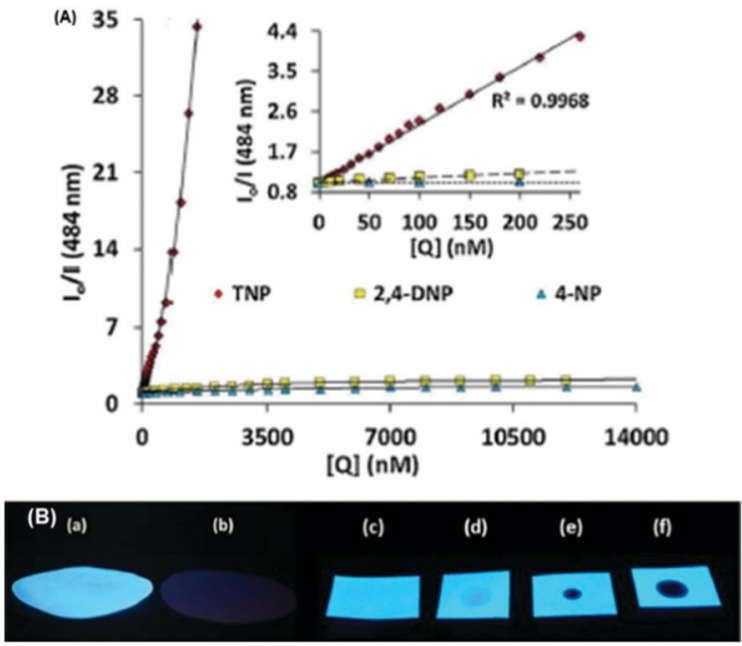

Fig. 26 (A) Fluorescence quenching of probe 79 at $484 \mathrm{~nm}$ with PA, DNP, and NP. (B) Fluorescence changes of 79-coated paper strips (a) before and (b) after being dipped into PA solution $(1 \mu \mathrm{M})$ or after exposure to (c) $\mathrm{H}_{2} \mathrm{O}$ or PA solutions with different concentrations: (d) $1 \mathrm{nM}$, (e) $3 \mathrm{nM}$, and (f) $10 \mathrm{nM}(4 \mu \mathrm{L})$, as seen under $365 \mathrm{~nm}$ illumination. Reprinted from ref. 89 , Copyright 2017 Elsevier.

PA with a fluorescence colour change from orange to dark in THF-water. Probe $\mathbf{8 0}$ formed a GSCT complex with PA via protonation of the amide oxygen, which was responsible for the fluorescence quenching. The non-phenolic nitroaromatic compounds TNT, ONT, 2,4-DNT and NB induced insignificant changes in the fluorescence of the aggregates. Paper strips coated with probe $\mathbf{8 0}$ showed $50 \%$ fluorescence quenching with $60 \mu \mathrm{L}$ of PA solution. 


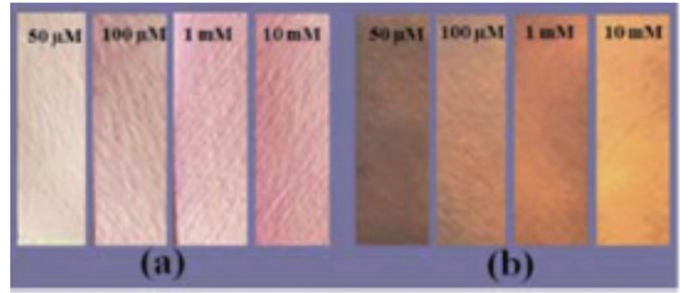

Fig. 27 Paper strips coated with probe $\mathbf{8 2}$ for the recognition of PA (50 $\mu \mathrm{M}$ to $10 \mathrm{mM}$ ) under (a) sunlight and (b) $365 \mathrm{~nm}$ UV light. Reprinted from ref. 92, Copyright 2018 Royal Society of Chemistry.

Perylene-based probe $\mathbf{8 1}^{91}$ (Chart 10) displayed respective $70 \%$ and $22 \%$ reductions in emission intensity in the presence of picric acid and 2,4-DNP in THF. Non-phenolic NACs caused much smaller fluorescence quenching. Protonation of the amide oxygen of $\mathbf{8 1}$ by picric acid and 2,4-DNP formed a nonfluorescent ground state complex. The $K_{\mathrm{SV}}$ and detection limit for PA are $6.02 \times 10^{3} \mathrm{M}^{-1}$ and $2.98 \mu \mathrm{M}$, respectively.

Rhodamine-based fluorescent and colorimetric probe $\mathbf{8 2}^{92}$ (Chart 10) revealed a new absorption maximum at $560 \mathrm{~nm}$ in 5 min with $200 \mu \mathrm{M} \mathrm{PA}$, with a colour change from colourless to pink and a maximum increase in fluorescence intensity at $586 \mathrm{~nm}$ in $80 \mathrm{~min}$ due to spiro-lactam ring-opening. The lowest detection limit for PA was found to be $0.82 \mu \mathrm{M}$. A BenesiHildebrand plot revealed a 1:1 stoichiometry between probe $\mathbf{8 2}$ and PA with an association constant of $5834 \mathrm{~L} \mathrm{~mol}^{-1}$. Paper strips coated with probe 82 solution detected $50 \mu \mathrm{M}$ PA with color change to pink (naked eye) and orange fluorescence under 365 light (Fig. 27).

Rhodamine 83a ${ }^{93}$ (Chart 10) displayed selective detection of $\mathrm{PA}$ in $\mathrm{MeOH}-\mathrm{H}_{2} \mathrm{O}(1: 4)$ with an increase in quantum yield from 0.065 to 0.611 . Upon the addition of PA, the appearance of a new absorption maximum at $554 \mathrm{~nm}$ and a 99-fold enhancement in emission intensity at $581 \mathrm{~nm}$ were observed for probe 83a due to spirolactam ring opening. Probe 83a could detect PA concentrations as low as $2 \times 10^{-11} \mathrm{M}$. Probe 83b lacking an $\mathrm{OH}$ moiety on the Schiff-base was only weakly sensitive to picric acid.

Rhodamine-appended hexaphenylbenzene-based probe $\mathbf{8 4}^{94}$ (Chart 10) with PA in methanol showed a colour change from colourless to pink (naked eye) and non-fluorescent to red (under $365 \mathrm{~nm}$ light). Probe $\mathbf{8 4}$ did not exhibit any emission band, but the addition of 30 equivalents of PA resulted in a 147 -fold enhancement at $578 \mathrm{~nm}(\Phi=0.82)$. Other NACs, such as 4-NP, 2,4-DNP, 2-NT, 2,4-DNT, 1,4-BQ, NM, 1,4-DNB, benzoic acid and 4-NBA did not cause any fluorescence or daylight colour change. The colour/fluorescence change was reversed with tetrabutylammonium hydroxide. Probe $\mathbf{8 4}$ could detect PA concentrations as low as $0.035 \mu \mathrm{M}$. Proton transfer from picric acid to the spiro-lactam ring resulted in opening of the spirolactam ring of rhodamine to the amide and activated the TBET process in $\mathbf{8 4}$ via the conjugated linker from the donor to the acceptor. TLC strips (Fig. 28) coated with the probe displayed a color change from colourless to pink and could detect $10^{-8} \mathrm{M}$ PA.

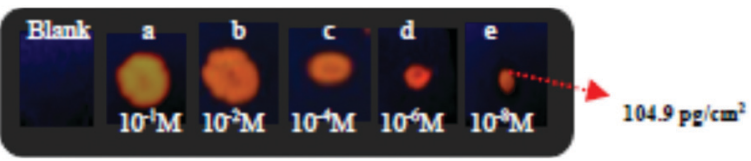

Fig. 28 Probe-84-coated paper strips upon interaction with different concentrations of PA [(a) 1.049 mg, (b) 0.1049 mg, (c) $1.049 \mu \mathrm{g}$, (d) 10.49 ng, and (e) 104.9 pg]. Reprinted from ref. 92, Copyright 2015 Royal Society of Chemistry.

\section{Positively charged probes for the detection of picric acid}

Due to the ease of the dissociation of picric acid to the picrate anion, it can form a neutral electrostatic complex with positively charged fluorophores, thus leading to the proximity of the fluorophore to the picrate anion and efficient electron/energy transfer processes. Positively charged probes bearing dialkylamino moieties can undergo protonation with picric acid and restrict the ICT from the dialkylamino moiety to the rest of the molecule. This restriction of ICT leads to a non-fluorescent complex in the presence of picric acid. These probes have been classified as mono-, di- and tripodal fluorescent derivatives, and are discussed in this order. A comparison of the solvents, LODs, $K_{\mathrm{SV}}$ values, emission maxima and applications of probes $85-128$ has been presented in Table 4.

\subsection{Monopodal cationic fluorescent probes for picric acid}

The quinoline derivatives 85 and $\mathbf{8 6}^{95}$ (Chart 11) having electrondonor groups on the quinoline moiety exhibited emission maxima at $580 \mathrm{~nm}$ and $593 \mathrm{~nm}$, respectively, in $\mathrm{MeOH}-\mathrm{H}_{2} \mathrm{O}$ (9:1), which revealed $86 \%$ and $87 \%$ fluorescence quenching with $100 \mathrm{ppm}$ PA, whereas derivative $87^{95}$ was silent to the presence of PA. In the ${ }^{1} \mathrm{H}$ NMR spectrum of $\mathbf{8 5}$, the lack of change in the chemical shift values even after the addition of 5 equivalents of picric acid suggested no protonation of the fluorophore, and DFT calculations indicated that electron transfer from the LUMO of the fluorophore to the picrate anion was the cause of the fluorescence quenching. In probe 86, a change in the chemical shifts in its ${ }^{1} \mathrm{H}$ NMR spectrum upon the addition of PA pointed to restriction of ICT and the formation of a non-fluorescent complex. Therefore, probes 85 and 86 followed different mechanisms for fluorescence quenching by picric acid. Thin films of probes 85-87 emitted in the orange-to-red region. Upon exposure to TFA vapor, the fluorescence colour of the film of probe $\mathbf{8 5}$ changed from orange to red, and the fluorescence of films of 86 and 87 was completely quenched without any appreciable shift in the emission maxima. These effects were reversed upon interaction with TEA vapor.

The ratiometric probe $\mathbf{8 8}^{96}$ (Chart 11) in a $100 \%$ aqueous medium displayed a red shift in fluorescence maximum from 390 to $440 \mathrm{~nm}$ after the addition of PA with a fluorescence colour change from blue to cyan (Fig. 29). The formation of a new emission band at $440 \mathrm{~nm}$ was assigned to the protonation of $\mathbf{8 8}$ at the quinoline nitrogen. A plot of the $I_{455 \mathrm{~nm}} / I_{390 \mathrm{~nm}}$ ratio with PA concentration showed a good linear relationship between $0.5 \mu \mathrm{M}$ and $20 \mu \mathrm{M}$. This probe was able to detect PA from real samples. 


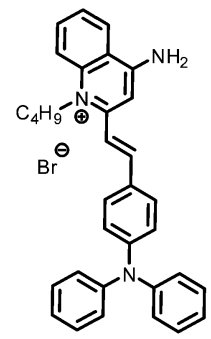

85

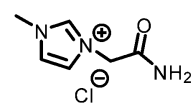

93

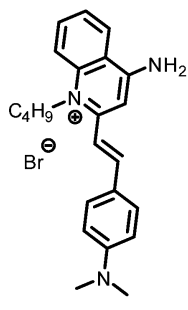

86<smiles></smiles>

87<smiles></smiles>

88
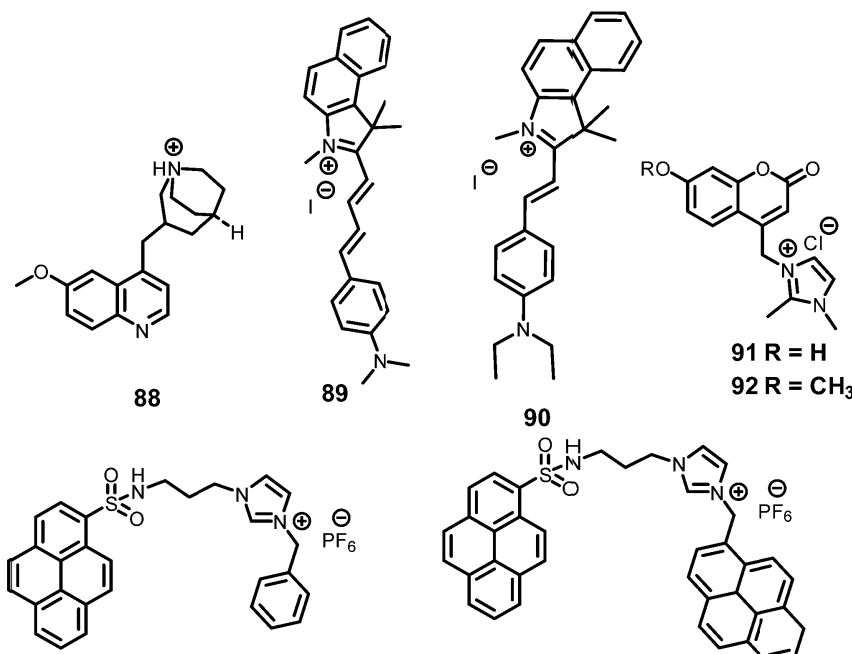

95
90

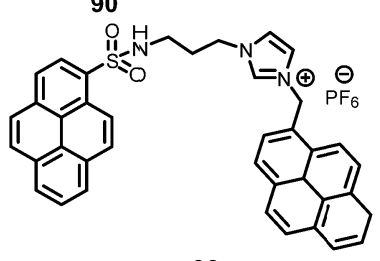

96

Chart 11 Structures of probes 85-96.

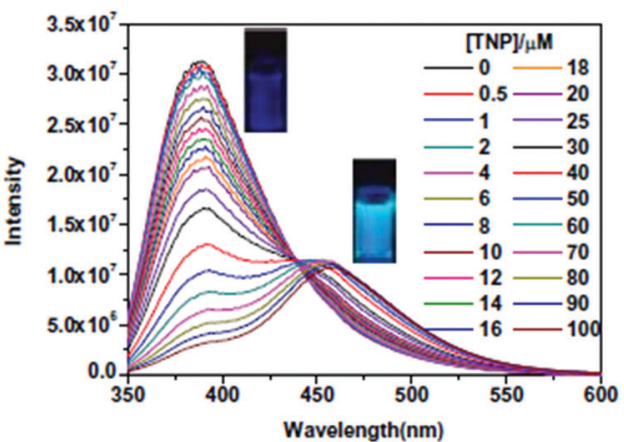

Fig. 29 Changes in the emission spectrum and emission colour of $\mathbf{8 8}$ $\left(1.0 \times 10^{-5} \mathrm{M}\right)$ with increasing amounts of PA. Reprinted from ref. 96, Copyright 2019 Elsevier.

Indolium-based probes $\mathbf{8 9}$ and $\mathbf{9 0}^{97}$ (Chart 11) in a THF- $\mathrm{H}_{2} \mathrm{O}$ (1:1) mixture exhibited $92 \%$ and $93 \%$ fluorescence quenching at their maxima of $510 \mathrm{~nm}$ and $620 \mathrm{~nm}$ for 89 and $720 \mathrm{~nm}$ for 90 with the incremental addition of PA solution. The protonation of the $N, N$-dialkylamino moiety by PA restricted ICT and was responsible for the fluorescence quenching. Paper strips coated with 89 and 90 could be used for detecting PA from real samples.

Coumaryl-linked imidazolium salts $\mathbf{9 1}$ and $\mathbf{9 2}^{\mathbf{9 8}}$ (Chart 11) showed decreased fluorescence intensity at $480 \mathrm{~nm}$ and $410 \mathrm{~nm}$, respectively, with increasing concentration of PA due to the formation a GSCT complex, as evidenced by ${ }^{1} \mathrm{H}$ NMR, UV-Vis and fluorescence lifetime studies. Among the other NACs, only 4-NP exhibited a fairly strong interaction with $\mathbf{9 1}$ and $\mathbf{9 2}$. These probes were able to detect PA using probe-coated TLC plates. Ionic liquid-based fluorophore $\mathbf{9 3}^{99}$ (Chart 11) demonstrated $91 \%$ and 93\% fluorescence quenching with $\mathrm{PA}$ and 4-NP, respectively, caused by the formation of a GSCT complex. The information for 2,4-DNP is not available.

Pyrene-appended imidazolium salts $\mathbf{9 4 - 9 6}^{100}$ (Chart 11) could detect PA with little interference from 2,4-DNP and 4-NP

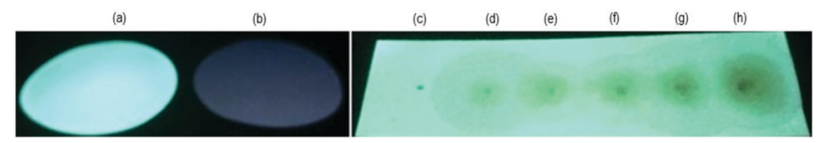

Fig. 30 Fluorescence changes of probe-96-coated paper strips with PA; (a) a 96-coated paper strip, (b) a 96-coated strip dipped in $1 \mu \mathrm{M}$ PA solution (in $100 \%$ water), and a $\mathbf{9 6}$-coated strip upon exposure to $5 \mu \mathrm{L}$ of aqueous solutions with the following concentrations of PA: (c) 0 , (d) $5 \mathrm{nM}$, (e) $10 \mathrm{nM}$, (f) $20 \mathrm{nM}$, (g) $50 \mathrm{nM}$, and (h) $100 \mathrm{nM}$. Observed under $365 \mathrm{~nm}$ light. Reprinted from ref. 100. Copyright 2016 Elsevier.

in PBS-DMSO (99.5 : 0.5) solution. The green emission of probe 96 was completely quenched with PA, and it formed a 1:2 stoichiometric complex. The loss of $\pi-\pi$ interactions between the two pyrene rings and electron transfer from pyrene to PA were responsible for the fluorescence quenching. Probes $\mathbf{9 4}$ and 95 also showed fluorescence quenching of their monomer emission bands. Paper strips (Fig. 30) coated with 96 were able to detect PA.

Squaraine-dansyl conjugate $\mathbf{9 7} \mathbf{7}^{\mathbf{1 0 1}}$ (Chart 12) displayed a ratiometric change in absorbance and fluorescence upon titration with PA in $\mathrm{CH}_{3} \mathrm{CN}$. With increasing amounts of PA, the solution of 97 exhibited reduced absorbance at $663 \mathrm{~nm}$ with the appearance of a new absorption maximum at $627 \mathrm{~nm}$. Upon excitation at $620 \mathrm{~nm}$, probe 97 displayed a blue-shift in fluorescence maximum from $684 \mathrm{~nm}$ to $644 \mathrm{~nm}$. The plot of $\mathrm{FI}_{644 \mathrm{~nm}} / \mathrm{FI}_{684 \mathrm{~nm}}$ with PA shows good linearity in the range 5-100 $\mu \mathrm{M}$, and the lowest detection limit was $70 \mathrm{nM}$. In probe 97 , protonation of the dimethylamine nitrogen restricted ICT and the twisted dimethylamino phenyl unit prevented $\pi-\pi$ interactions of the squaraine plane with PA, reducing the efficiency of electron and energy transfer. Paper strips coated with probe $\mathbf{9 7}$ could detect PA with a color change from a blue to a brownish color (Fig. 31).

\subsection{Dipodal dicationic fluorescent probes for picric acid}

The fluorescent probe $\mathbf{9 8}^{102}$ (Chart 12) exhibited a varied distribution in differently charged micelles, which further 


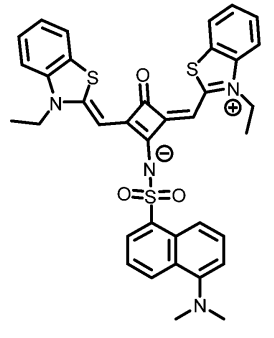

97

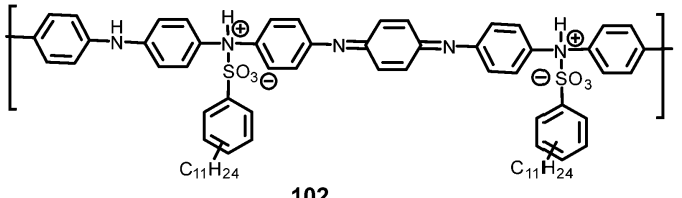

102

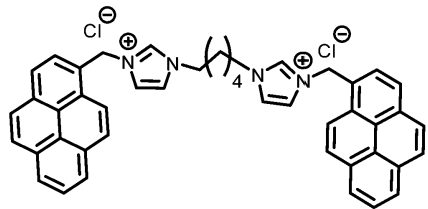

98

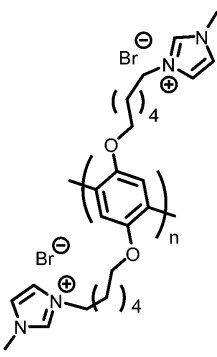

99

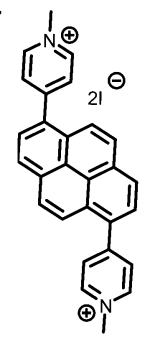

100

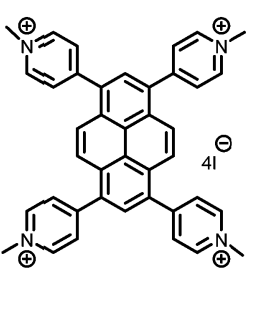

101

Chart 12 The structures of probes 97-105.
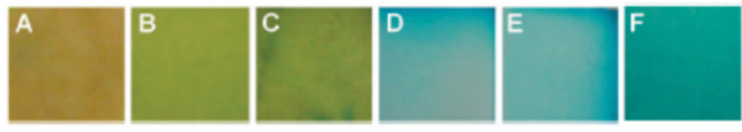

Fig. 31 Visual color changes of probe-97-coated paper strips with different amounts of $P A$; the $[P A]$ values are (A) $10^{-2} \mathrm{M}$, (B) $10^{-4} \mathrm{M}$, (C) $10^{-6} \mathrm{M}$, (D) $10^{-9} \mathrm{M}$, (E) $10^{-11} \mathrm{M}$, and (F) no PA. Reprinted from ref. 101, Copyright 2013 Royal Society of Chemistry.
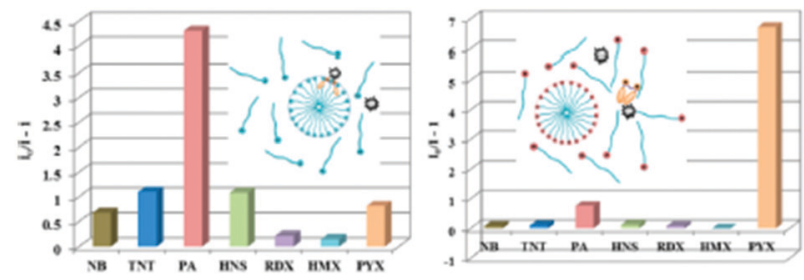

Fig. 32 Fluorescence quenching efficiency of explosives. (left) Probe 98 $(1 \mu \mathrm{M})$-SDS (8 mM) sensor system; (right) Probe $98(1 \mu \mathrm{M})-\mathrm{DTAB}(14 \mathrm{mM})$ sensor system. [explosives] $=100 \mu \mathrm{M}$. Reprinted from ref. 102, Copyright 2014 American Chemical Society.

influenced the sensing behaviour of the obtained micellar sensor systems towards explosives. The UV-Vis, steady-state and time-resolved emission studies revealed that probe $\mathbf{9 8}$ is encapsulated by SDS, but not by the cationic surfactant DTAB. The solution of $\mathbf{9 8}$ in SDS showed preferential fluorescence quenching with PA (Fig. 32), but in DTAB solution, the most selective quenching was observed with PYX. The quenching mechanism of the two micellar sensor systems by explosives was static in nature.

Imidazolium-based conjugated polyelectrolyte $\mathbf{9 9}^{\mathbf{1 0 3}}$ (Chart 12) revealed fluorescence quenching efficiency following the order $\mathrm{PA}>2,4-\mathrm{DNP}>4$-NP, but neutral NACs did not cause fluorescence quenching. The ease of the dissociation of PA in water accelerated the electrostatic interaction with cationic probe $\mathbf{9 9}$ and resulted in a decrease in emission intensity at $406 \mathrm{~nm}$ with a colour change from blue to dark under UV light. Paper strips
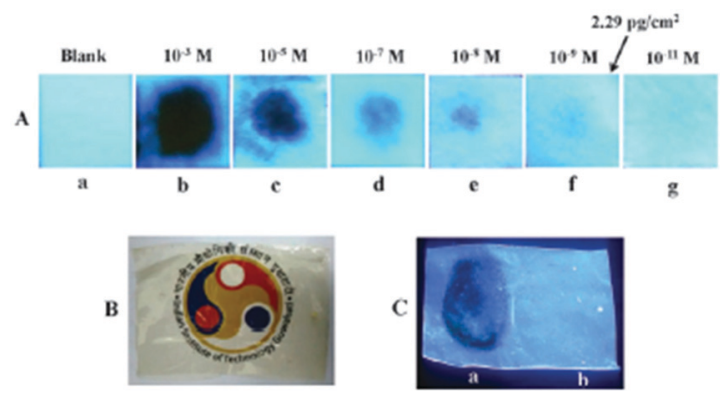

Fig. 33 (A) The colour of fluorescent test strips under UV light (a) before and after $(\mathrm{b}-\mathrm{g})$ treatment with $10 \mu \mathrm{L}$ of solutions of various concentrations of PA. (B) Probe-99-doped transparent chitosan film in daylight. (C) Visualization of 99-doped CS fluorescent film under UV light: (a) dark spot of a residual PA thumbprint and (b) a thumb impression as a control (at $365 \mathrm{~nm}$ ). Reprinted from ref. 103, Copyright 2015 Royal Society of Chemistry.

coated with 99 could detect $2.29 \mathrm{pg} \mathrm{cm}^{-2}$ PA. A transparent fluorescent film of commercial chitosan with $5 \%$ of probe 99 was also used for the detection of PA (Fig. 33).

Pyrenoviologen cationic derivatives 100 and $\mathbf{1 0 1}^{104}$ (Chart 12) possessing high quantum yields of $64 \%$ and $95 \%$, respectively, displayed electrostatic interactions with picrate anions in water, and electron transfer between them lead to the fluorescence response. The fluorescence emission spectra of $100(10 \mu \mathrm{M})$ at $513 \mathrm{~nm}$ and $101(10 \mu \mathrm{M})$ at $482 \mathrm{~nm}$ were completely quenched upon the addition of PA $(55 \mu \mathrm{M})$.

Dodecylbenzene-sulfonic acid (DBSA)-doped polyaniline $\mathbf{1 0 2}^{105}$ (Chart 12) in the solvent NMP underwent fluorescence quenching at $475 \mathrm{~nm}$ in the order PA $>1,3-\mathrm{DNB} \approx \mathrm{NB}$. The results with 2,4-DNP and 4-NP were not discussed. The FE-SEM and AFM images of $\mathbf{1 0 2}$ displayed changes in morphology after the addition of PA (Fig. 34).

Perylene diimide probes $\mathbf{1 0 3 - 1 0 5}{ }^{\mathbf{1 0 6}}$ (Chart 12) displayed quenching of their yellow fluorescence upon the addition of PA and 4-nitroaniline (4-NA) with equal ease in DMF and water 

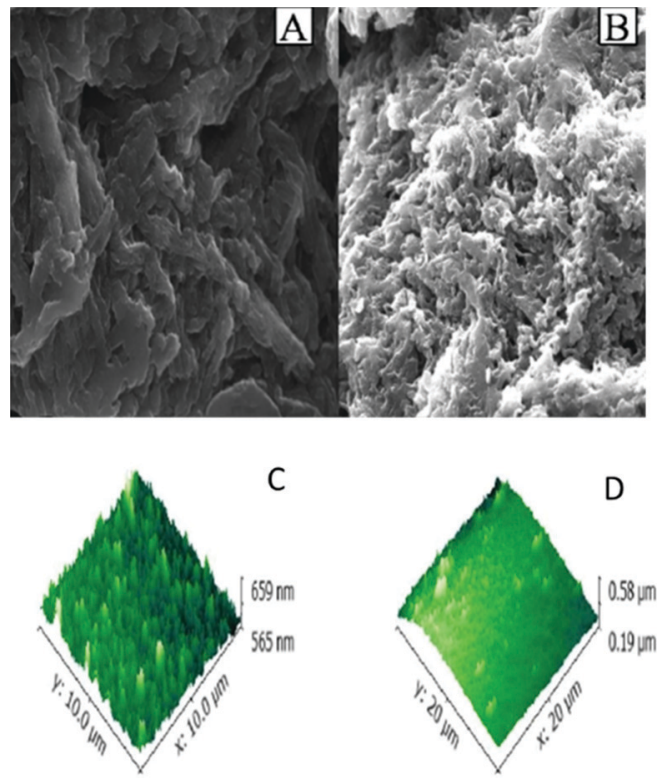

Fig. 34 (a) FESEM images of probe 102 and (b) probe $102+$ PA. (c) AFM images of 102 and (d) 102 + PA. Reprinted from ref. 105, Copyright 2018 Wiley Online.

(pH range 1.0 to 10.0). The probes showed stronger fluorescence in DMF than in water.

\subsection{Tripodal tricationic fluorescent probes for picric acid}

Anthracene-functionalized tris-imidazolium salts $106-107^{107}$ (Chart 13) found applications for the detection of picric acid in organic and aqueous media. Both 106 and 107 exhibited characteristic anthracene monomer emission in DMSO, with $92 \%$ and $91 \%$ quenching, respectively, upon the addition of
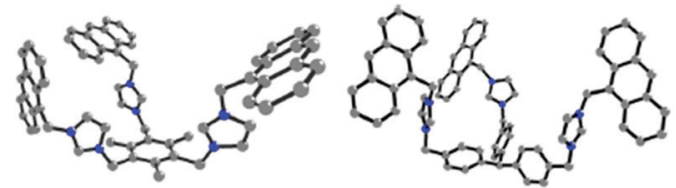

Fig. 35 The X-ray crystal structure of 106 (left) and the energy-optimized structure of 107 (right). Reprinted from ref. 107, Copyright 2013 American Chemical Society.

100 equivalents of PA. Other NACs displayed much smaller fluorescence quenching, but the study with 2,4-DNP - the most interfering nitrophenol - is not available. Probes 106 and 107 showed static quenching due to the ground-state charge-transfer complex formation. X-ray diffraction and computational studies reveal that from among several possibilities, 106 and 107 adopt a cis,cis, cis conformation and exhibit a bowl-shaped structure in the solid state (Fig. 35). The ${ }^{1} \mathrm{H}$ NMR and DFT studies of 106 and 107 with PA and the X-ray crystal structure of complex of 106 with PA showed the formation of $1: 2$ stoichiometric probe $\cap$ 2PA complex via the replacement of two bromide ions with picrate anions.

The X-ray crystal structures and DFT optimization studies of tripodal probes $\mathbf{1 0 8}$ and $\mathbf{1 0 9}^{\mathbf{1 0 8}}$ (Chart 13) show that the three biphenyl substituents are oriented on the same side of the triethylbenzene to form a pseudo-cavity, which is more preorganised for the encapsulation of PA in comparison to 106 and 107. Upon excitation at $290 \mathrm{~nm}$, the solution of $\mathbf{1 0 8}$ displayed a decrease in the emission intensity at $402 \mathrm{~nm}$ due to a combination of electrostatic, hydrogen-bonding and $\pi-\pi$ interactions with the picrate anion (Fig. 36). The Job's plot of 108 revealed a $1: 1$ stoichiometric complex with PA with a $\log \beta_{11}$ value of $5.82 \pm 0.06$. The solution of 109 in HEPES buffer displayed a decrease in emission intensity at $470 \mathrm{~nm}$ with a colour change

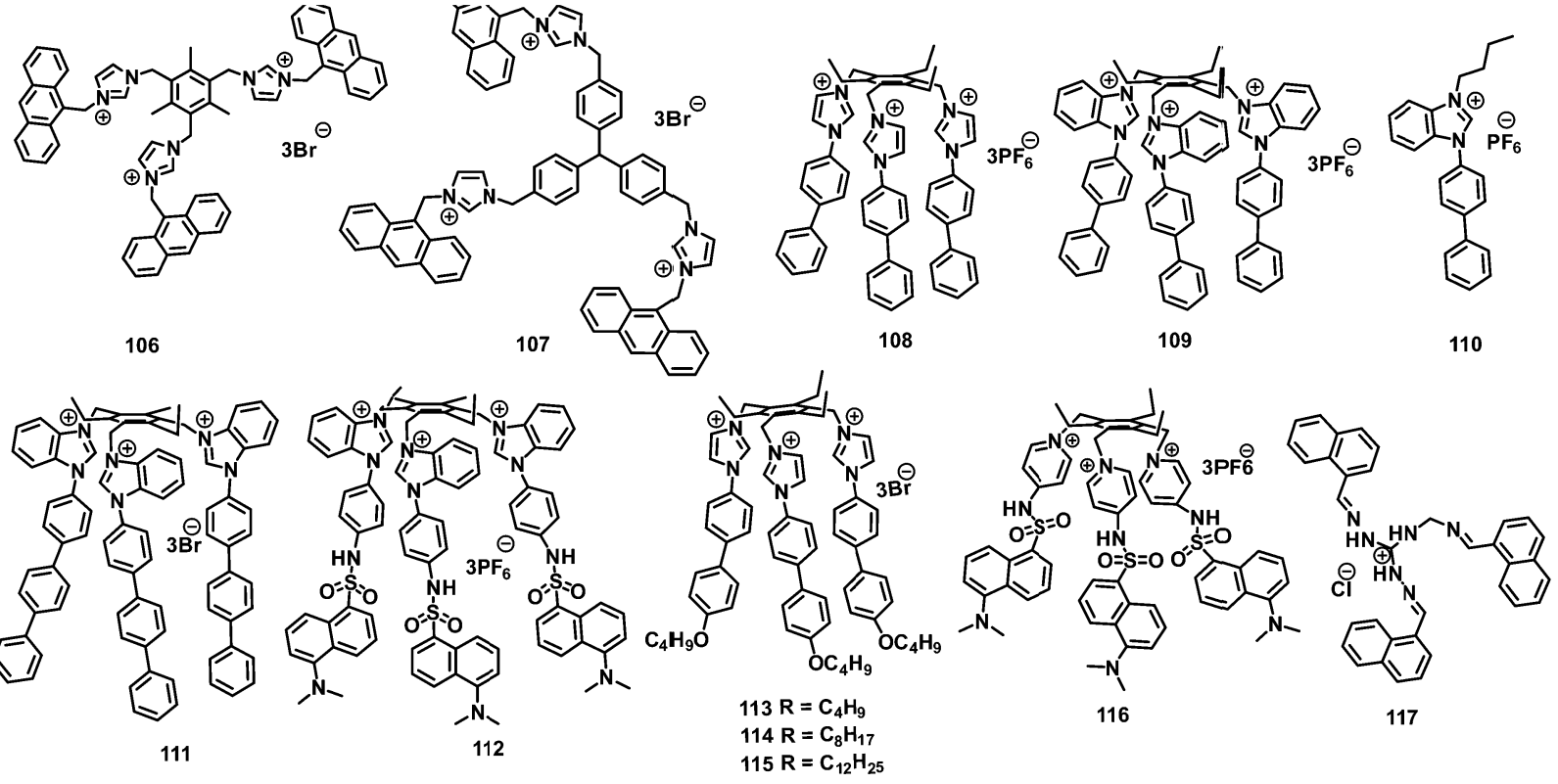

Chart 13 Structures of probes 106-117. 

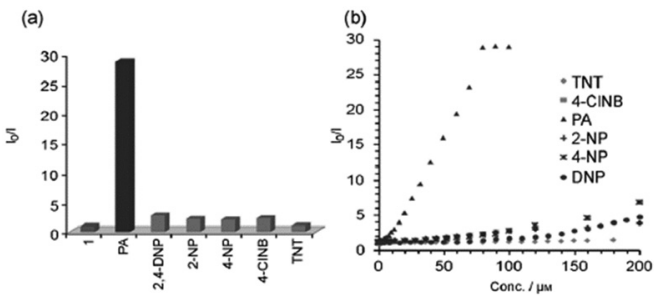

Fig. 36 (a) Quenching efficiency of 108 with NACs. (b) Stern-Volmer plots of the effects of various NACs on the fluorescence intensity of 108 (HEPES buffer/DMSO (98:2)). Reprinted from ref. 108, Copyright 2014 Wiley Online.

from blue to dark in the presence of PA. The poor efficiency of monopod 110 towards PA further highlighted the role of preorganization in 108 and 109 for the highly sensitive and selective recognition of PA. The significant up-field shift $(\Delta \delta=$ $0.8 \mathrm{ppm}$ ) of the PA protons in ${ }^{1} \mathrm{H}$ NMR titration studies confirmed that PA was encapsulated in the cavity of 108 and 109. Paper strips coated with probe 109 detected $137 \mathrm{ag} \mathrm{cm}$ PA in solution. The paper strips of 109 could also detect PA vapor in $120 \mathrm{~s}$.

Tripod $\mathbf{1 1 1}^{109}$ (Chart 13), with an extended hydrophobic pseudo-cavity in comparison to the biphenyl in $\mathbf{1 0 8}$ due to the presence of the triphenylene moiety, could detect $5 \times 10^{-13}$ M PA in water (2\% DMSO) and $2.29 \times 10^{-20} \mathrm{~g} \mathrm{~cm}^{-2}$ PA using coated paper strips. The molecules of 111 self-assembled to form a rod-like morphology in an aqueous medium, as observed through field-emission SEM, TEM and dynamic light scattering studies. With the gradual addition of PA, these aggregates underwent an aggregation-disaggregation process to form complex morphological structures $\left(10^{-12}-10^{-10} \mathrm{M} \mathrm{PA}\right)$ and then spherical aggregates at $10^{-9}-10^{-8} \mathrm{M}$ PA (Fig. 37). Further increasing the amount of PA to $10^{-7}-10^{-6} \mathrm{M}$ resulted in the dissolution of these spherical aggregates to give well-dispersed spheres. During fluorescence studies, these aggregates demonstrated super-amplified fluorescence quenching $(>97 \%)$ by $10^{-5}$ to 0.2 equivalents of PA. Thin films of tripod 111 exhibited fluorescence quenching within $6 \mathrm{~min}$ in the presence of PA.

Dansyl-conjugated probe $\mathbf{1 1 2}^{\mathbf{1 1 0}}$ (Chart 13) in HEPES buffer (2\% DMSO) showed amplified quenching at $540 \mathrm{~nm}$ in the

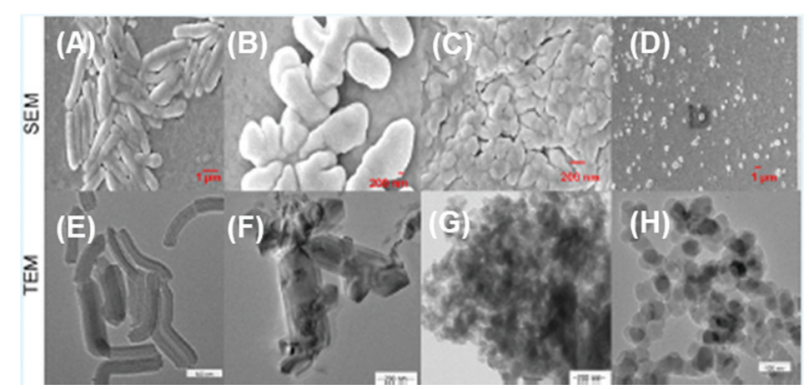

Fig. 37 Morphological (upper panels: SEM images, lower panels: TEM images) changes in TRIPOD 111 upon the addition of various amounts of picric acid: $(A$ and $E)[P A]=0 M,(B, F)[P A]=10^{-12} M,(C, G)[P A]=10^{-8} \mathrm{M}$, and $(D, H)[P A]=10^{-7} M$. Reprinted from ref. 109, Copyright 2015 American Chemical Society.

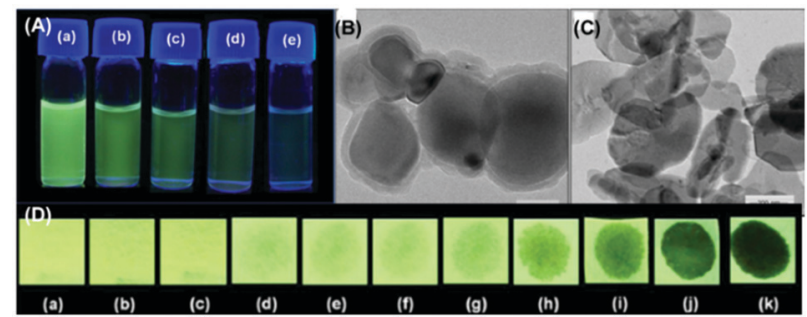

Fig. 38 (A) Visual fluorescence changes of probe 112 in blank solution (a) and with increasing concentrations of PA: (b) $50 \mathrm{pM}$, (c) $1 \mathrm{nM}$, (d) $2 \mathrm{nM}$, and (e) $4 \mathrm{nM}$. (B and C) TEM images of (B) probe $111(1 \mu \mathrm{M})$ and $(C)$ probe $111(1 \mu M)+P A(10 \mu M)$. (D) Photographs of probe-112-coated paper strips (under $365 \mathrm{~nm}$ UV light): (a) a virgin test strip, (b) a paper strip with a drop of water, and strips with $6 \mu$ of PA solutions with concentrations of (c) $10^{-14} \mathrm{M}$, (d) $10^{-13} \mathrm{M}$, (e) $10^{-12} \mathrm{M}$, (f) $10^{-11} \mathrm{M}$, (g) $10^{-10} \mathrm{M}$, and (h) $10^{-9}$ M. Reprinted from ref. 110, Copyright 2016 Elsevier.

presence of PA, with an associated change in the fluorescence color from yellow to dark (Fig. 38A). The morphology of probe 112 (Fig. 38B) changed after the addition of 1 equivalent of PA (Fig. 38C). Paper strips coated with 112 detected $13.7 \mathrm{ag} \mathrm{cm}^{-2}$ PA using the contact mode method (Fig. 38D). Probe 112 exhibited a combination of electrostatic and hydrophobic $\pi-\pi$ interactions with the picrate anion.

Imidazolium-based fluorescent probes 113-115 ${ }^{\mathbf{1 1 1}}$ (Chart 13) were used for the detection of nitroaromatics such as PA, 2,4DNP, TNT and CIDNB in water-DMSO (98:2). Among the three probes, probe 113 did not undergo aggregation and remained in the molecularly dissolved state due to its short alkyl chains, but the other two probes (114 and 115) self-assembled in water.

Upon excitation at $290 \mathrm{~nm}$, probes 113-115 displayed emission maxima at $454 \mathrm{~nm}, 448 \mathrm{~nm}$ and $412 \mathrm{~nm}$, respectively. Upon the addition of 0.1 equivalents of nitroaromatic derivatives such as PA, 2,4-DNP, TNT and Cl-DNB to a solution of 114, 92\%, 89\%, 73\% and $51 \%$ quenching of the emission intensity was observed, respectively. Similarly, probe 115 also showed 94\%, 93\%, 73\% and $66 \%$ fluorescence quenching with PA, 2,4-DNP, TNT and Cl-DNB, respectively. Probe 114 is 10, 6000, and 16000 times more selective towards PA in comparison to 2,4-DNP, TNT and Cl-DNB due to the RET process. Paper strips coated with probe 114 detected $2.29 \times 10^{-20} \mathrm{~g} \mathrm{~cm}^{-2}$ PA (Fig. 39A-Q) by the contact mode, whereas probes 113 and 115 were less sensitive to PA. Probe 114 showed morphological changes after the addition of PA (Fig. 39b-e). Probes 114 and 115 could detect PA in the vapor phase in $30 \mathrm{~s}$.

Pyridinium-dansyl conjugate-based tripod $\mathbf{1 1 6}^{\mathbf{1 1 2}}$ (Chart 13) underwent aggregation in water (2\% DMSO) with emission at $480 \mathrm{~nm}(\Phi=0.71)$, and these aggregates displayed amplified fluorescence quenching with only PA owing to the excited state energy transfer from 116 to PA. Other NACs, including the nitrophenols 2,4-DNP and 4-NP, had minimal effect on the fluorescence of the aggregates of 116. Probe 116 exhibited a linear change in fluorescence over a large range of PA concentration from $10^{-13}$ to $10^{-5} \mathrm{M}$. SEM and TEM images revealed changes in the morphology of probe $\mathbf{1 1 6}$ from leaf-like structures to a spherical shape with PA (Fig. 40a-f). Paper strips coated with 

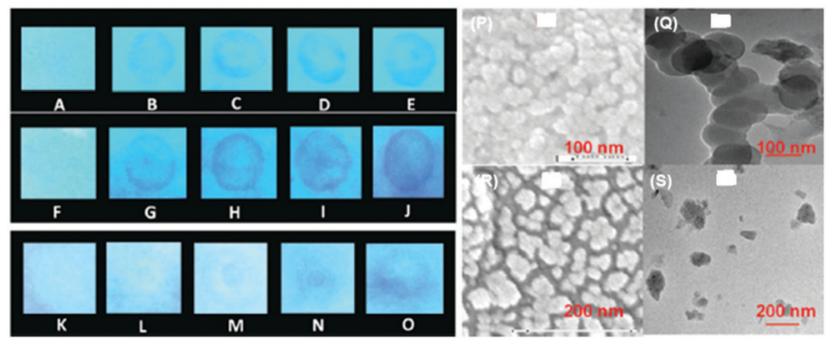

Fig. 39 Fluorescence of probe-coated paper strips upon interaction with $10 \mu \mathrm{l}$ of solutions with different concentrations of PA. (A-E) Probe 113 with (A) water; (B) $10^{-13} \mathrm{M} \mathrm{PA}$; (C) $10^{-11} \mathrm{M} \mathrm{PA}$; (D) $10^{-9} \mathrm{M} \mathrm{PA}$; and (E) $10^{-7} \mathrm{M} \mathrm{PA}$. (F-J) Probe 114 with (F) water; (G) $10^{-17} \mathrm{M} \mathrm{PA}$; (H) $10^{-15} \mathrm{M} \mathrm{PA}$; (I) $10^{-13} \mathrm{M}$ PA; and (J) $10^{-11} \mathrm{M}$ PA. (K-O) Probe 115 with (K) water; (L) $10^{-17} \mathrm{M}$ PA; (M) $10^{-15}$ M PA; (N) $10^{-13}$ M PA; and (O) $10^{-11}$ M PA. SEM (P) and TEM (Q) images of probe 114 alone, and (R) and (S) probe 114 with PA (1 equiv.). Reprinted from ref. 111, Copyright 2016 Royal Society of Chemistry.

probe 116 could detect $137 \mathrm{fg} \mathrm{cm}^{-2}$ PA in the solid state (Fig. 40g). The fluorescence lifetime of $\mathbf{1 1 6}$ increased from $0.73 \mathrm{~ns}$ to $1.45 \mathrm{~ns}$ in the presence of PA, which pointed to dynamic fluorescence quenching of aggregates of $\mathbf{1 1 6}$ with sub-micromolar amounts of PA.

The tripodal Schiff base $\mathbf{1 1 7}^{113}$ (Chart 13) with H-bonding donor triaminoguanidinium moieties, the requisite hydrophobicity and $\pi$-electron-rich naphthalene moieties formed $\pi$-stacked crystals. When dispersed in water, these crystals ${ }^{113}$ displayed fluorescence quenching at $480 \mathrm{~nm}$ in accordance with the acidity of the phenolic protons in the order PA $>2,4-\mathrm{DNP}>4$-NP, but neutral NACs caused minimal fluorescence quenching.

The stilbazolium-based dipodal ${ }^{114}$ probe 118 (Chart 14) with both absorption and emission in the visible region formed aggregates with an absorption maximum at $475 \mathrm{~nm}$ (red colour), which demonstrated a highly selective and sensitive change in colour from red to light-yellow with picric acid. The LOD for picric acid is $100 \mathrm{pM}$, which is the lowest in the literature using UV-Visible spectroscopy. These aggregates with fluorescence in the red region $(615 \mathrm{~nm})$ exhibited fluorescence quenching selectively with picric acid. TNT and other NACs induced inconsequential changes in the visible spectrum of the aggregates of 118, even when present in excess.

Upon the addition of water to its DMSO solution, tripod $\mathbf{1 1 9}^{115}$ (Chart 14) displayed aggregation-based fluorescence

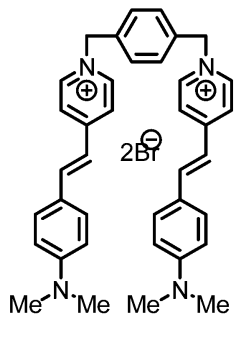

118

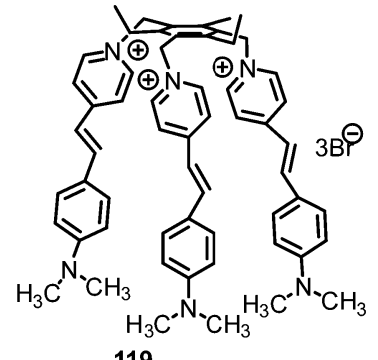

119
Chart 14 Structures of probes 118 and 119.

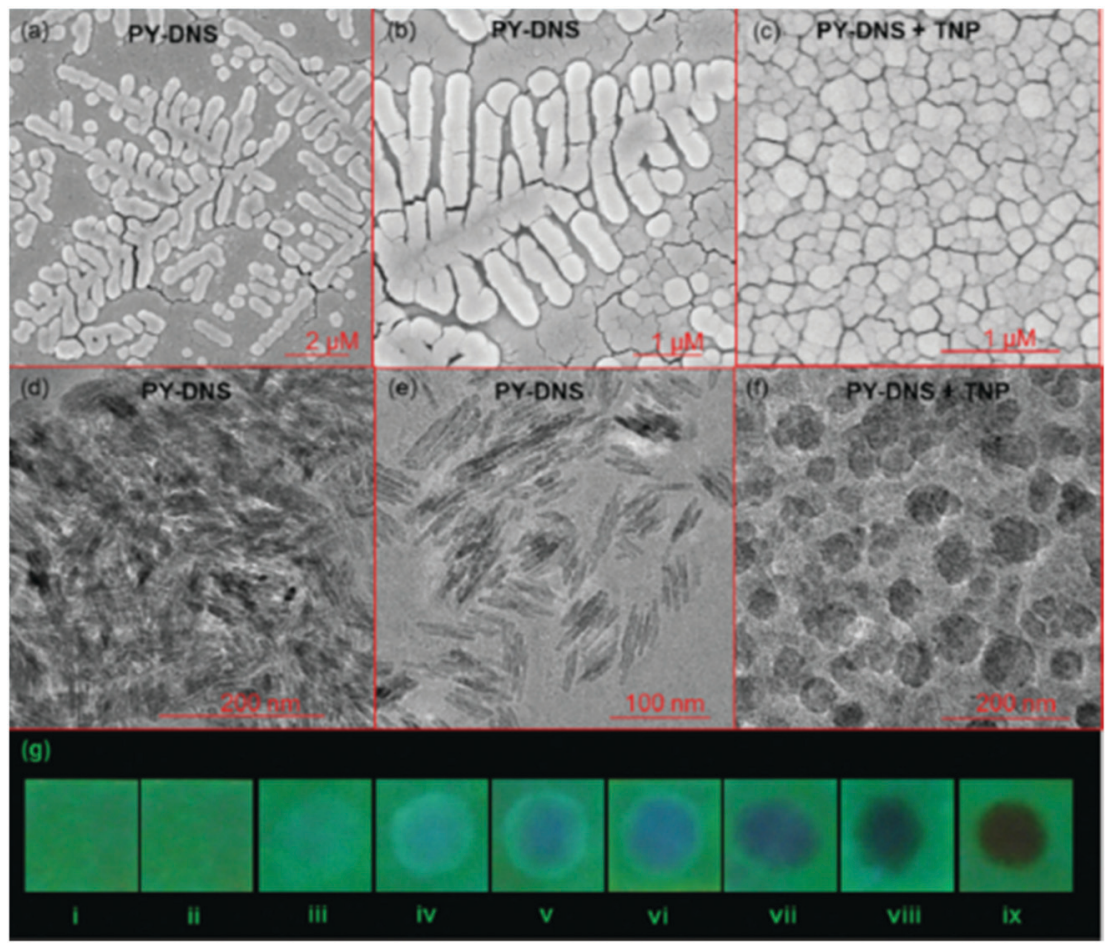

Fig. 40 ( $a$ and b) SEM images of thin films of 116 alone and (c) a 116 and PA (1:1) solution obtained on a glass plate. (d and e) TEM images of two different sections of thin film of 116. (f) A TEM image of thin film from the $1: 1$ solution of 116 and PA. (g) Photographs of probe 116-coated paper strips: (i) a virgin test strip; (ii) a strip with water; (iii-ix) strips with $6 \mu \mathrm{L}$ of solutions of PA with different concentrations: (iii) $10^{-13} \mathrm{M}$; (iv) $10^{-12} \mathrm{M}$; (v) $10^{-11} \mathrm{M}$; (vi) $10^{-10} \mathrm{M}$; (vii) $10^{-9} \mathrm{M}$; (viii) $10^{-8} \mathrm{M}$; and (ix) $10^{-7} \mathrm{M}$. Reprinted from ref. 112, Copyright 2017 Royal Society of Chemistry. 


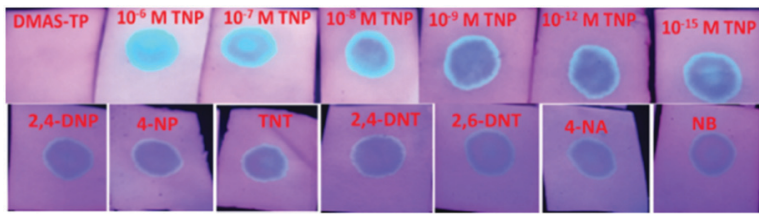

Fig. 41 Paper strips coated with probe 119 (DMAS-TP) (1 mM) demonstrated changes in their fluorescence upon treatment with solutions of varying concentrations of picric acid and $10^{-6} \mathrm{M}$ solutions of other NACs (10 $\mu \mathrm{l}$ each). Reprinted from ref. 115, Copyright 2021 Royal Society of Chemistry.

quenching with a blue-shift in emission maximum from $635 \mathrm{~nm}$ to $615 \mathrm{~nm}$, pointing to the formation of $\mathrm{H}$-aggregates. These aggregates with picric acid exhibited simultaneous fluorescence reduction at $615 \mathrm{~nm}$ and an increase in fluorescence intensity between 510-540 $\mathrm{nm}$, leading to ratiometric behaviour for picric acid. Paper strips coated with aggregates of $\mathbf{1 1 9}$ differentiated PA from other NACs through a fluorescence colour change from pink-red to blue with picric acid only (Fig. 41) and provided unprecedented discrimination of TNP from other NACs. Silica nanoparticles with probe 119 adsorbed on them highlighted latent fingerprints on a variety of substrates including aluminium foil, metal sheets, coins, ceramic tiles, etc., with a high resolution with possible applications in modern forensics.

TD-DFT studies of $\mathbf{1 1 8}$ and $\mathbf{1 1 9}$ demonstrated that restriction in ICT owing to proton transfer from picric acid to the dimethylamino group was responsible for the depletion of the colour of the probes with picric acid and that the proximity of the picrate anion to the probe resulted in charge transfer from the picrate to the DMAS moiety, leading to the non-emissive/ poorly emissive excited state.

\section{Metal complexes for the detection of picric acid}

The weak fluorescence of the hydrazone-based probe $\mathbf{1 2 0}^{116}$ (Chart 15) in a 95\% aqueous medium (5\% DMSO) was enhanced with a blue-shift of the emission maximum from $529 \mathrm{~nm}$ to $485 \mathrm{~nm}$ upon the addition of $\mathrm{Al}^{3+}$ ions. The increased fluorescence was assigned to the formation of a stable chelated system with high rigidity. The high fluorescence of the in situ prepared 120-Al(III) ensemble was quenched by the addition of PA, with a detection limit of $12.15 \mathrm{nM}$. An INHIBIT logic gate was also elaborated using this probe. Furthermore, test strips of $\mathbf{1 2 0}$ were also able to detect the presence of PA. Similarly, another AIEE-active Al(III) complex, $121,{ }^{117}$ was used for the detection of picric acid in a pure aqueous system and a detection limit of $1.67 \mu \mathrm{M}$ was calculated. However, the 121- $\mathrm{Al}^{3+}$ ensemble exhibited slightly more quenching with DNP as compared to PA.

The AIEE-based hexaphenylbenzene derivative $\mathbf{1 2 2}^{\mathbf{1 1 8}}$ (Chart 15) exhibited an increase in quantum yield from 0.48 to 0.72 and a 7.14-fold enhancement in emission intensity at $460 \mathrm{~nm}$ with 30 equivalents of $\mathrm{Hg}^{2+}$ in $\mathrm{H}_{2} \mathrm{O}-\mathrm{THF}(4: 6)$. The $1: 1$ stoichiometric 122- $\mathrm{Hg}^{2+}$ ensemble was further used for the detection of PA through the fluorescence quenching process. The quenching in FL by PA was assigned to electrostatic interaction between the host and guest and electron transfer from the excited $122-\mathrm{Hg}^{2+}$ complex to $\mathrm{PA}$, as confirmed by $\mathrm{pH}$ and ${ }^{1} \mathrm{H}$ NMR titration studies. Other nitro derivatives, such as TNT, 2,4-DNT, 1,3-DNB, etc., did not show any effect on the fluorescence intensity of this ensemble because of the lack of tendency to protonate the $N, N$-dimethylamino group. Furthermore, paper strips (Fig. 42) coated with $122-\mathrm{Hg}^{2+}$ could detect PA concentrations as low as $0.03 \mu \mathrm{M}$.

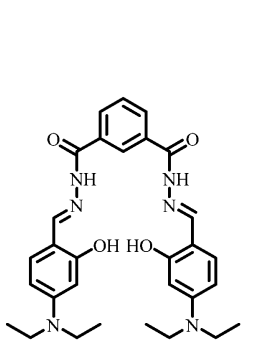

120

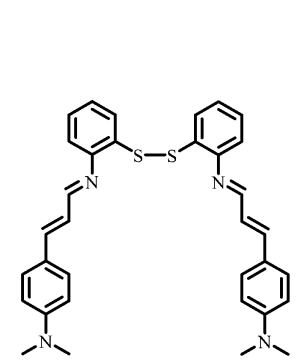

123

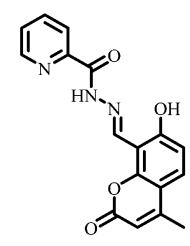

121

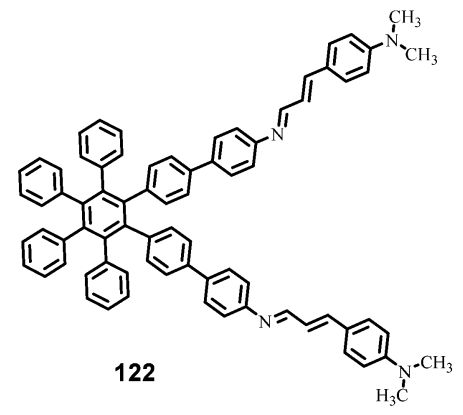<smiles>CN(C)c1cc[n+](C)cc1</smiles>

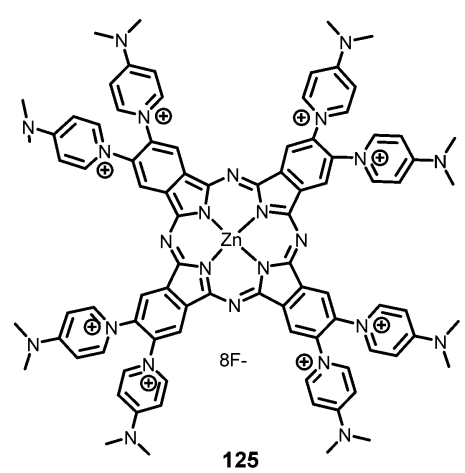

Chart 15 Structures of probes 120-125. 


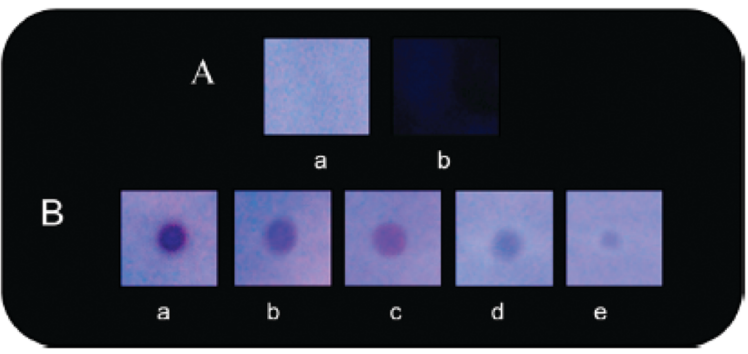

Fig. 42 (A) Paper strips of the $\mathbf{1 2 2}-\mathrm{Hg}^{2+}$ ensemble (a) before and (b) after being dipped into PA solution ( $10^{-3} \mathrm{M}$ in THF). (B) Demonstration of the effect of different concentrations of PA on test strips of the $122-\mathrm{Hg}^{2+}$ ensemble [(a) $229 \times 10^{3} \mathrm{ppm}$, (b) $229 \mathrm{ppm}$, (c) $2.29 \mathrm{ppm}$, (d) $22.9 \mathrm{ppb}$, and (e) $0.22 \mathrm{ppb}$. All images were taken under $365 \mathrm{~nm}$ UV illumination. Reprinted from ref. 118, Copyright 2013 American Chemical Society.

$\mathrm{Hg}^{2+}$ interacts with the sulphur and the imino nitrogen of probe $123^{119}$ (Chart 15) to form a 1:2 stoichiometric complex $123 \cap\left(\mathrm{Hg}^{2+}\right)_{2}$ with a nearly 290-fold increase in quantum yield from 0.001 to 0.290 . The formation of nanoaggregates of $123 \cap$ $\left(\mathrm{Hg}^{2+}\right)_{2}$ was confirmed by the appearance of level-off long wavelength tails in its absorbance spectra. This highly bluefluorescent $123 \cap\left(\mathrm{Hg}^{2+}{ }_{2}\right.$ complex $\left(\lambda_{\mathrm{em}}=458 \mathrm{~nm}\right)$ became weakly fluorescent $\left(\lambda_{\mathrm{em}}=00 \mathrm{~nm}\right)$ with $\mathrm{PA}$, whereas other nitroaromatics such as TNT, 2,4-DNT, 1,3-DNB, nitromethane, NT, NB, and DMDNB did not show any effect on the fluorescence intensity. The protonation of the amine nitrogen followed by electron transfer from $123\left(\mathrm{Hg}^{2+}\right)_{2}$ to PA was responsible for the fluorescence quenching mechanism. NOR and INHIBIT logic gates were also constructed using PA and $\mathrm{H}^{+}$ as inputs, and emission at 458 and $404 \mathrm{~nm}$ as outputs.

The water-soluble ZnPc derivatives 124 and $\mathbf{1 2 5}^{\mathbf{1 2 0}}$ (Chart 15) with four and eight 4-dimethylaminopyridines gave quantum yields of 0.11 and 0.16, respectively, in DMSO. Probes 124 and 125 showed $87 \%$ and $89 \%$ fluorescence quenching at $680 \mathrm{~nm}$ and $695 \mathrm{~nm}$, respectively, with 10 equivalents of PA due to the protonation of the $N, N$-dimethyl amino units, which prevented intramolecular charge transfer from the dimethylamino groups to the macrocycle core. Both probe $\mathbf{1 2 4}$ and $\mathbf{1 2 5}$ followed the quenching order NM $<\mathrm{NB}<\mathrm{NT}<4$-NP $<2$,4-DNT $<2$,4DNP $<$ TNT $<$ PA and could detect PA concentrations as low as $0.7 \pm 0.1$ and $1.1 \pm 0.1 \mathrm{ppm}$, respectively. The thin films of $\mathbf{1 2 4}$ and 125 showed 28.6, 9.8, 9.2, and 7.5\% fluorescence quenching in $240 \mathrm{~s}$ by the vapor of PA, TNT, 2,4-DNP, and 2,4-DNT, respectively.

\section{Miscellaneous}

BODIPY derivative $\mathbf{1 2 6}^{121}$ (Chart 16) displayed 95\% quenching of the emission intensity at $600 \mathrm{~nm}$ in the presence of 500 equivalents of PA due to the enhancement in intermolecular PET. The down-field shift of the ${ }^{19} \mathrm{~F}$ NMR signal in the presence of PA supported hydrogen bonding between fluorine and the phenolic hydrogen of PA. All other NACs resulted in less than $30 \%$ fluorescence quenching. Furthermore, 126 can be used for instant visualization of traces of PA.

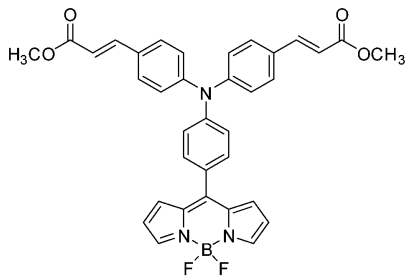

126

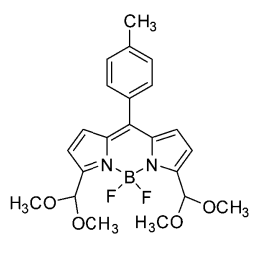

127
Chart 16 Structures of probes 126 and 127

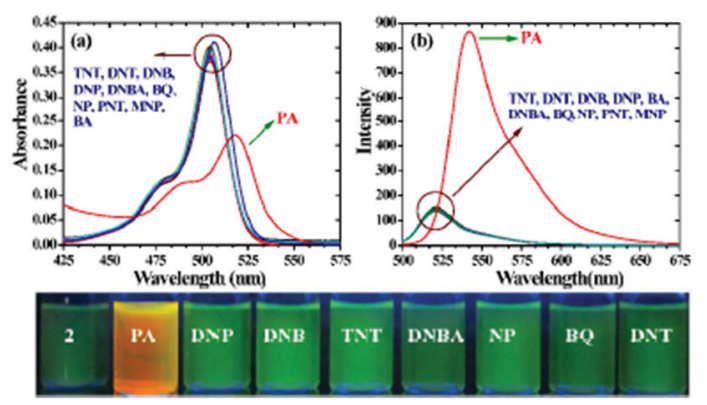

Fig. 43 Changes in the (a) absorption and (b) emission intensity of BODIPY 126 (5 $\mu \mathrm{M}$ ) with nitroaromatics (50 equiv.) in $\mathrm{CH}_{3} \mathrm{CN}-\mathrm{H}_{2} \mathrm{O}$ (9:1; v/v) solution. Bottom panel: Color changes observed upon the addition of various nitroaromatic compounds to BODIPY 126 under a UV lamp. Reprinted from ref. 121, Copyright 2015 Royal Society of Chemistry.

BODIPY-based turn-on chemodosimeter $127^{122}$ (Chart 16) exploited the strong acidic character of picric acid for highly selective hydrolysis of the acetal to the aldehyde in $\mathrm{CH}_{3} \mathrm{CN}-$ water $(9: 1)$. Upon the addition of $>20$ equivalents of picric acid, the absorption maximum was red-shifted from 504 to $516 \mathrm{~nm}$ and the emission maxima from 518 to $535 \mathrm{~nm}$, along with a six-fold enhancement in the emission intensity (Fig. 43). The fluorescence colour of the solution changed from pale green to bright yellow-orange due to the inhibition of PET. In the solid state, thin films of $\mathbf{1 2 7}$ displayed a red-shifted emission band at $612 \mathrm{~nm}$, which exhibited 83\% quenching of its fluorescence intensity upon exposure to saturated PA vapour for $500 \mathrm{~s}$. Other NACs did not cause fluorescence quenching in these films.

BSA protein probe $\mathbf{1 2 8}^{\mathbf{1 2 3}}$ in an aqueous medium displayed $80.1 \%$ fluorescence quenching at $348 \mathrm{~nm}$ with $20 \mu \mathrm{M}$ PA due to electron transfer and Förster resonance energy transfer mechanisms, as well as acid-base pairing interactions between the amino groups of $\mathbf{1 2 8}$ and PA. The response and equilibrium time was found to be less than $1 \mathrm{~min}$. The $\alpha$-helix content of BSA decreased with the addition of PA.

\section{Conclusions}

Picric acid ( $\mathrm{p} K_{\mathrm{a}}$ 0.42), one of the most acidic nitroaromatic explosive materials, has the advantage of being able to selectively protonate basic sites such as amines (both aromatic and aliphatic), imines, aza-heterocycles (pyridine, imidazole), amides, etc., that are present in fluorophores. Other closely related nitrophenol 
derivatives, such as 2,4-DNP ( $\mathrm{p} K_{\mathrm{a}}$ 4.04) and 4-nitrophenol $\left(\mathrm{p} K_{\mathrm{a}}\right.$ 7.07), have poor capacity to protonate aromatic amines and other basic sites in comparison to picric acid. The protonation of basic nitrogen/oxygen in the fluorophore activates electrostatic interactions between the protonated fluorophore and the picrate anion. Alternately, the picrate anion can undergo electrostatic interactions with positively charged fluorescent probes. The proximity between the fluorophore and picrate anion that arises due to the strong electrostatic interactions facilitates electron/energy transfer processes and thus leads to selective fluorescence quenching with picric acid over other phenolic and non-phenolic nitroaromatic derivatives. This has defined a distinct feature for the design of fluorescent probes for the selective detection of picric acid over other nitroaromatic compounds.

In general, picric acid is a natural fluorescence quencher via either the formation of non-fluorescent ground state charge transfer complexes due to the protonation of the basic site in the fluorophore or due to electron/energy transfer from the fluorophore in the excited state to the ground state of picric acid. However, fluorescence quenching is inherently a negative signal. Molecular probes that show an increase in fluorescence or a shift in the wavelength of the fluorescence maximum upon interaction with an analyte are always preferred, as these provide a positive signal for analysis.

However, FE and ratiometric fluorescence changes in response to PA have only been observed in a limited number of examples. Probe $\mathbf{9 7},{ }^{101}$ which is a conjugate of two fluorophores, namely, squaraine and dansyl moieties, displayed a blue-shift in its fluorescence maximum from $684 \mathrm{~nm}$ to $644 \mathrm{~nm}$ in $\mathrm{CH}_{3} \mathrm{CN}$ and $\mathrm{CH}_{3} \mathrm{CN}$-water $(9: 1)$. In this case, the protonation of the dimethylamine nitrogen inhibited PET from the dansyl moiety and released the fluorescence of the squaraine moiety. In another case, the BODIPY probe $25^{52}$ displayed a 300 -fold enhancement in emission intensity with PA in ethanol. Another ICT-based probe, $119,{ }^{115}$ showed the distinct appearance of blue fluorescence upon the treatment of probe-coated paper strips with picric acid. In all these examples, the picric-acid-mediated protonation at the amine nitrogen is the key mechanistic feature. In the curcumin-based probes 27 and $28,{ }^{54}$ the protonation of the amine by picric acid induced the aggregation of the resulting salts, and thus aggregation-induced emission enhancement was observed.

Furthermore, the detection of picric acid vapor using fluorescent probes can provide an advantage for device formation. However, only a few cases in which thin films ${ }^{108,109,111,120}$ of a probe exhibit fluorescence quenching with picric acid within a few minutes have been reported, along with other cases in which a probe deposited on a TLC plate $^{53,89}$ or THF-water ${ }^{33}$ solutions of a probe detect picric acid vapor.

In future, we anticipate the development of fluorescent probes for picric acid with two or more fluorescent moieties whose signals before and after interaction with picric acid differ, thus providing an increase or ratiometric change in the fluorescence. Fluorescence probes with increased ICT upon protonation with picric acid will appear in the literature, which are expected to display a shift in the fluorescence maximum to longer wavelengths with or without ratiometric changes. Fluorescence probes exhibiting a decrease in ICT upon protonation with a blue-shift in the fluorescence maximum will be developed.

Most of the fluorescent probes applied for the detection of picric acid emit in the blue or green region of the visible light spectrum and are plagued by interference from the background fluorescence of natural samples. There are only a few examples of red-emitting probes that have found application in the detection of picric acid. Increasing emphasis will be placed on the development of red- or NIR-emitting probes in future. Such probes are expected to open up new vistas for investigating the effects of PA in live cells and tissues. The development of fluorescent probes for the selective detection of PA vapor is another noteworthy area for future research.

\section{Abbreviations}

ACN Acetonitrile

ACQ

AFM

AIE

AIEE

BODIPY

BQ

ClDNB

CT

DBSA

DFT

DLS

DMF

DMNB

DMSO

DNB

DNBA

2,4- DNP

2,4-DNT

DTAB

ESIPT

FE

FI

FRET

FQ

GSCT

$\mathrm{HCHO}$

HEPES

HOMO

ICT

IFE

LOD

LUMO

$\mathrm{MeOH}$

MOF

NA

NACs

$\mathrm{NB}$

NM
Aggregation-caused quenching

Atomic force microscopy

Aggregation-induced enhancement

Aggregation-induced emission enhancement

Boron-dipyrromethene

1,4-Benzoquinone

Chlorodinitrobenzene

Charge transfer

Dodecylbenzene-sulfonic acid

Density functional theory

Dynamic light scattering

$N, N$-Dimethylformamide

Dimethylnitrobenzene

Dimethyl sulfoxide

Dinitrobenzene

1,4-Dinitrobenzoic acid

2,4-Dinitrophenol

2,4-Dinitrotoulene

Dodecyltrimethylammonium bromide.

Excited-state intramolecular proton transfer

Fluorescence enhancement

Fluorescence intensity

Förster resonance energy transfer

Fluorescence quenching

Ground-state charge transfer

Formaldehyde

4-(2-Hydroxyethyl)-1-piperazineethanesulfonic acid

Highest occupied molecular orbital

Internal charge transfer

Inner filter effect

Limit of detection

Lowest unoccupied molecular orbital

Methanol

Metal organic framework

Nitroaniline

Nitroaromatics

Nitrobenzene

Nitromethane 


$\begin{array}{ll}\text { NMR } & \text { Nuclear magnetic resonance } \\ \text { NMP } & \text { N-Methyl-2-pyrrolidone } \\ \text { 4-NP } & \text { 4-Nitrophenol } \\ \text { NT } & \text { Nitrotoulene } \\ \text { PA } & \text { Picric acid } \\ \text { PBS } & \text { Phosphate buffer saline } \\ \text { PET } & \text { Photo-induced energy transfer } \\ \text { pKa } & \text { Acid dissociation constant } \\ \text { PYX } & \text { 2,6-Bis(picrylamino)-3,5-dinitropyridine } \\ \text { RDX } & \text { Hexahydro-1,3,5-trinitro-1,3,5-triazine } \\ \text { RET } & \text { Resonance energy transfer } \\ \text { RIR } & \text { Restricted intramolecular rotation } \\ \text { SDS } & \text { Sodium dodecylsulfate } \\ \text { SEM } & \text { Scanning electron microscopy } \\ \text { TBET } & \text { Through-bond energy transfer } \\ \text { TEA } & \text { Triethylamine } \\ \text { TEM } & \text { Transmission electron microscopy } \\ \text { TFA } & \text { Trifluoroacetic acid } \\ \text { THF } & \text { Tetrahydrofuran } \\ \text { TNP } & \text { Trinitrophenol } \\ \text { TNT } & \text { Trinitrotoulene } \\ \text { TPE } & \text { Tetraphenylethylene } \\ \text { V.P. } & \text { Vapour pressure }\end{array}$

\section{Author contributions}

Sukhvinder Dhiman, Nancy Singla, Manzoor Ahmad and Prabhpreet Singh: review writing; Subodh Kumar: conceptualization, review writing and fund raising.

\section{Conflicts of interest}

There are no conflicts to declare.

\section{Acknowledgements}

This work was supported by the Department of Science and Technology, New Delhi, SERB grant EMR/2016/001535. We thank UGC for the UPE and PURSE programmes to the university and DST for the FIST program. S. Dhiman is thankful to the CSIR, India for a Senior Research Fellowship (Grant no. 09/254(0304)/ 2020-EMR-I). SK thanks UGC for a UGC-BSR faculty F.4-5(11)/ 2019 (BSR) fellowship.

\section{References}

1 J. Akhavan, The chemistry of explosives, Royal Society of Chemistry, 2011.

2 S. Shanmugaraju and P. S. Mukherjee, Chem. Commun., 2015, 51, 16014-16032.

3 P. Wexler, Encyclopedia of Toxicology, 2nd edn, 2005.

4 P. Wexler, Encyclopedia of Toxicology, 3rd edn, 2014.

5 M. Russel, The Chemistry of Fireworks: Edition 2, 2009, p. 138.
6 P. G. Thorne and T. F. Jenkins, Special Report, USA Cold Regions Research and Engineering Laboratory, Hanover, NH, 1995, pp. 95-120.

7 P. G. Thorne and T. F. Jenkins, Field Anal. Chem. Technol., 1997, 1, 165-170.

8 S. H. Yalkowsky, Y. He and P. Jain, Handbook of Aqueous Solubility Data, 2nd edn, CRC Press, Boca Raton, FL, 2010, p. 200.

9 R. M. Hebert and A. M. Jackovitz, Wildlife Toxicity Assessment for Picric Acid (2,4,6-Trinitrophenol), 2015, pp. 271-277.

10 M. Takahashi, H. Ogata, H. Izumi, K. Yamashita, M. Takechi, M. Hirata-Koizumi, E. Kamata, R. Hasegawa and M. Ema, Congenit. Anom., 2004, 44, 204-214.

11 J. F. Wyman, M. P. Serve, D. W. Hobson, L. H. Lee and D. E. Uddin, J. Toxicol. Environ. Health, 1992, 37, 313-327.

12 (a) K. R. Cooper, D. T. Burton, W. L. Goodfellow and D. H. Rosenblatt, J. Toxicol. Environ. Health, 1984, 14, 731-747; (b) K.-M. Wollin and H. H. Dieter, Arch. Environ. Contam. Toxicol., 2005, 49, 18-26.

13 J. Y. Shen, J. F. Zhang, Y. Zuo, L. J. Wang, X. Y. Sun, J. S. Li, W. Q. Han and R. He, J. Hazard. Mater., 2009, 163, 1199-1206.

14 (a) M. E. Germain and M. J. Knapp, Chem. Soc. Rev., 2009, 38, 2543-2555; (b) Y. Salinas, R. Martınez-Manez, M. D. Marcos, F. Sancenon, A. M. Costero, M. Parraad and S. Gilad, Chem. Soc. Rev., 2012, 41, 1261-1296; (c) G. V. Zyryanov, D. S. Kopchuk, I. S. Kovalev, E. V. Nosova, V. L. Rusinov and O. N. Chupakhin, Russ. Chem. Rev., 2014, 83, 783-819.

15 (a) K. K. Kartha, A. Sandeep, V. K. Praveen and A. Ajayaghosh, Chem. Rec., 2015, 15, 252-265; (b) X. Sun, Y. Wang and Y. Lei, Chem. Soc. Rev., 2015, 44, 8019-8061; (c) S. Shanmugaraju and P. S. Mukherjee, Chem. - Eur. J., 2015, 21, 6656-6666; (d) M. Chhatwal, R. Mittal, R. D. Gupta and S. K. Awasthi, J. Mater. Chem. C, 2018, 6, 12142-12158; (e) E. V. Verbitskiy, G. L. Rusinov, O. N. Chupakhin and V. N. Charushin, Dyes Pigm., 2020, 180, 108414; $(f)$ A. S. Tanwar, N. Meher, L. R. Adil and P. K. Iyer, Analyst, 2020, 145, 4753-4767.

16 M. E. Walsh, Talanta, 2001, 54, 427-438.

17 P. T. Sukhanov, A. A. Kushnir, E. V. Churilina, N. V. Maslova and G. V. Shatalov, Anal. Chem., 2017, 72, 468-472.

18 (a) J. Yinon, Mass Spectrom. Rev., 1982, 1, 257-307; (b) J. C. Mathurin, T. Faye, A. Brunot and J. C. Tabet, Anal. Chem., 2000, 72, 5055-5062; (c) A. Prakash, S. Chandra and D. Bahadur, Carbon, 2012, 50, 4209-4219; (d) D. Lin, J. Wu, M. Wang, F. Yan and H. Ju, Anal. Chem., 2012, 84, 3662-3668. 19 (a) M. Krausa and K. Schorb, J. Electroanal. Chem., 1999, 461, 10-13; (b) C. L. M. Palenzuela, F. Novotný, P. Krupička, Z. Sofer and M. Pumera, Anal. Chem., 2018, 90, 5753-5757; (c) A. Ramachandran, J. S. Arya Nair and S. K. Yesodha, ACS Sustainable Chem. Eng., 2019, 7, 6732-6743.

20 (a) J. M. Sylvia, J. A. Janni, J. D. Klein and K. M. Spencer, Anal. Chem., 2000, 72, 5834-5840; (b) A. Hakonen, P. O. Andersson, M. S. Schmidt, T. Rindzevicius and M. Kall, Anal. Chim. Acta, 2015, 893, 1-13.

21 (a) F. Qiu, Y.-H. Huang, Q. M. Ge, M. Liu, H. Cong and Z. Tao, Spectrochim. Acta, Part A, 2020, 226, 117583; (b) V. Bharadwaj, J. E. Park, S. K. Sahoo and H.-J. Choi, ChemistrySelect, 2019, 4, 10895-10901. 
22 (a) A. Kumar, A. Kumar and D. S. Pandey, Dalton Trans., 2016, 45, 8475-8484; (b) N. Goel and N. Kumar, Inorg. Chim. Acta, 2017, 463, 14-19.

23 (a) S. Senthilkumar, R. Goswami, N. L. Obasi and S. Neogi, ACS Sustainable Chem. Eng., 2017, 5, 11307-11315; (b) H.-R. Fu, L.-B. Yan, N.-T. Wu, L.-F. Ma and S.-Q. Zang, J. Mater. Chem. A, 2018, 6, 9183-9191; (c) S. Xing, Q. Bing, H. Qi, J. Liu, T. Bai, G. Li, Z. Shi, S. Feng and R. Xu, ACS Appl. Mater. Interfaces, 2017, 9, 23828-23835.

24 (a) Y. Wang, X. Chang, N. Jing and Y. Zhang, Anal. Methods, 2018, 10, 2775-2784; (b) J. Li, L. Zhang, P. Li, Y. Zhang and C. Dong, Sens. Actuators, B, 2018, 258, 580-588.

25 (a) K. Shanmugaraj and S. Abraham John, New J. Chem., 2018, 42, 7223-7229; (b) W. J. Zhang, S. G. Liu, L. Han, Y. Ling, L. L. Liao, S. Mo, H. Q. Luo and N. B. Li, Anal. Methods, 2018, 10, 4251-4256.

26 (a) X.-D. Zhang, J.-A. Hua, J.-H. Guo, Y. Zhao and W.-Y. Sun, J. Mater. Chem. C, 2018, 6, 12623-12630; (b) X. Yin, S. Meng and J. Xie, Polyhedron, 2018, 139, 262-266; (c) L. Li, J. Cheng, Z. Liu, L. Song, Y. You, X. Zhou and W. Huang, ACS Appl. Mater. Interfaces, 2018, 10, 44109-44115.

27 CRC Handbook of Chemistry and Physics, 95th edn, ed. W. M. Haynes, CRC Press LLC, Boca Raton, FL, 2014-2015, pp. 5-97.

28 (a) R. Sun, X. Huo, H. Lu, S. Feng, D. Wang and H. Liu, Sens. Actuators, B , 2018, 265, 476-487; (b) A. Biswas, D. Giri, D. Das, A. De, S. K. Patra and R. Samanta, J. Org. Chem., 2017, 82, 10989-10996; (c) S. Kumar, N. Venkatramaiah and S. Patil, J. Phys. Chem. C, 2013, 117, 7236-7245; (d) N. Wang, J.-C. Yang, L.-D. Chen, J. Li, Y. An, C.-W. Lu and Y.-Q. Tian, New J. Chem., 2017, 41, 2786-2792; (e) W. Xue, Y. Zhang, J. Duan, D. Liu, Y. Ma, N. Shi, S. Chen, L. Xie, Y. Qian and W. Huang, J. Mater. Chem. C, 2015, 3, 8193-8199.

29 (a) N. Venkatramaiah, A. D. G. Firmino, F. A. Almeida Paz and J. P. C. Tome, Chem. Commun., 2014, 50, 9683-9686; (b) V. Bhalla, H. Arora, H. Singh and M. Kumar, Dalton Trans., 2013, 42, 969-974; (c) S. Shanmugaraju, H. Jadhav, R. Karthik and P. S. Mukherjee, RSC Adv., 2013, 3, 4940-4950; (d) H. Ma, F. Li, L. Yao, Y. Feng, Z. Zhang and M. Zhang, Sens. Actuators, B, 2018, 259, 380-386; (e) E. Hussain, Y. Li, C. Cheng, H. Zhuo, S. A. Shahzad, S. Ali, M. Ismail, H. Qi and C. Yu, Talanta, 2020, 207, 120316.

30 (a) N. Venkatramaiah, S. Kumar and S. Patil, Chem. - Eur. J., 2012, 18, 14745-14751; (b) S. Shanmugaraju, S. A. Joshi and P. S. Mukherjee, J. Mater. Chem., 2011, 21, 9130-9138; (c) S. S. Babu and S. K. Shanmugam, J. Mater. Chem. C, 2017, 5, 4788-4796; (d) Y. Chandrasekaran, N. Venkatramaiah and S. Patil, Chem. - Eur. J., 2016, 22, 5288-5294.

31 (a) R. Hu, J. L. Maldonado, M. Rodriguez, C. Deng, C. K. W. Jim, J. W. Y. Lam, M. M. F. Yuen, G. RamosOrtiz and B. Z. Tang, J. Mater. Chem., 2012, 22, 232-240; (b) H. Li, H. Wu, E. Zhao, J. Li, J. Z. Sun, A. Qin and B. Z. Tang, Macromolecules, 2013, 46, 3907-3914.

32 (a) C. Y. K. Chan, J. W. Y. Lam, C. Deng, X. Chen, K. S. Wong and B. Z. Tang, Macromolecules, 2015, 48, 1038-1047; (b) J. Li, J. Liu, J. W. Y. Lama and B. Z. Tang, RSC Adv., 2013, 3, 8193-8196.
33 V. Vij, V. Bhalla and M. Kumar, ACS Appl. Mater. Interfaces, 2013, 5, 5373-5380.

34 M. K. Chahal and M. Sankar, Anal. Methods, 2015, 7, 10272-10279.

35 A. Pandith, A. Kumar, J. Y. Lee and H. S. Kim, Tetrahedron Lett., 2015, 56, 7094-7099.

36 A. K. Bandela, S. Bandaru and C. P. Rao, Chem. - Eur. J., 2015, 21, 13364-13374.

37 V. Mahendran and S. Shanmugam, RSC Adv., 2015, 5, 92473-92479.

38 V. Bhalla, H. Arora and M. Kumar, $R S C A d v ., 2015,5$, 32637-32642.

39 P. Vishnoi, M. G. Walawalkar, S. Sen, A. Datta, G. N. Patwari and R. Murugavel, Phys. Chem. Chem. Phys., 2014, 16, 10651-10658.

40 P. Vishnoi, M. G. Walawalkar and R. Murugavel, Cryst. Growth Des., 2014, 14, 5668.

41 P. Vishnoi, S. Sen, G. N. Patwari and R. Murugavel, New J. Chem., 2015, 39, 886.

42 S. Nagendran, P. Vishnoi and R. Murugavel, J. Fluoresc., 2017, 27, 1299-1305.

43 K. Ponnuvel, G. Banuppriya and V. Padmini, Sens. Actuators, B, 2016, 234, 34-45.

44 S. S. Babu and S. Shanmugam, ChemistrySelect, 2018, 3, 4075-4081.

45 W. Fang, W. Zhao, P. Pei, R. Liu, Y. Zhanga, L. Konga and J. Yang, J. Mater. Chem. C, 2018, 6, 9269-9276.

46 X. Lu, G. Zhanga, D. Li, X. Tian, W. Ma, S. Li, Q. Zhang, H. Zhou, J. Wu and Y. Tian, Dyes Pigm., 2019, 170, 107641.

47 A. Shylaja, S. R. Rubina, S. S. Roja and R. R. Kumar, Dyes Pigm., 2020, 174, 108062.

48 A. S. Tanwar, S. Hussain, A. H. Malik, M. A. Afro and P. K. Iyer, ACS Sens., 2016, 1, 1070-1077.

49 M. Sathiyaraj, K. Pavithra and V. Thiagarajan, New J. Chem., 2020, 44, 8402-8411.

50 P. Kumar, D. Arya, D. Nain, A. Singh, A. Ghosh and D. Amilan Jose, Dyes Pigm., 2019, 166, 443-450.

51 J. Gao, X. Chen, S. Chen, H. Meng, Y. Wang, C. Li and L. Feng, Anal. Chem., 2019, 91, 13675-13680.

52 Y. Erande, S. Chemate, A. More and N. Sekar, RSC Adv., 2015, 5, 89482-89487.

53 K. Maiti, A. K. Mahapatra, A. Gangopadhyay, R. Maji, S. Mondal, S. S. Ali, S. Das, R. Sarkar, P. Datta and D. Mandal, ACS Omega, 2017, 2, 1583-1593.

54 B. Gogoi and N. S. Sarma, ACS Appl. Mater. Interfaces, 2015, 7, 11195-11202.

55 S. Kaur, A. Gupta, V. Bhalla and M. Kumar, J. Mater. Chem. C, 2014, 2, 7356-7363.

56 S. Kaur, V. Bhalla, V. Vij and M. Kumar, J. Mater. Chem. C, 2014, 2, 3936-3941.

57 A. Sil, D. Giri and S. K. Patra, J. Mater. Chem. C, 2017, 5, 11100-11110.

58 S. Maity, M. Shyamal, D. Das, A. Maity, S. Dey and A. Misra, New J. Chem., 2018, 42, 1879-1891.

59 V. Kachwal, P. Alam, H. R. Yadav, S. S. Pasha, A. R. Choudhury and I. R. Laskar, New J. Chem., 2018, 42, 1133-1140. 
60 A. Kathiravan, A. Gowri, T. Khamrang, M. D. Kumar, N. Dhenadhayalan, K.-C. Lin, M. Velusamy and M. Jaccob, Anal. Chem., 2019, 91, 13244-13250.

61 Y. Ma, Y. Zhang, X. Liu, Q. Zhang, L. Kong, Y. Tian, G. Li, X. Zhang and J. Yang, Dyes Pigm., 2019, 163, 1-8.

62 H. Li, R. Jia and Y. Wang, Spectrochim. Acta, Part A, 2020, 228, 117793.

63 J. Pan, F. Tang, A. Ding, L. Kong, L. Yang, X. Tao, Y. Tian and J. Yang, RSC Adv., 2015, 5, 191-195.

64 P. Ghosh and P. Banerjee, Anal. Chim. Acta, 2017, 965, 111-122.

65 D. C. Santra, M. K. Bera, P. K. Sukul and S. Malik, Chem. Eur. J., 2016, 22, 2012-2019.

66 J. B. Arockiam and S. Ayyanar, Sens. Actuators, B, 2017, 242, 535-544.

67 Y. Peng, A.-J. Zhang, M. Dong and Y.-W. Wang, Chem. Commun., 2011, 47, 4505-4507.

68 M. Dong, Y.-W. Wang, A.-J. Zhang and Y. Peng, Chem. Asian J., 2013, 8, 1321-1330.

69 Z.-H. Fu, Y.-W. Wang and Y. Peng, Chem. Commun., 2017, 53, 10524-10527.

70 G. Chakraborty and S. K. Mandal, ACS Omega, 2018, 3, 3248-3256.

71 B. Pramanik, S. Das and D. Das, Chem. - Asian J., 2020, 15, 4291-4296.

72 X. Cao, N. Zhao, H. Lv, Q. Ding, A. Gao, Q. Jing and T. Yi, Langmuir, 2017, 33, 7788-7798.

73 S. S. Harmalkar, A. V. Naik, M. K. Nilajakar and S. N. Dhuri, ChemistrySelect, 2020, 5, 8447-8454.

74 P. Sakthivel, K. Sekar, S. Singaravadivel and G. Sivaraman, ChemistrySelect, 2019, 4, 3817-3822.

75 H.-L. Ding, L.-D. Chen, N. Wang, K. Li, Y. An and C.-W. Lü, Talanta, 2019, 195, 345-353.

76 Jigyasa and J. K. Rajput, Sens. Actuators, B, 2018, 259, 990-1005.

77 R. Ahmed, A. Ali, M. Ahmad, A. Alsalme, R. A. Khan and F. Ali, New J. Chem., 2020, 44, 20092-20100.

78 Y.-C. Wu, S.-H. Luo, L. Cao, K. Jiang, L.-Y. Wang, J.-C. Xie and Z.-Y. Wang, Anal. Chim. Acta, 2017, 976, 74-83.

79 J.-F. Xiong, J.-X. Li, G.-Z. Mo, J.-P. Huo, J.-Y. Liu, X.-Y. Chen and Z.-Y. Wang, J. Org. Chem., 2014, 79, 11619-11630.

80 S. Chaudhary, H. Sharma and M. D. Milton, ChemistrySelect, 2018, 3, 4598-4608.

81 R. Sodkhomkhum, M. Masik, S. Watchasit, C. Suksai, J. Boonmak, S. Youngme, N. Wanichacheva and V. Ervithayasuporn, Sens. Actuators, B, 2017, 245, 665-673.

82 S. Zhang, H. Zhu, J. Huang, L. Kong, Y. Tian and J. Yang, ChemistrySelect, 2019, 4, 7380-7387.

83 B. K. Kundu, R. Pragti, S. M. Mobin and S. Mukhopadhyay, New J. Chem., 2019, 43, 11483-11492.

84 A. S. M. Islam, M. Sasmal, D. Maiti, A. Dutta, B. Show and M. Ali, ACS Omega, 2018, 3, 10306-10316.

85 A. Panigrahi, B. P. Sahu, S. Mandani, D. Nayak, S. Giri and T. K. Sarma, J. Photochem. Photobiol., A, 2019, 374, 194-205.

86 M. Shyamal, D. Das, P. K. Giri, S. Maity and A. Misra, Mater. Today Chem., 2019, 14, 100193.
87 (a) H. Ma, C. He, X. Li, O. Ablikim, S. Zhang and M. Zhang, Sens. Actuators, B, 2016, 230, 746-752; (b) Y. Ma, L. Zhao, Y. Li, J. Liu, Y. Yang and T. Chu, Tetrahedron, 2018, 74, 2684-2691.

88 Q. Lin, X.-W. Guan, Y.-Q. Fan, J. Wang, L. Liu, J. Liu, H. Yao, Y.-M. Zhang and T.-B. Wei, New J. Chem., 2019, 43, 2030-2036.

89 A. Kumar and P. S. Chae, Sens. Actuators, B, 2017, 240, 1-9. 90 P. Lasitha and E. Prasad, RSC Adv., 2015, 5, 41420-41427.

91 S. Maity, M. Shyamal, P. Mazumdar, G. P. Sahoo, R. Maity, G. S. Morán and A. Misra, J. Mol. Liq., 2016, 224, 255-264.

92 E. Zhang, P. Ju, P. Guo, X. Hou, X. Hou, H. Lv, J. Wang and Y. Zhang, RSC Adv., 2018, 8, 31658-31665.

93 M. Ghosh, S. Ta, M. Banerjee, M. Mahiuddin and D. Das, ChemistrySelect, 2018, 3, 6145-6151.

94 R. Chopra, V. Bhalla, M. Kumar and S. Kaur, $R S C A d v$, 2015, 5, 24336-24341.

95 Y. Ma, Y. Zhang, L. Kong and J. Yang, CrystEngComm, 2019, 21, 94-101.

96 J. Du, J. Liu, Y. Ren, C. Wang, F. Bai and H. Hao, Spectrochim. Acta, Part A, 2019, 211, 287-290.

97 N. Nagamani, S. Lakshmanan, D. Govindaraj, C. Ramamoorthy, N. Ramalakshmi and S. A. Antony, Spectrochim. Acta, Part A, 2019, 207, 321-327.

98 S. Kumari, S. Joshi, T. C. Cordova-Sintjago, D. D. Pant and R. Sakhuja, Sens. Actuators, B, 2016, 229, 599-608.

99 S. K. Patil, D. V. Awale, M. M. Vadiyar, S. A. Patil, S. C. Bhise, A. H. Gore, G. B. Kolekar, J. H. Kim and S. S. Kolekar, ChemistrySelect, 2017, 2, 4124-4130.

100 A. Kumar, A. Pandith and H.-S. Kim, Sens. Actuators, B, 2016, 231, 293-301.

101 Y. Xu, B. Li, W. Li, J. Zhao, S. Sun and Y. Pang, Chem. Commun., 2013, 49, 4764-4766.

102 L. Ding, Y. Bai, Y. Cao, G. Ren, G. J. Blanchard and Y. Fang, Langmuir, 2014, 30, 7645-7653.

103 S. Hussain, A. H. Malik, M. A. Afroza and P. K. Iyer, Chem. Commun., 2015, 51, 7207-7210.

104 N. Yan, J. Song, F. Wang, L. Kan, J. Song, W. Wang, W. Ma, W. Zhang and G. He, Chin. Chem. Lett., 2019, 30, 1984-1988.

105 V. Lakshmidevi, C. V. Yelamaggad and A. Venkataraman, ChemistrySelect, 2018, 3, 2655-2664.

106 P. S. Hariharan, J. Pitchaimani, V. Madhu and S. P. Anthony, J. Fluoresc., 2016, 26, 395-401.

107 B. Roy, A. K. Bar, B. Gole and P. S. Mukherjee, J. Org. Chem., 2013, 78, 1306-1310.

108 R. Kumar, S. Sandhu, P. Singh, G. Hundal, M. S. Hundal and S. Kumar, Asian J. Org. Chem., 2014, 3, 805-813.

109 S. Sandhu, R. Kumar, P. Singh, A. Mahajan, M. Kaur and S. Kumar, ACS Appl. Mater. Interfaces, 2015, 7, 10491-10500.

110 N. Tripathi, S. Sandhu, P. Singh, A. Mahajan, M. Kaur and S. Kumar, Sens. Actuators, B, 2016, 231, 79-87.

111 S. Sandhu, R. Kumar, P. Singh and S. Kumar, J. Mater. Chem. C, 2016, 4, 3209-3216.

112 N. Tripathi, P. Singh and S. Kumar, New J. Chem., 2017, 41, 8739-8747.

113 S. Mukherjee, A. V. Desai, A. I. Inamdar, B. Manna and S. K. Ghosh, Cryst. Growth Des., 2015, 15, 3493-3497. 
114 S. Dhiman, G. Kumar, V. Luxami, P. Singh and S. Kumar, New J. Chem., 2020, 44, 10870-10877.

115 S. Dhiman, M. Ahmad, G. Kumar, V. Luxami, P. Singh and S. Kumar, J. Mater. Chem. C, 2021, 9, 1097-1106.

116 S. Sharma, G. Dubey, B. S. Sran, P. V. Bharatam and G. Hundal, ACS Omega, 2019, 4, 18520-18529.

117 R. Purkait, A. Dey, S. Deya, P. P. Ray and C. Sinha, New J. Chem., 2019, 43, 14979-14990.

118 V. Bhalla, S. Kaur, V. Vij and M. Kumar, Inorg. Chem., 2013, 52, 4860-4865.
119 M. Kumar, S. I. Reja and V. Bhalla, Org. Lett., 2012, 14, 6084-6087.

120 S. Kasthuri, P. Gawas, S. Maji, N. Veeraiah and N. Venkatramaiah, ACS Omega, 2019, 4, 6218-6228.

121 M. Hengchang, Z. Zhongwei, J. Yuanyuan, Z. Lajia, Q. Chunxuan, C. Haiying, Y. Zengming, Y. Zhiwang and Z. Lei, RSC Adv., 2015, 5, 87157-87167.

122 S. Madhu, A. K. Bandela and M. Ravikanth, RSC Adv., 2014, 4, 7120-7123.

123 X. Sun, X. Ma, C. V. Kumar and Y. Lei, Anal. Methods, 2014, 6, 8464-8468. 